Introducción a la teoría de conjuntos, operadores booleanos y teoría del concepto para profesionales de la información documental

MIGUEL ÁNGEL RENDÓN ROJAS

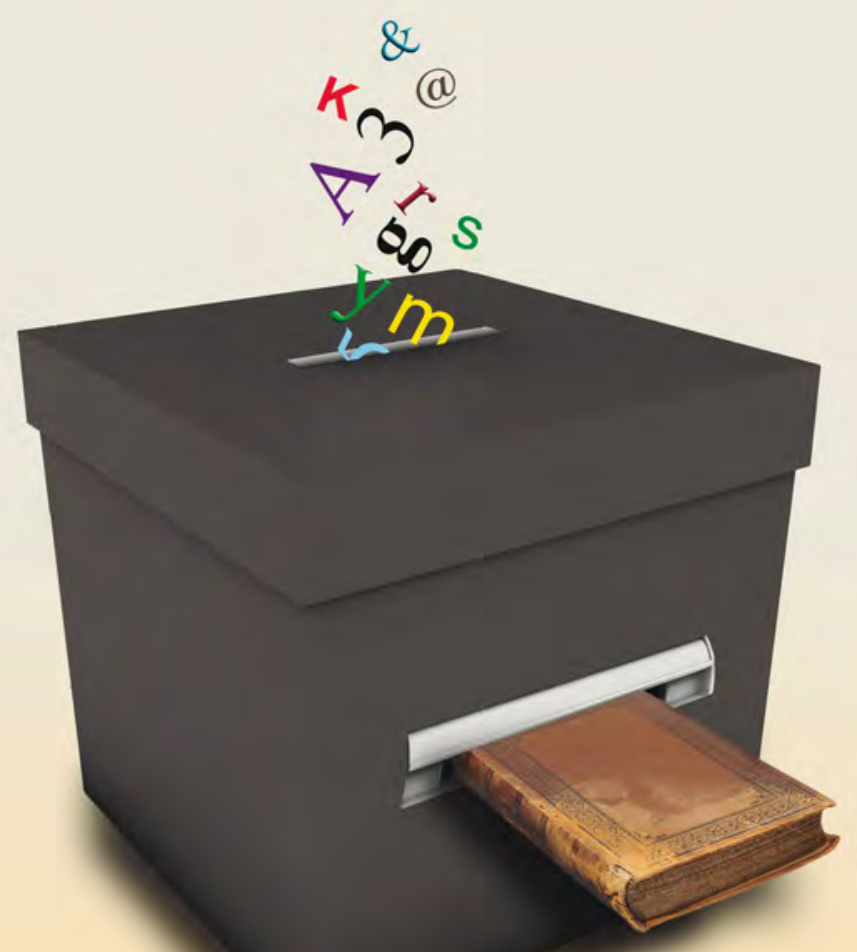




\section{La presente obra está bajo una licencia de:}

\section{http://creativecommons.org/licenses/by-nc-sa/3.0/deed.es MX}

\section{Atribución-No Comercial-Licenciamiento Reciproco 3.0 Unported}

Eres libre de:

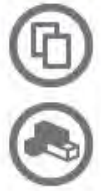

copiar, distribuir y comunicar públicamente la obra

hacer obras derivadas

Bajo las condiciones siguientes:

Atribución - Debes reconocer la autoría de la obra en los términos

especificados por el propio autor o licenciante.

No comercial - No puedes utilizar esta obra para fines comerciales.

Licenciamiento Recíproco - Si alteras, transformas o creas una obra a

partir de esta obra, solo podrás distribuir la obra resultante bajo una licencia

igual a ésta.

\section{Esto es un resumen fácilmente legible del: texto legal (de la licencia completa)}

En los casos que sea usada la presente obra, deben respetarse los términos especificados en esta licencia.
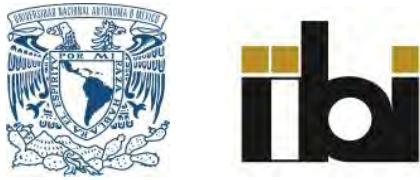
Introducción a la teoría de conjuntos, los operadores booleanos

y la teoría del concepto para profesionales de la información documental 
Instituto de Investigaciones Bibliotecológicas y de la Información 


\section{Introducción a la teoría de conjuntos, los operadores booleanos y la teoría del concepto para profesionales de la información documental}

Miguel Ángel Rendón Rojas

Universidad Nacional Autónoma de México 2017 
QA248 Rendón Rojas, Miguel Ángel

R45 Introducción a la teoría de conjuntos, los operadores booleanos y la teoría del concepto para profesionales de la información documental / Miguel Ángel Rendón Rojas. - México : UNAM, Instituto de Investigaciones Bibliotecológicas y de la Información, 2017.

xii, 156 p. - ( Teorías y métodos)

ISBN: 978-607-02-9485-3

1. Teoría de Conjuntos 2. Operadores Booleanos 3. Recuperación de Información I. t. II. ser.

Diseño de portada: Mario Ocampo Chávez

Primera edición, 2017

DR (C) UnIVERsidad NACIONAL AuTónOma DE MÉXICO

Ciudad Universitaria, 04510, Ciudad de México

Impreso y hecho en México

ISBN: 978-607-02-9485-3

Publicación dictaminada 


\section{Tabla de contenido}

Prólogo $\ldots \ldots \ldots \ldots \ldots \ldots \ldots \ldots \ldots \ldots \ldots \ldots \ldots \ldots \ldots \ldots$ vii

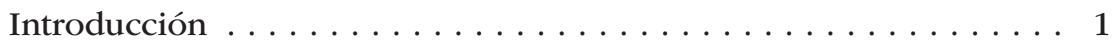

LA LÓGICA, SU NATURALEZA Y FUNCIÓN $\ldots \ldots \ldots \ldots \ldots \ldots \ldots 1$

DOS ASPECTOS DEL CONOCIMIENTO . . . . . . . . . . 5

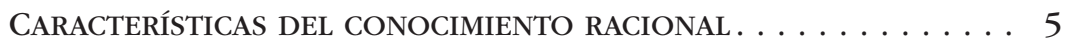

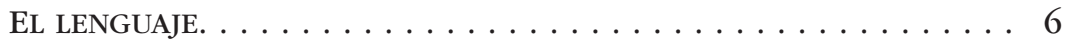

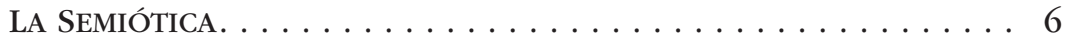

LA LÓGICA FORMAL $\ldots \ldots \ldots \ldots \ldots \ldots \ldots \ldots$

Capítulo I. TEORÍA de CONJUnTOS $\ldots \ldots \ldots \ldots \ldots \ldots \ldots \ldots$

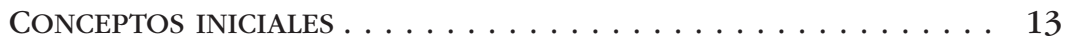

Tipos de conjuntos $\ldots \ldots \ldots \ldots \ldots \ldots \ldots \ldots \ldots \ldots \ldots$

RELACIÓN ENTRE CONJUNTOS . . . . . . . . . . . . 28

OPERACIÓN ENTRE CONJUNTOS $\ldots \ldots \ldots \ldots \ldots \ldots \ldots \ldots . \ldots \ldots$

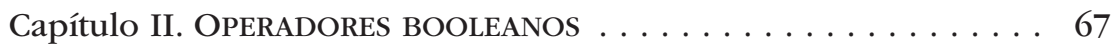

Álgebra de BOOLE . . . . . . . . . . . . . . . . . . . . . . 69

Capítulo III. TEORÍA DEL CONCEPTO . . . . . . . . . . . . . . . . 79

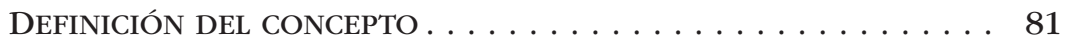

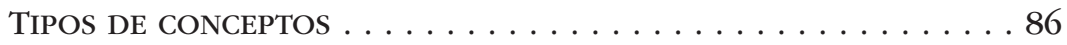

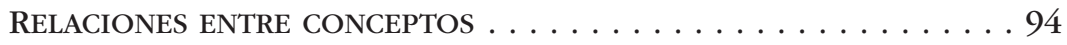

RELACIONES ENTRE JUICIOS . . . . . . . . . . . . . . 105 
OPERACIONES ENTRE CONCEPTOS . . . . . . . . . . . . . 110

LÓGICAS NO-CLÁSICAS . . . . . . . . . . . . . . . 122

Bibliografía . . . . . . . . . . . . . . . . . . . . . 125

Índice de ejercicios. . . . . . . . . . . . . . . . . . . . . . . . 129 


\section{Prólogo}

robablemente muchos de nosotros, al ser usuarios de una
biblioteca y buscar acceso a sus materiales, hemos utilizado
los catálogos en línea. Al llenar los campos con los datos correspondientes para encontrar el documento que necesitamos, se nos informa que se pueden utilizar los llamados "operadores booleanos", generalmente expresados en inglés con las palabras and, or, not para encontrar más fácilmente los materiales que buscamos. Como usuarios de bibliotecas, quizá nunca nos hayamos preguntado qué procesos suceden en la máquina cuando realizamos esas búsquedas más específicas o delimitadas por los operadores booleanos.

Sin embargo, los especialistas en información documental -bibliotecarios, archivistas, gestores de información documental, entre otros- que ya no son solamente usuarios de catálogos, necesitan poseer un conocimiento completo de qué son, cómo operan y por qué funcionan de esa manera los operadores booleanos. Dichas personas, gracias a su formación en un nivel superior de educación, pueden ser llamadas profesionales de la información documental porque cuentan con conocimientos teóricos que les ayudan a explicar y dar razón del manejo, la organización y la recuperación de información. El estudio de la teoría de conjuntos y el álgebra de Boole permite llegar a comprender el sustento lógico en el que se basa la 
combinación de términos o palabras que ofrece como resultado un listado de obras, y evita ver ese proceso como una "actividad" que sucede en una caja negra a la que se le introducen ciertos datos para que ofrezca otros a la salida sin saber cómo y por qué ocurrió aquello. Más aún, la clasificación documental como actividad teórica tiene en la división de conceptos o clases (conjuntos) uno de sus fundamentos; a su vez, la división puede ser explicada como una operación lógica realizada en y con los conjuntos. De ahí que si se estudia la teoría de conjuntos y del concepto, se puede entender de una manera clara y explícita el funcionamiento de los operadores booleanos y el mecanismo de la clasificación.

Finalmente, el conocimiento de la teoría del concepto desde el punto de vista lógico nos proporciona una herramienta para el trabajo intelectual porque nos guía en la formación y el uso de conceptos, lo que permite alejarnos de ambigüedades y ganar en claridad y precisión en nuestro pensamiento y en la exposición de nuestras ideas. Es por eso que este tipo de conocimiento es útil para cualquier persona que realice un trabajo intelectual, ya sea estudiante, profesor, investigador o profesional de cualquier área. Poseer una cultura lógica-metodológica mínima y saber manejar conceptos es parte de ella, siempre será una exigencia y necesidad para el que se precie de querer investigar la verdad y comunicar sus pensamientos de forma ordenada y clara.

El presente libro es el material que a través de los años he ido elaborando al impartir el seminario "Información y documentación electrónicas: lógica booleana” en el Programa de Posgrado en Bibliotecología y Estudios de la Información en la Universidad Nacional Autónoma de México (UNAM). La idea era ofrecer a los alumnos más que un libro de texto, una guía que les permitiera trabajar de manera autónoma e ir construyendo su conocimiento. ${ }^{1}$

1 La idea de una obra que guiara a los estudiantes para que ellos mismos construyan sus conocimientos fue tomada de Javier Salazar Resines (1970, 1971). 
Así pues, los objetivos de este libro son reconocer las principales operaciones que se realizan con conjuntos; comprender cómo se forman los nuevos conjuntos a partir de esas operaciones; realizar esas operaciones; identificar la relación existente entre las operaciones que se realizan con conjuntos y los operadores booleanos; describir y analizar lo que se entiende por concepto como forma del pensamiento; construir conceptos de acuerdo a las reglas lógicas correspondientes; distinguir diferentes clases de conceptos y relaciones entre éstos; comprender y aplicar la limitación, generalización y división de conceptos como operaciones lógicas en los conceptos; relacionar las operaciones lógicas realizadas en los conceptos con las operaciones que se realizan con los conjuntos, y explicar la clasificación como una operación lógica en conceptos o clases mediante la introducción o eliminación de conectivos.

El texto presenta al lector la explicación del tema a tratar en un primer momento y, posteriormente, le ofrece una serie de ejercicios que le permiten aplicar lo que fue expuesto anteriormente. Esto le permite, por un lado, reafirmar lo leído, sacar a la luz ciertas dudas que puedan aparecer y que en un principio no se había percatado que tenía y, por otro lado, propicia el trabajo independiente y hasta cierto punto autodidacta. Aunque esto último es una de las intenciones del texto, se recomienda que se tenga un profesor o tutor que oriente y guíe el aprendizaje.

Así pues, dejemos al lector adentrarse en el estudio de la teoría de conjuntos; conocer, comprender y manejar los operadores booleanos, y finalizar con la teoría del concepto. 


\section{Introducción}

\section{LA LÓGICA, SU NATURALEZA Y FUNCIÓN}

omo ya se mencionó, esta obra fue concebida como un apo-
yo didáctico para los estudiantes que cursan el seminario
"Información y documentación electrónicas: lógica boole-
na" en la maestría de Bibliotecología y Estudios de la Información
que ofrece la unAM. En dicho seminario, se tenía el objetivo de que
los alumnos comprendieran lo que son y cómo funcionan los ope-
radores booleanos, de tal manera que el centro sobre el que gira el
contenido de este trabajo son precisamente las nociones de esos
operadores. Sin embargo, para comprender esos conectivos, utiliza-
mos las operaciones entre conjuntos, por lo que en el primer capí-
tulo abordamos la teoría de conjuntos para posteriormente, en el
segundo capítulo, ya con esas herramientas teóricas, presentemos
la lógica booleana. Finalmente, como corolario de nuestro curso,
aprovechamos los conocimientos que se obtuvieron sobre opera-
ciones entre conjuntos y operadores booleanos para adentrarnos
en la teoría del concepto, por lo que en un tercer capítulo se presen-
tan las nociones nucleares de dicha teoría.
Debido a que todo el contenido de este libro gira en torno a pro-
blemáticas lógicas, consideramos pertinente antes de iniciar nuestra
exploración en los temas que vamos a tratar, introducir al estudiante 
en la naturaleza y las características específicas de la Lógica como ciencia. Es común escuchar en la vida cotidiana que se emplea el término "lógica" y sus derivados como adjetivo o adverbio de manera generalizada, sin un campo establecido. Así, por ejemplo, se afirma "si suelto de mi mano este objeto pesado, lógicamente se va a caer", "si un número no es par, por lógica es non", "si meto la mano al fuego, lógicamente me quemo", "no se tapó al salir a la calle cuando hacía frío y lógicamente se enfermó", "es lógico que si no planeo mis actividades, saldrán mal", "si los trabajadores no reciben una remuneración justa, lógicamente habrá protestas públicas" o "es lógico que primero se ponen los calcetines y luego los zapatos". En todas las expresiones anteriores, aunque se utiliza la palabra lógica o sus derivados, estrictamente hablando, nada tienen que ver con lo que en realidad es la Lógica, y más bien se tienen enunciados que resultan verdaderos por otras razones. En los ejemplos proporcionados, se alude a leyes físicas, matemáticas, químicas; cuestiones de carácter biológico, administrativo, político, o al sentido común respectivamente. De esta forma, no todo lo obvio es lógico, así como tampoco lo es aquello que necesariamente tiene que suceder, ni lo que dicta el sentido común. La Lógica tiene un campo muy específico de aplicación que trataremos de aclarar a continuación.

Es comúnmente aceptado que la Lógica como ciencia tiene como su creador a Aristóteles. Durante más de veintidós siglos, se creyó que la Lógica era una ciencia terminada, que después de su creación ya no podía desarrollarse más. Es conocida la opinión de Kant al respecto:

Que la lógica ha llevado ya esa marcha segura desde los tiempos más remotos, puede colegirse por el hecho de que, desde Aristóteles, no ha tenido que dar un paso atrás [...] Notable es también en ella el que tampoco hasta ahora hoy ha podido dar un paso adelante. Así pues, según toda apariencia, hállese conclusa y perfecta. ${ }^{2}$

2 Immanuel Kant. 
La afirmación anterior se realiza porque, a excepción de los trabajos de Leibniz, en la Edad Moderna, la Lógica se desarrolló poco o nada, y se desconocían los aportes de los estoicos y de la escuela de Megara en materia de lo que actualmente se conoce como lógica de enunciados (o de proposiciones) en la Edad Antigua, así como tampoco se conocía el pensamiento medieval en general y la lógica medieval en particular, con sus interesantes propuestas por ejemplo en semántica lógica, lógica modal o teoría de la consecuencia. Pero a partir del siglo XIX y durante todo el siglo XX, se redescubrieron esos trabajos de la Antigüedad y la Edad Media, así como también empezó a darse una convergencia de las Matemáticas con la Lógica.

De esta manera, surgió la Lógica contemporánea, la cual se desarrolló gracias al trabajo de varios pensadores, matemáticos y lógicos que realizaron diferentes aportaciones en diversos campos, como por ejemplo, la teoría intuitiva de conjuntos de G. Cantor; ${ }^{3}$ el álgebra de la lógica de G. Boole, ${ }^{4}$ y la creación de un lenguaje preciso que expresara "el pensamiento puro", y que dio origen al lenguaje y los sistemas de la lógica de enunciados y la lógica de predicados propuestos originalmente por G. Frege y retomado posteriormente por B. Russell y A. Whitehead en su zesfuerzo por fundamentar las Matemáticas, ${ }^{5}$ así como los trabajos de otros pensadores. ${ }^{6}$

Independientemente de que en los sistemas propuestos por Cantor y Frege se llegaron a descubrir serios problemas, conocidos como

3 Cf. Georg Cantor Grundlage einer Mannigfaltigkeitslebre. (Fundamento de una teoría de la pluralidad).

4 Cf. George Boole.

5 Gottlob Frege. Begriffsschrift, eine der arithmetischen nachgebildete Formelsprache des reinen Denkens. (Ideografía: un lenguaje formalizado del pensamiento puro a base del lenguaje aritmético); Gottlob Frege Die grundlagen der arithmetik; eine logisch-mathematische untersuchung uber den begriff der $z a h l$. Versión en español: Gottlob Frege. Los fundamentos de la aritmética: Investigación lógico-matemática sobre el concepto del número. Barcelona: Laia; Bertrand Russell y Alfred Whitehead. Principia Mathematica, I, II, III.

6 No se pueden pasar por alto las aportaciones de Augustus de Morgan, Giuseppe Peano, Charles Peirce, Leibniz, entre otros. 
paradojas, y que para evadirlos se elaboraron diferentes propuestas como la teoría de tipos de Russell; el intuicionismo en lógica y matemáticas de Heyting y Brouwer, y el formalismo y constructivismo de Hilbert, ${ }^{7}$ podemos afirmar que la teoría de conjuntos, el álgebra de Boole, así como la lógica proposicional y de cuantificadores de Frege-Russell, resultaron ser una poderosa herramienta para entender el proceso de razonamiento y tuvieron rasgos semejantes. Las operaciones entre conjuntos, unión, intersección y complemento tenían su equivalente en los operadores booleanos "o", "y", "no" y con los conectivos lógicos de la disyunción (o), la conjunción (y) y la negación (no). Esta semejanza estructural, que resalta el carácter lógico de las problemáticas que se tratan en este libro, nos permite ofrecer una introducción desde el punto de vista de la lógica que devele su naturaleza y características esenciales, así como resaltar la importancia metodológica de esta área del conocimiento para un pensamiento correcto, lo que al mismo tiempo nos servirá para adentrarnos al contenido de este texto y su comprensión como material de naturaleza lógica.

Un primer acercamiento a lo que es la Lógica nos muestra que ésta tiene dos facetas. Por un lado, la Lógica es una ciencia en cuanto tiene un objeto de estudio y descubre ciertas leyes que rigen un proceso; por otro, es un instrumento de trabajo ya que con base en las leyes que descubre es posible utilizarla en el trabajo intelectual como una herramienta que nos ayuda a obtener ciertos resultados. Para identificar y poner en claro cuál es ese objeto de estudio y las leyes particulares de la Lógica, realizaremos un breve análisis que empezará con el conocimiento, continuará con el lenguaje y finalizará con la semiótica.

$7 \quad$ El objetivo de este trabajo exige limitarnos únicamente a mencionar tanto la existencia de las paradojas como el nombre de las propuestas para evadirlas. Entrar en un análisis detallado nos desviaría de nuestro tema central ya que son cuestiones muy especializadas que implican varias diferencias muy sutiles y complejas. Para los interesados, se recomienda consultar a Arend Heyting y David Hilbert. 


\section{DOS ASPECTOS DEL CONOCIMIENTO}

El conocimiento implica una relación recíproca y activa entre dos elementos, el que conoce y la realidad que se conoce. A estos se les ha denominado sujeto y objeto respectivamente. El primero tiende hacia el objeto y se posesiona de él (gnoseológicamente hablando), es decir, hay una intencionalidad del sujeto hacia el objeto; por otra parte, el objeto "se da", "actúa” sobre el sujeto. Por supuesto que esa distinción entre sujeto y objeto no es absoluta, algo dado y terminado, sino que la filosofía contemporánea nos ha mostrado la complejidad de su interrelación. Ahora podemos afirmar que, en cierta manera, el sujeto construye al objeto y el objeto hace al sujeto. Para no caer en relativismos o subjetivismos, reconocemos que ontológicamente existe una realidad externa, pero el sujeto construye los objetos al dotarlos de sentido, no son invenciones ni creaciones ex nibilo pero tampoco entes acabados y eternos.

Sin adentrarnos en la discusión del estatus ontológico del sujeto y el objeto, podemos diferenciar dos aspectos en ese proceso cognitivo: el aspecto sensitivo y el racional. Algunos los identifican como dos etapas del conocimiento, aunque esa situación levanta muchas polémicas puesto que es muy difícil separarlos en secuencia como dos aspectos del conocimiento. Dejemos ese problema a la teoría del conocimiento y, constatando sólo el hecho de la existencia de esos dos aspectos, realicemos un análisis de ellos. El conocimiento sensitivo se da por medio de sensaciones, percepciones y representaciones; se caracteriza por ser inmediato, concreto, contingente y no descubre leyes. Por el contrario, el conocimiento racional tiene otras características que se verán a continuación.

\section{CARACTERÍSTICAS DEL CONOCIMIENTO RACIONAL}

El conocimiento racional se realiza a través de conceptos, juicios y raciocinios (en la lógica contemporánea se habla de términos, 
enunciados o proposiciones $\mathrm{y}$ argumentos respectivamente). Las características distintivas de este conocimiento son que es un conocimiento mediato puesto que no se captan de manera inmediata, por ejemplo, los conceptos, sino que son construidos de manera a posteriori; es general puesto que el discurso racional se refiere no a una cosa individual sino a un conjunto de ellas, y, finalmente, una característica que nos interesa particularmente es que se encuentra ligado al lenguaje.

El lenguaje es la "biosfera" del pensamiento, sin lenguaje no hay pensamiento, de ahí el aforismo de L. Wittgenstein "Los límites de mi mundo son los límites de mi lenguaje”. Es en el lenguaje donde se fija y expresa el pensamiento.

\section{EL LENGUAJE}

El lenguaje es un fenómeno muy complejo que puede ser abordado desde diversos puntos de vista: antropológico, fisiológico, sociológico, lingüístico, etc. Para el objetivo de este trabajo, el lenguaje nos interesa, de acuerdo con la última característica del conocimiento racional, como instrumento y medio del conocimiento. Sólo a través de él podemos introducirnos en el mundo del pensamiento y estudiar las leyes que lo rigen. Desde el punto de vista que nos incumbe, el lenguaje es un sistema de signos, es decir, lo tomaremos como un sistema semiótico.

\section{LA SEMIÓTICA}

La Semiótica es la ciencia general de los signos, creada por Charles Sanders Peirce y desarrollada por Charles William Morris. En ocasiones, sobre todo en la Europa continental, se utiliza el término Semiología. De manera general, se entiende por signo un objeto material que 
representa, está en lugar de, significa, denota, refiere a otro objeto. Dependiendo del fundamento por el que se dé un nexo entre un signo y su significado, Morris propuso distinguir diferentes clases de signos: los iconos, los índices y los símbolos.

Los iconos son aquellos signos que representan un objeto con base en su semejanza. Por ejemplo, las fotografías representan personas; los mapas lugares; el dibujo de una impresora en la pantalla de la computadora el proceso de imprimir.

Los índices son signos que se relacionan con sus significados debido a una relación causa-efecto entre ellos. De este modo, tenemos que el humo es signo del fuego, las nubes obscuras de la lluvia, el aroma de determinada flor, etcétera.

Los símbolos son una clase especial de signos que representan a su objeto no por la semejanza con ellos ni por su relación de causaefecto, sino por un consenso social y arbitrario. Una paloma blanca no tiene nada que ver con la paz, pero se le utiliza para representarla; los signos taquigráficos, los símbolos químicos, y las palabras orales o escritas también se encuentran dentro de esta clase de signos.

$\mathrm{Al}$ analizar un sistema semiótico, descubrimos que siempre cuenta con los siguientes elementos: los signos propiamente dichos, los objetos denotados por los signos y los usuarios de los signos. Estos elementos pueden relacionarse entre sí; las ramas de la semiótica estudian estas relaciones. La sintaxis estudia la relación de los signos con otros signos independientemente del significado que éstos tengan; la semántica estudia la relación de los signos con los objetos denotados, los significados, y la pragmática estudia la relación de los usuarios con los signos.

Un sistema semiótico muy sencillo es el semáforo, donde encontramos las relaciones entre sus símbolos, que son la secuencia de aparición de colores: rojo-verde-amarillo-rojo. La sintaxis establece que no pueden aparecer dos luces al mismo tiempo, o que del rojo se pase al amarillo, por ejemplo. Las relaciones semánticas indican que el color rojo significa alto; el verde, siga, y el amarillo precaución. 
Introducción a la teoría de conjuntos...

Las relaciones pragmáticas incluyen al usuario y varían de acuerdo a éstos; así, por ejemplo, para unos el color amarillo puede significar acelerar porque es la última oportunidad para no detenerse, mientras que para otros significa frenar porque la experiencia les ha enseñado que de lo contrario los pueden golpear.

\section{LA LÓGICA FORMAL}

Ahora podemos decir que la Lógica estudia el conocimiento racional inferido-deductivo dado a través del lenguaje, y lo estudia desde un punto de vista sintáctico y semántico. Semánticamente, estudia las leyes que rigen la obtención de conocimientos verdaderos a partir de otros conocimientos verdaderos. Es decir, estudia el paso de unas expresiones lingüísticas, llamadas enunciados, valoradas como verdaderas, a otras expresiones lingüísticas verdaderas. Esa relación necesaria de enunciados verdaderos iniciales, llamadas premisas, a otros verdaderos, llamados conclusión, se conoce como consecuencia lógica. Lo anterior significa que, según las leyes de la Lógica, es imposible obtener una conclusión falsa a partir de premisas verdaderas.

Sobre lo anterior, es importante señalar que la Lógica no estudia qué es la verdad y si esos enunciados de los que partimos son verdaderos y por qué lo son, de eso se encargará la teoría del conocimiento en el primer caso y las ciencias particulares en el segundo. Lo que hace la Lógica como instrumento de trabajo intelectual es cuidar que no se pierda la verdad de los enunciados iniciales en el paso que se hace de cadenas de inferencias, por lo que podemos afirmar que la Lógica es el pastor de la verdad: cuida que no se pierda la verdad.

En el aspecto sintáctico, la Lógica muestra y demuestra cómo unos símbolos iniciales pueden ser transformados en otros de acuerdo con ciertas reglas de formación y transformación de símbolos, independientemente de lo que signifiquen. Es con base en estas relaciones sintácticas con lo que trabajan las computadoras. Así pues, tanto 
desde el punto semántico como el sintáctico, el contenido concreto de las expresiones queda excluido del campo de la Lógica, a ésta no le interesa qué se dice, sobre qué se razona, sino cómo se razona, la corrección o incorrección lógica depende únicamente de la relación entre estructuras, que se denominan formas lógicas, de los enunciados que se manejen. Por lo tanto, estudiar Lógica tiene como objetivo primordial reconocer esas estructuras y sus relaciones, así como poder reproducir conscientemente esas cadenas de inferencia.

Debido a que la Lógica está ligada al lenguaje y todos lo utilizamos, todos utilizamos reglas lógicas de una manera natural, pero al estudiar esas reglas se puede perfeccionar la cultura lógica y, por lo tanto, la actividad racional y científica. Es en este punto donde se resalta el papel de la Lógica como instrumento de trabajo intelectual. 
Capítulo I

TEORÍA DE CONJUNTOS 


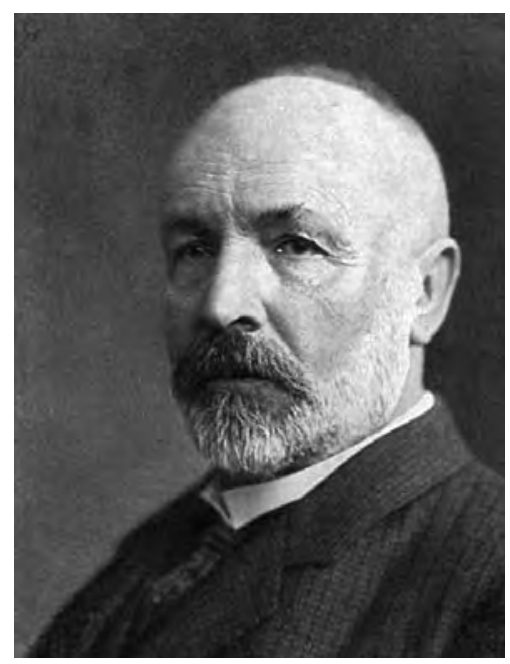

Gregor Cantor (1845-1918)

\section{CONCEPTOS INICIALES}

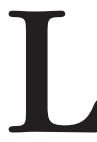

a noción de conjunto, también en ocasiones llamado clase, es primitiva. Es decir, no puede darse una definición en el sentido estricto porque no existe un concepto más general que éste. Se pueden emplear sinónimos como "grupo", "colección", "reunión de objetos", etcétera.

A pesar de que no se puede dar una definición exacta, es posible llegar a entender lo que es un conjunto (clase). De hecho, utilizamos esa noción en la vida diaria. Por ejemplo, hablamos de jauría, bosque, mamíferos, alumnos de una institución educativa, entre otros muchos casos. En todos ellos, entendemos que cada una de esas agrupaciones contiene individuos (perros, árboles, animales que alimentan a sus crías con leche, personas respectivamente) pero son vistas como un todo unitario. A continuación, se presentan otros ejemplos de conjuntos (clases): 
Introducción a la teoría de conjuntos...

\{El conjunto de documentos de una colección bibliotecaria\}

\{El conjunto de archivos de mi computadora\}

\{Las letras del alfabeto\}

\{El conjunto de planetas del sistema solar\}

\{El conjunto de puntos de una recta\}

$\{\mathrm{a}, \mathrm{e}, \mathrm{i}, \mathrm{o}, \mathrm{u}\}$

$\{2,4,6,8\}$

$\{1,2,3,4,5,6,7,8,9\}$

\{Los mexicanos\}

$\{1,2,3, \ldots\}$

\section{EJERCICIOS}

\section{Ejercicio 1}

Proporciona cinco ejemplos de conjuntos.

\section{Noción de conjunto (clase)}

Podemos decir que un conjunto (clase) es una colección (empleando la palabra colección como un sinónimo) de individuos definidos y distinguibles (personas, animales, cosas, ideas, símbolos) que pueden concebirse como una unidad. ${ }^{8}$ Así pues, la teoría de conjuntos descansa en una noción intuitiva de conjunto consistente en captar una colección de objetos como una sola entidad.

8 Las nociones definición y distinción serán aclaradas cuando se hable sobre la noción de elemento. 
Es importante señalar que las nociones de conjunto y sistema no son idénticas. El conjunto es un concepto más primitivo a partir del cual se puede definir un sistema. Esto significa que todo sistema es un conjunto pero no todo conjunto es un sistema. Por lo general, se entiende por sistema un conjunto cuyos elementos están interrelacionados. La nota distintiva que caracteriza a un sistema son las relaciones recíprocas entre los elementos que lo componen. Así, podemos dar ejemplos de sistemas tales como el sistema solar, un ecosistema, el sistema nervioso, el sistema social, un sistema de clasificación documental, entre otros. En todos ellos, descubrimos que, antes que nada, son un conjunto. El sistema solar es el conjunto del Sol, los planetas, los asteroides, los satélites y los cometas; un ecosistema es un conjunto de agua, fuentes de energía, seres vivos, componentes químicos; el sistema nervioso es un conjunto de cerebro, cerebelo, bulbo raquídeo, médula espinal, nervios, neuronas; un sistema social es un conjunto de instituciones sociales, de seres sociales; un sistema de clasificación es un conjunto de reglas de notación para formular códigos y símbolos que identifican el tema de un documento, los criterios de la taxonomía, entre otros elementos.

Sin embargo, incluso a simple vista, todos esos sistemas son mucho más que conjuntos. Lo importante no es que estén agrupados los planetas, el Sol, los satélites, los asteroides y los cometas, sino la interacción recíproca existente entre ellos que está tan bellamente expresada en la ley de la gravitación universal donde la atracción es directamente proporcional a sus masas e inversamente proporcional a sus distancias. Un cambio en uno de los elementos afecta todo el sistema. Otro ejemplo de la mayor complejidad de un sistema frente a un conjunto es mostrado con toda su fuerza en las catástrofes ecológicas, que son inducidas por la alteración de un elemento del ecosistema, ya sea la temperatura de la atmósfera o del agua, la desaparición de una especie o la ausencia o sobresaturación de un componente químico (ozono, $\mathrm{CO}_{2}$, 
Introducción a la teoría de conjuntos...

nitratos, etc.), cualquier modificación influye en todos los elementos. Así pues, es importante no confundir los conceptos de conjunto y sistema.

\section{Noción de elemento}

Los individuos que forman una colección se llaman miembros o elementos del conjunto. Al ofrecer la noción de conjunto, se ha afirmado que es una colección de individuos definidos y distinguibles. Aclaremos ahora lo que significa esto último. Un individuo está definido cuando puede advertirse si pertenece o no a un conjunto dado. Por ejemplo:

- Sonora es un elemento del conjunto de "Estados Unidos Mexicanos".

- Florida no es un elemento del conjunto de "Estados Unidos Mexicanos".

- $a$ es un elemento del conjunto de las vocales.

- $c$ no es un elemento del conjunto de las vocales.

Pero, ¿sería posible afirmar que: El objeto jutripisbu pertenece al conjunto de los metamegacuasiobjetos? Primero sería necesario definir el objeto jutripisbu así como el conjunto de los metamegacuasiobjetos. Lo anterior se debe de tomar en cuenta antes de empezar discusiones sobre la pertenencia o no de un objeto a un conjunto dado, llámese este último el conjunto de "las bibliotecas virtuales", de los “documentos electrónicos", etcétera. Por otro lado, dos elementos son distinguibles si al elegir dos elementos cualesquiera, se puede diferenciar si pertenecen a distintos conjuntos o si se trata de dos miembros del mismo. Por ejemplo:

- El libro de Erich Fromm El arte de amar no pertenece al conjunto de libros sobre sexualidad. 
- El libro Kamasutra pertenece al conjunto de libros sobre sexualidad.

Así pues, podemos distinguir los libros El arte de amar de Erich Fromm y el Kamasutra por la no pertenencia del primero y la pertenencia del segundo al conjunto de libros sobre sexualidad. Por otro lado, podemos afirmar que:

- Fiódor Mijáilovich Dostoievsky pertenece al conjunto de escritores rusos clásicos.

- El conde León Tolstoi pertenece al conjunto de escritores rusos clásicos.

- El autor de Ana Karénina y Resurrección pertenece al conjunto de escritores rusos clásicos.

Estamos en la posibilidad de distinguir a Fiódor Mijáilovich Dostoievsky y al conde León Tolstoi como dos elementos diferentes de un mismo conjunto: el conjunto de escritores rusos clásicos. Asimismo, es posible confirmar que los dos últimos elementos (conde León Tolstoi y autor de Ana Karénina y Resurrección) son uno mismo.

\section{EJERCICIOS}

\section{Ejercicio 2}

¿Es posible identificar los elementos de los conjuntos dados al inicio de este libro, cuándo se habla de definición de conjuntos y cuáles son algunos de esos elementos?:

\{El conjunto de documentos de una colección bibliotecaria\} 
Introducción a la teoría de conjuntos...

\{El conjunto de archivos de mi computadora\}

\{Las letras del alfabeto\}

\{El conjunto de planetas del sistema solar\}

\{El conjunto de puntos de una recta $\}$

$\{\mathrm{a}, \mathrm{e}, \mathrm{i}, \mathrm{o}, \mathrm{u}\}$

$\{2,4,6,8\}$

$\{1,2,3,4,5,6,7,8,9\}$ 
\{Los mexicanos\}

$\{1,2,3, \ldots\}$

\section{Ejercicio 3}

Proporciona dos ejemplos donde sea posible identificar los elementos de unos conjuntos.

\section{Ejercicio 4}

Proporciona dos ejemplos donde no sea posible identificar los elementos de unos conjuntos.

\section{Representación de conjuntos}

Se emplearán letras mayúsculas para representar conjuntos: A, B, $\mathrm{C}, \ldots, \mathrm{Z}$ y, si es necesario, se utilizarán esas letras con subíndices: $A_{1}, B_{1}, C_{1}, \ldots, Z_{1}, A_{2}, B_{2}, C_{2}, \ldots, Z_{2}, A_{3}, B_{3}, C_{3}, \ldots, Z_{3}, A_{n}, B_{n}, C_{n}, \ldots, Z_{n}$. De este modo, podemos representar los conjuntos dados anteriormente de la siguiente manera:

$\mathrm{A}=\{\mathrm{El}$ conjunto de documentos de una colección bibliotecaria $\}$

$\mathrm{B}=\{\mathrm{El}$ conjunto de archivos de mi computadora $\}$

$\mathrm{C}=\{$ Las letras del alfabeto $\}$ 
$\mathrm{D}=\{\mathrm{El}$ conjunto de planetas del sistema solar $\}$

$\mathrm{E}=\{\mathrm{El}$ conjunto de puntos de una recta $\}$

$\mathrm{F}=\{\mathrm{a}, \mathrm{e}, \mathrm{i}, \mathrm{o}, \mathrm{u}\}$

$\mathrm{G}=\{2,4,6,8\}$

$\mathrm{H}=\{1,2,3,4,5,6,7,8,9\}$

$\mathrm{I}=\{$ Los mexicanos $\}$

$\mathrm{J}=\{1,2,3, \ldots\}$

\section{Representación de los elementos de un conjunto}

Se emplearán letras minúsculas, con subíndices si son necesarios, para representar los elementos de un conjunto. Las primeras letras del abecedario: $a, b, c, \ldots, a_{1}, b_{1}, c_{1}, \ldots, a_{2}, b_{2}, c_{2}, \ldots, a_{3}, b_{3}, c_{3}, \ldots$ , $a_{n}, b_{n}, c_{n}, \ldots$, representarán elementos particulares y las últimas letras: $\mathrm{x}, \mathrm{y}, \mathrm{z}, \mathrm{x}_{1}, \mathrm{y}_{1}, \mathrm{z}_{1}, \mathrm{x}_{2}, \mathrm{y}_{2}, \mathrm{z}_{2}, \mathrm{x}_{3}, \mathrm{y}_{3}, \mathrm{z}_{3}, \ldots, \mathrm{x}_{\mathrm{n}}, \mathrm{y}_{\mathrm{n}}, \mathrm{z}_{\mathrm{n}}$, cualquier elemento del conjunto.

Así pues, para el conjunto A, podemos escribir que tiene los siguientes elementos:

$a=$ el libro de Bunge, Mario. Epistemología. Barcelona: Ariel, 1980.

$b=$ el libro de Lafuente López, Ramiro. Biblioteca digital y orden documental. México: CUIB-UNAM, 1999.

$c=$ el libro de Torres Vargas, Georgina Araceli. Lineamientos para el análisis de términos en bibliotecología. México: CUIBUNAM, 1998.

$x=$ un documento cualquiera que pertenezca a esa colección.

\section{Pertenencia de un elemento a un conjunto}

Para indicar que un individuo $x$ es un elemento o miembro de un conjunto $A$, se emplea el símbolo $\in$. Así, tenemos que $x \in A$ expresa que $x$ pertenece a $A$ o que $x$ es un elemento de $A$. 
De este modo, tenemos si $D$ es el conjunto de los planetas del sistema solar y $m$ representa a Mercurio, entonces, para indicar que $m$ es elemento de $D$ o $m$ pertenece a $D$, se emplea la expresión $m \in D$.

\section{EJERCICIOS}

\section{Ejercicio 5}

Si $d$ representa el libro de José López Yepes, La documentación como disciplina. Teoría e historia. España: Eunsa, 1995. Segunda edición, y $A$ es el conjunto de documentos de una biblioteca, entonces ¿cómo se representaría la expresión $d$ es elemento de $A$ ?

\section{Ejercicio 6}

Si $b$ representa el libro de Miguel Angel Rendón Rojas. Bases teóricas y filosóficas de la Bibliotecología. México: CUIB-UNAM, 1998. Primera reimpresión, y $A$ es el mismo conjunto que en el ejemplo anterior, entonces, ¿cómo se lee la expresión: $b \in \mathrm{A}$ ?

Para indicar que un individuo $x$ no es un elemento o miembro del conjunto $A$, se emplea el símbolo $\notin$ Así, tenemos que $x \notin A$ expresa que $x$ no pertenece a $A$, o que $x$ no es un elemento de $A$. Entonces, si $D$ representa el conjunto de planetas del sistema solar y $a$ representa la estrella Alfa Centauri, entonces para indicar que $a$ no es elemento de $D$ o $a$ no pertenece a $D$, se emplea la expresión $a \notin D$. 
Introducción a la teoría de conjuntos...

\section{EJERCICIOS}

\section{Ejercicio 7}

Si $m$ representa el libro de Jostein Gaarder, El mundo de Sofía. Séptima reimpresión. México: Editorial Patria, 1996, ¿cómo se indicaría que dicho libro no pertenece al conjunto de documentos de la biblioteca representado por la letra $A$ ?

\section{Descripción extensional de conjuntos}

Un conjunto se puede describir al enumerar sus elementos o miembros. Este tipo de descripción se denomina extensional. Esta representación es posible cuando el número de elementos además de ser finito, es reducido. La representación extensional de algunos conjuntos infinitos es factible si está determinada por la ley de sucesión en que ocurren los elementos.

Los conjuntos $\mathrm{F}=\{\mathrm{a}, \mathrm{e}, \mathrm{i}, \mathrm{o}, \mathrm{u}\}, \mathrm{G}=\{2,4,6,8\}$ y $\mathrm{H}=\{1,2,3,4,5,6$, $7,8,9\}$ están dados extensionalmente, es decir, se enumeran todos los elementos que los constituyen. Como ya se habrá notado, los elementos suelen encerrarse dentro de corchetes.

El conjunto $\mathrm{J}=\{1,2,3, \ldots\}$ también está dado de manera extensional, aunque no se enumeran todos sus elementos, pero los puntos suspensivos nos indican que el orden dado al principio seguirá sucesivamente.

El conjunto $\mathrm{D}=\{\mathrm{El}$ conjunto de planetas del sistema solar $\}$ se puede dar extensionalmente de la siguiente manera: $\mathrm{D}=\{$ Mercurio, Venus, Tierra, Marte, Júpiter, Saturno, Urano, Neptuno, Plutón\}.

El conjunto $\mathrm{A}=\{\mathrm{El}$ conjunto de documentos de una colección bibliotecaria\} hipotéticamente se puede dar por enumeración, pero fácticamente es muy problemático. 


\section{EJERCICIOS}

\section{Ejercicio 8}

De los cinco ejemplos de conjuntos que se te pidieron en el ejercicio 1 , ¿cuáles son los que se presentaron extensionalmente?

\section{Descripción intensional}

En ocasiones, principalmente desde el punto de la Lógica, pero también para la clasificación documental, que no es más que la aplicación de una operación lógica, es importante describir los conjuntos a partir de la propiedad o las propiedades que hacen que una colección de objetos pueda concebirse como una unidad.

Por ejemplo, los conjuntos $A, B, C, D, E$ e $I$ están dados por la presencia de propiedades comunes en sus elementos. Si representamos con $P$ la propiedad de "ser documento de una colección bibliotecaria”, entonces tenemos que el conjunto $A$ se forma de la siguiente manera: $A=\{x / P x\}$. Que se lee: $A=A$ es el conjunto, $x=$ de todas las $x, /=$ tales que, $P x=$ tienen (cumplen, satisfacen) la propiedad $P$. (Los corchetes no tienen un significado en lenguaje natural, sólo tienen la función de agrupar la expresión del lado derecho).

De la misma forma, si $Q$ es la propiedad de ser archivo de mi computadora, entonces el conjunto $B$ se forma de la siguiente manera: $B=\{x / Q x\}$, que en lenguaje natural se lee: $B$ es el conjunto de todas las $x$ que tienen la propiedad $Q$.

Para el conjunto $C$, tenemos la propiedad "ser letra del alfabeto" que presentaremos con la letra $R$. De esta forma, $C=\{x / R x\}$, donde $C$ es el conjunto de todas las $x$ que tienen la propiedad de ser letra del alfabeto. 
Introducción a la teoría de conjuntos...

\section{EJERCICIOS}

\section{Ejercicio 9}

Si la propiedad de $S$ es "ser planeta del sistema solar", la propiedad $T$ representa a la propiedad "ser punto de una recta" y $U$ representa a la propiedad "ser mexicano”, entonces, ¿cómo se darían intensionalmente los conjuntos $D, E$ e $I$ de la página 24 y 25 (en esta versión)?

\section{Ejercicio 10}

De los cinco ejemplos de conjuntos que se te pidieron, ¿cuáles son lo que se presentaron intensionalmente?

\section{TIPOS DE CONJUNTOS}

\section{Conjunto finito}

Un conjunto es finito si se pueden conocer sus elementos con exactitud. Por ejemplo:

Si $P_{1}$ es la propiedad "ser estado fronterizo de la República mexicana con Guatemala”, entonces podemos formar el conjunto $K=\left\{x / P_{1} x\right\}$.

Si $P_{2}$ es la propiedad "ser elemento químico", tenemos el conjunto $L=\left\{x / P_{2} x\right\}$.

Si $P_{3}$ es la propiedad "ser mexicano mayor de 18 años", es posible obtener el conjunto $M=\left\{x / P_{3} x\right\}$. 
Si $P_{4}$ es la propiedad "ser postulado de la geometría euclidiana", se puede formar el conjunto $N=\left\{x / P_{4} x\right\}$.

\section{EJERCICIOS}

\section{Ejercicio 11}

Proporciona cinco ejemplos de conjuntos finitos.

\section{Conjunto infinito}

Un conjunto es infinito cuando tiene un número interminable de elementos que no se pueden conocer con exactitud. Ejemplos:

$\mathrm{O}=\{$ Los números enteros $\}$.

$\mathrm{P}=\{$ Los teoremas de la lógica de predicados $\}$.

$\mathrm{Q}=\{$ Las fracciones decimales del número $\pi\}$.

$\mathrm{R}=\{$ Las caras de una esfera $\}$.

\section{EJERCICIOS}

\section{Ejercicio 12}

Proporciona cinco ejemplos de conjuntos infinitos. 
Introducción a la teoría de conjuntos...

\section{Conjunto universal}

Un conjunto universal es el que contiene todos los elementos que se van a mencionar en una presentación; se representa con una $U$ mayúscula. Ejemplos:

$U=\{$ Seres humanos $\}$ cuando se habla del conjunto de los mexicanos.

$U=\{$ Números enteros $\}$ en el discurso sobre el conjunto de los dígitos.

$U=\{$ Libros publicados $\}$ dentro del marco del conjunto de los libros sobre Biología.

$U=\{$ Palabras del español $\}$ si se está analizando el conjunto de las palabras agudas.

\section{Diagramas de Euler-Venn}

Se emplean también representaciones gráficas (diagramas de Euler-Venn) para definir los elementos del universo o de un conjunto de dicho universo. El universo $U$ se representará con un rectángulo; un círculo representa un conjunto dentro de ese universo, y un punto un elemento. Así, por ejemplo, si tomamos el primer conjunto universal mencionado arriba, tenemos:

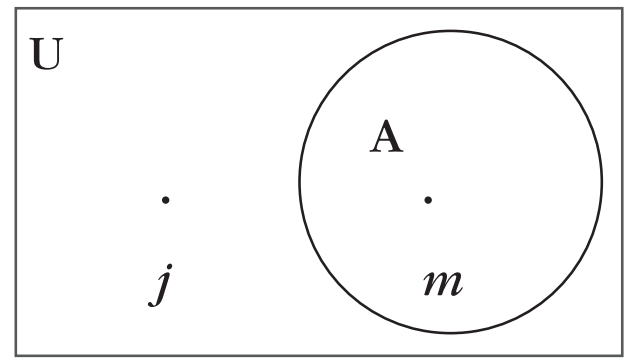

$U=\{$ Seres humanos $\}$

$A=\{$ mexicanos $\}$ 
$J=$ John que nació y vive en Londres

$m=$ Mario que nació y vive en Pátzcuaro, Michoacán.

Podemos observar que $j U$ pero $j A, m U$ y $m A$.

\section{EJERCICIOS}

\section{Ejercicio 13}

Proporciona cinco ejemplos de conjuntos universales y el contexto donde se utilizan.

\section{Conjunto vacío}

Es el conjunto que no contiene ningún elemento, se representa con el signo $\varnothing$. Ejemplos:

$S=\{$ Los triángulos con dos ángulos rectos $\}$

$T=\{$ Las letras que están antes de la A en nuestro alfabeto $\}$

$U=\{$ Enteros múltiples de 7 , mayores de 1 y menores de 6$\}$

$V=\{$ Libros sobre física cuántica escritos por Aristófanes $\}$

\section{EJERCICIOS}

\section{Ejercicio 14}

Proporciona cinco ejemplos de conjuntos vacíos. 
Introducción a la teoría de conjuntos...

\section{Conjunto unitario}

Es el conjunto que contiene un solo elemento. Ejemplos:

$W=\{$ Las letras de nuestro alfabeto que están después de la A y antes de la $\mathrm{C}\}$

$X=\{$ Enteros múltiples de 5, mayores de 7 y menores de 12\}

$Y=\{$ Autores de La divina comedia $\}$

$Z=\{$ Presidentes de los Estados Unidos Mexicanos de 1995 a 1999\}

\section{EJERCICIOS}

\section{Ejercicio 15}

Proporciona cinco ejemplos de conjuntos unitarios.

\section{RELACIÓN ENTRE CONJUNTOS}

\section{Igualdad}

Los conjuntos A y B son iguales si y sólo si tienen los mismos elementos. Esto no hace alusión al orden de los elementos. De esta forma si: 
$A_{1}=\{a, e, i, o, u\}$ y $B_{1}=\{i, u, o, e, a\}$ podemos decir que $A_{1}=B_{1}$

Asimismo, tampoco se hace referencia al número de veces que aparece cada elemento. Por consecuencia, si

$$
\begin{aligned}
C_{1}= & \{1,2,3,4,5\} \text { y } D_{1}=\{1,1,1,2,2,3,4,5,5,5,5,5\}, \text { es posible } \\
& \text { afirmar que } C_{1}=D_{1} .
\end{aligned}
$$

\section{EJERCICIOS}

\section{Ejercicio 16}

Dados dos conjuntos $A_{2}=\{1, a, 2, b, 3, c\}$ y $B_{2}=\{c, c, c, c, a, b, b$, $3,3,3,2,1,1,1,1\}$, ¿se puede decir que $A_{2}=B_{2}$ ?

\section{Inclusión}

Un conjunto $A$ está contenido o incluido dentro de $B$ si todos los elementos de $A$ son elementos de $B$.

Pueden darse dos casos:

1. Todos los elementos de $A$ son elementos de $B$, pero no todos los elementos de $B$ son elementos de $A$. Es decir, podemos encontrar elementos de $B$ que no son elementos de $A$ :

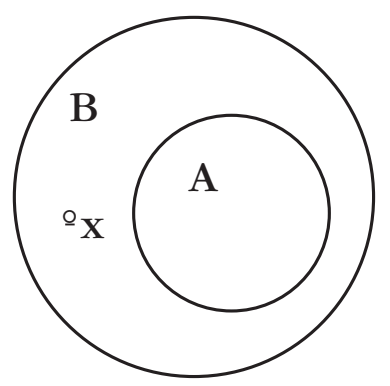


Introducción a la teoría de conjuntos...

Si $y A$, entonces necesariamente $y B$, aunque es posible encontrar una $x$ tal que $x B$ pero $x A$.

Lo anterior se expresa: $A B$ y se lee: " $A$ está contenido (incluido) en $B$ " o " $A$ es subconjunto propio de $B$ ".

2. También puede suceder que $A$ esté contenido en $B$, es decir, que todos los elementos de $A$ son elementos de $B$, pero al mismo tiempo $A=B$, es decir, no hay elementos que pertenezcan a $B$ y que no pertenezcan a $A$.

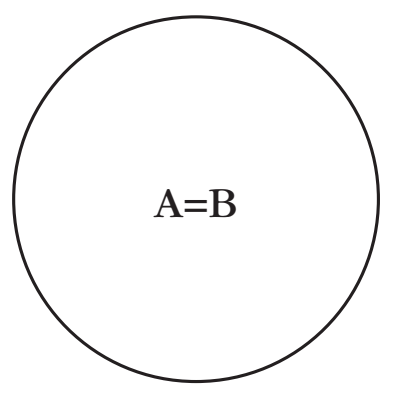

En ese caso, se dice que $A$ es subconjunto impropio de $B$ y se simboliza $A B$.

\section{EJERCICIOS}

\section{Ejercicio 17}

Proporciona dos ejemplos de inclusión entre conjuntos. 


\section{OPERACIÓN ENTRE CONJUNTOS}

Con los conjuntos, es posible realizar ciertas operaciones que dan por resultado otro conjunto. De este modo, si $A$ y $B$ son dos conjuntos cualquiera $\mathrm{y} *$ una operación que relaciona a los conjuntos anteriores, entonces $A^{*}=C$ y $A^{*} B=C$, donde $C$ también es un conjunto. En el primer caso, se trata de una operación unaria y en el segundo de una binaria.

\section{Complemento}

Una primera operación con los conjuntos es el complemento o la diferencia. Existen dos tipos de complementos, el complemento absoluto y el relativo.

\section{Complemento absoluto}

Dado un conjunto universal $U=$ \{Libros publicados $\}$ y un conjunto $E_{1}=\{x / F x\}$, donde $F$ es la propiedad de "ser de Filosofía" (es decir, el conjunto $E_{1}$ es el conjunto de los libros de Filosofía), podemos encontrar objetos que pertenecen a $\mathrm{E}_{1}$ y consecuentemente a $U$. Así, por ejemplo, si

$a=$ Metafísica de Aristóteles;

$b=$ República de Platón;

$c=$ Crítica de la razón pura de Kant;

$d=E l$ ser y el tiempo de Heidegger;

$e=$ El corán;

$f=$ El poema del Mío Cid;

$g=$ El servicio de consulta de Estela Morales,

entonces podemos afirmar que 
Introducción a la teoría de conjuntos...

$\begin{array}{lcl}a \in E_{1} & y & a \in U ; \\ b \in E_{1} & y & b \in U ; \\ c \in E_{1} & y & c \in U ; \\ d \in E_{1} & y & d \in U ; \\ e \in U & \text { pero } & e \notin E_{1} ; \\ f \in U & \text { pero } & f \notin E_{1} ; \\ g \in U & \text { pero } & g \notin E_{1}\end{array}$

Lo que se muestra en el siguiente diagrama:

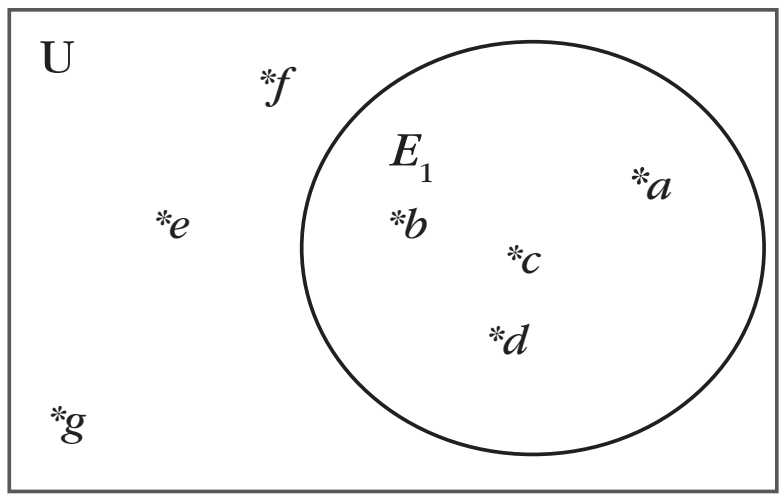

Por lo tanto, podemos constatar que existen elementos que pertenecen a $U$ pero no pertenecen a $E_{1}$. De esta manera, se puede obtener el conjunto de esos elementos que cumplen con las condiciones indicadas. A dicho conjunto, lo representaremos como $\bar{E}_{1}$, y se define de la siguiente manera:

$$
\bar{E}_{1}=\left\{x / x \in \boldsymbol{U} y x \notin E_{1}\right\}
$$

Este conjunto se denomina complemento de $E_{1}$ con respecto a $U$.

En el siguiente diagrama, el conjunto $\bar{E}_{1}=\left\{x / x \in \boldsymbol{U} y \quad x \notin E_{1}\right\}$ se representa con la zona coloreada: 


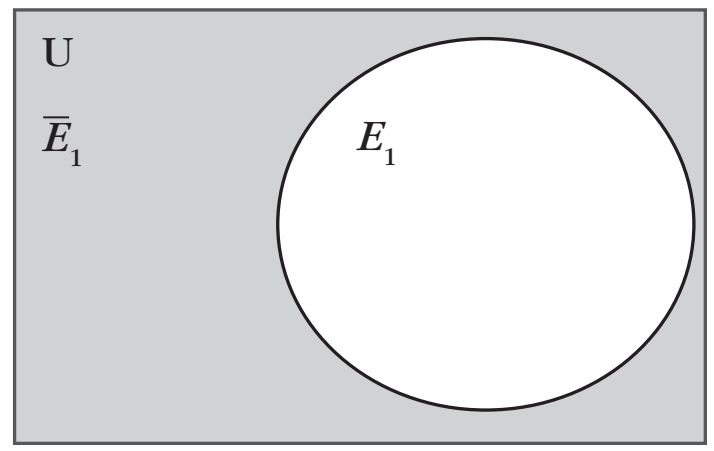

\section{EJERCICIOS}

Dado los conjuntos anteriores:

$U=\{$ Libros publicados $\}$

$E_{1}=\{x / F x\} \mathrm{y}$

$\bar{E}_{1}=\left\{x / x \in \boldsymbol{U} y \quad x \notin E_{1}\right\}$

donde $F=$ "ser libro de Filosofía",

indique a cuál de los dos conjuntos $E_{1}$ o $\bar{E}_{1}$ pertenecen los siguientes elementos:

\section{Ejercicio 18}

La fenomenología del espíritu de Hegel $\in$

\section{Ejercicio 19}

Historiales clinicos de Sigmund Freud $\in$ 
Introducción a la teoría de conjuntos...

\section{Ejercicio 20}

El modelo matemático de Bradford de Salvador Gorbea Portal $\in$

\section{Ejercicio 21}

Problemas y argumentos filosóficos de J. W. Cornman $\in$

Ahora bien, el conjunto $\bar{E}_{1}=\left\{x / x \in \boldsymbol{U} y x \notin E_{1}\right\}$ es tal, que para toda $x$ de ese conjunto, $F x$ ( $x$ tiene la propiedad $F$ ) es falsa; por lo tanto, para toda $x$ del conjunto $\bar{E}_{1}, n o-F x$ es verdadero.

Si utilizamos el signo $\sim$ para la negación, entonces la expresión $\sim F x$ se lee: las $x$ que no son $F$.

Podemos describir el conjunto $\bar{E}_{1}$ de la siguiente manera:

$\bar{E}_{1}=\{x / \sim F x\}$

De esta manera, el complemento de $E_{1}$ con respecto a $U$ es el conjunto de los elementos de $U$ que no son de Filosofía.

Así pues, es fácil descubrir que el complemento del complemento de un conjunto es igual al conjunto inicial.

\section{Complemento relativo de un conjunto con respecto a otro}

Sean

$U=\{$ el conjunto de libros publicados $\}$

$E_{1}=\{$ el conjunto de libros de Filosofía $\}$

$E_{2}=\{$ el conjunto de libros de Epistemología $\}$

Entonces, gráficamente tenemos: 


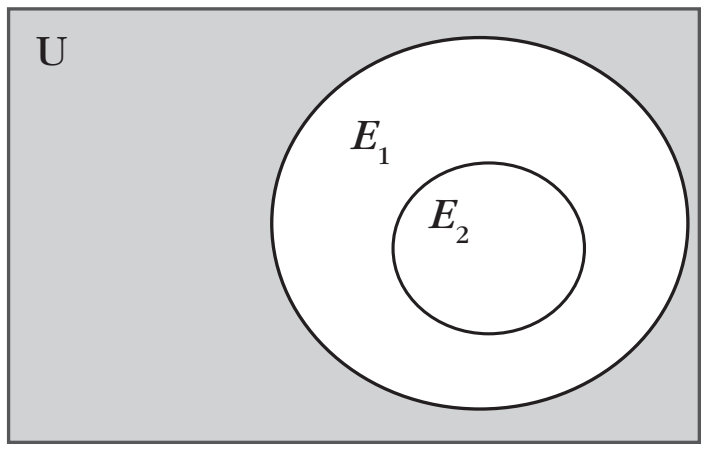

Utilizando la relación de inclusión tenemos que:

$E_{1} \subset \boldsymbol{U}\left(E_{1}\right.$ está incluido o es subconjunto de $U$ )

$E_{2} \subset E_{1}\left(E_{2}\right.$ está incluido o es subconjunto de $\left.E_{1}\right)$

De acuerdo con el diagrama anterior, el complemento de $E_{1}$ con respecto a $U$ se representa con las líneas horizontales:

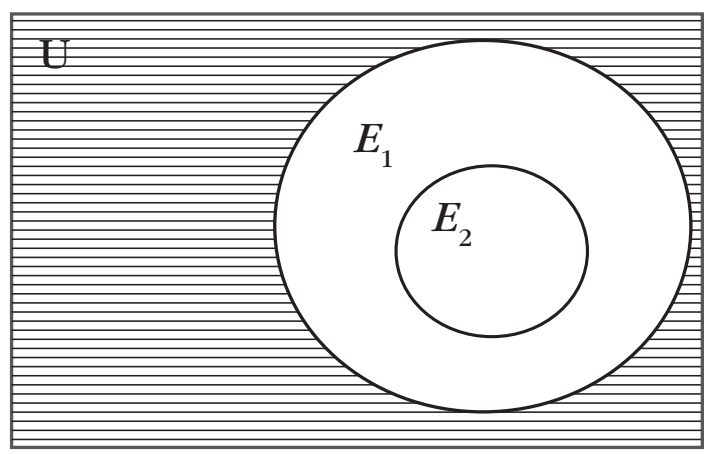

Dicho complemento $E_{1}$, como ya sabemos, se llama complemento absoluto o simplemente complemento. Podemos obtener un complemento de un conjunto respecto a otro, que no es el universo. En 
Introducción a la teoría de conjuntos...

este caso, es el complemento de $E_{1}$ con respecto a $E_{2}$. Ese complemento se llama complemento relativo o diferencia. Se representa $E_{1}-E_{2}=\left\{x / x \in E_{1} y x \notin E_{2}\right\}$. O bien, si $F$ es la propiedad de ser un libro de Filosofía y $E$ es la propiedad de ser un libro de Epistemología, la diferencia de $E_{1}$ con respecto a $E_{2}$ se escribe $E_{1}-E_{2}=\{x\}$ Fx $y \sim E x\}$.

En el diagrama, el conjunto $E_{1}-E_{2}$ se indica con líneas inclinadas:

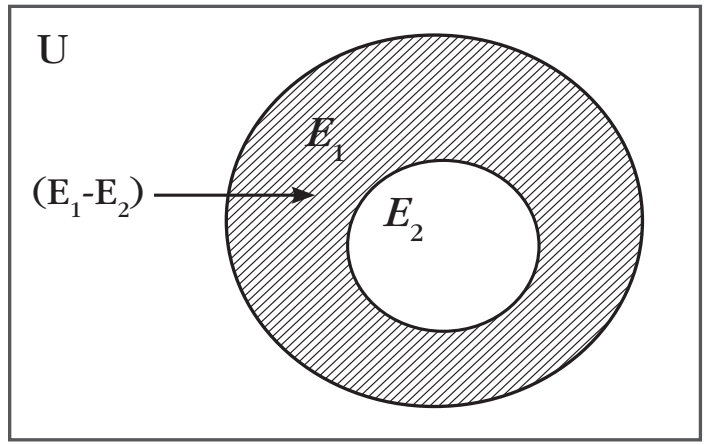

Ahora bien, es posible realizar repetidamente el complemento de un conjunto cuantas veces se requiera. Así, por ejemplo, si tenemos como conjuntos dados:

$$
\begin{aligned}
U & =\{1,2,3,4,5,6,7,8,9,10\} \\
A & =\{1,3,5,7\}
\end{aligned}
$$

El conjunto $\bar{A}$ es $\{2,4,6,8,9,10\}$, pero es posible obtener el complemento de ese conjunto, es decir, el complemento del complemento de $\overline{\bar{A}}$ representado como $\overline{\bar{A}}$, el cual contiene los elementos que pertenecen al universo y no se encuentran en $\bar{A}$. De esta manera, tenemos que $\bar{A}=\{1,3,5,7\}$, por lo que descubrimos que $A=\overline{\bar{A}}$. 


\section{EJERCICIOS}

Indique en el siguiente diagrama

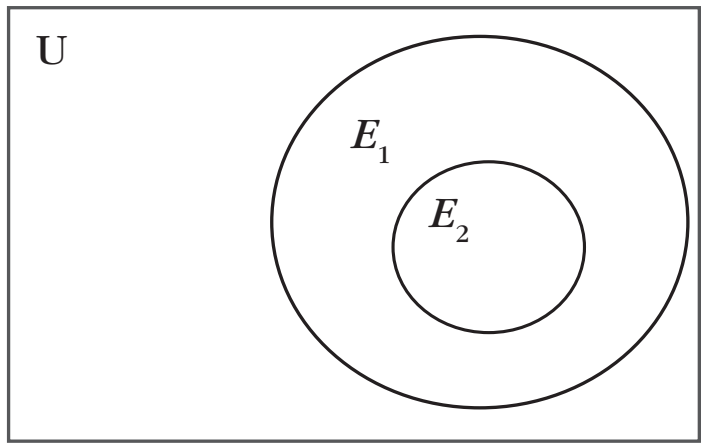

Ejercicio 22

Un punto $a$, tal que $a \in E_{2}$.

Ejercicio 23

Un punto $b$, tal que $b \in E_{1}$.

Ejercicio 24

Un punto $c$, tal que $c \in \bar{E}_{1}$.

Ejercicio 25

Un punto $d$, tal que $d \in \bar{E}_{2}$.

Ejercicio 26

Un punto $e$, tal que $e \notin \bar{E}_{2}$.

Ejercicio 27

Un punto $f$, tal que $f \notin E_{1}$.

Ejercicio 28

Un punto $g$, tal que $g \notin \bar{E}_{2}$. 
Introducción a la teoría de conjuntos...

\section{Ejercicio 29}

Un punto $h$, tal que $b \notin \bar{E}_{1}$.

\section{Ejercicio 30}

Un punto $i$, tal que $i \in \mathrm{E}_{1}$ e $i \notin \mathrm{E}_{2}$.

\section{Ejercicio 31}

Un punto $j$, tal que $j \in\left(E_{1}-E_{2}\right)$.

\section{Ejercicio 32}

Un punto $k$, tal que $k \in E_{2}$ y $k \notin \bar{E}_{1}$.

\section{Ejercicio 33}

Un punto $l$, tal que $l \notin \bar{E}_{1}$ y $l \in E_{2}$.

\section{Ejercicio 34}

Un punto $m$, tal que $m \in E_{2}$ y $m \notin E_{1}$.

\section{Intersección}

Se tienen los siguientes conjuntos:

$U=\{x / L x\}$, donde $L$ es la propiedad "ser libro".

$A_{2}=\{x / B x\}$, donde $B$ es la propiedad "ser libro de Bibliotecología".

$A_{3}=\{x / E x\}$, donde $E$ es la propiedad "ser libro en el idioma español”.

Es posible formar el conjunto de todos los elementos que pertenezcan a $A_{2}$ y $A_{3}$ simultáneamente. Dicho conjunto se denomina intersección de $A_{2}$ y a $A_{3}$ y se representa $A_{2} \cap A_{3}$. Podemos definir la intersección de $A_{2}$ y a $A_{3}$ como $A_{2} \cap A_{3}=\left\{x / x \in A_{2}\right.$ y $\left.x \in A_{3}\right\}$. La anterior expresión se lee: "La intersección de $A_{2} y A_{3}$ es el conjunto de todas las $x$, tales que $x \in A_{2} y x \in A_{3}$ simultáneamente". 
De esta manera, $A_{2} \cap A_{3}$ es el conjunto de todas las $x$, que pertenecen a $A_{2}$ y a $A_{3}$ simultáneamente.

Gráficamente, la intersección de $A_{2}$ y $A_{3}$ se representa de la siguiente manera:

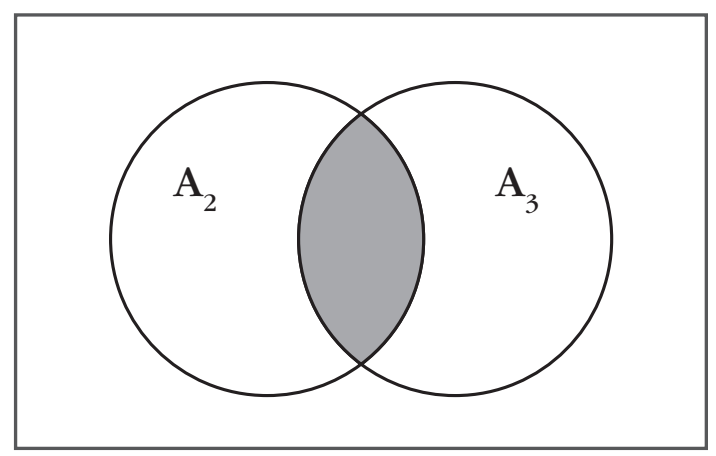

Si tenemos los conjuntos:

$\boldsymbol{U}=\{x / H x\}$, donde $H$ es la propiedad "ser hombre".

$B_{2}=\{x / F x\}$, donde $F$ es la propiedad "ser filósofo".

$B_{3}=\{x / A x\}$, donde $A$ es la propiedad "ser alemán".

Entonces el conjunto $B_{2} \cap B_{3}=\left\{x / x \in B_{2} y x \in B_{3}\right\}$, es decir, el conjunto de todos los filósofos que son alemanes.

De este modo,

Kant $\in\left(B_{2} \cap B_{3}\right)$

Fichte $\in\left(B_{2} \cap B_{3}\right)$

Schelling $\in\left(B_{2} \cap B_{3}\right)$

Hegel $\in\left(B_{2} \cap B_{3}\right)$

Feuerbach $\in\left(B_{2} \cap B_{3}\right)$

$\operatorname{Marx} \in\left(B_{2} \cap B_{3}\right)$ 
Introducción a la teoría de conjuntos...

Nietzsche $\in\left(B_{2} \cap B_{3}\right)$

Husserl $\in\left(B_{2} \cap B_{3}\right)$

Dilthey $\in\left(B_{2} \cap B_{3}\right)$

Adorno $\in\left(B_{2} \cap B_{3}\right)$

Horkheimer $\in\left(B_{2} \cap B_{3}\right)$

Heidegger $\in\left(B_{2} \cap B_{3}\right)$

Habermas $\in\left(B_{2} \cap B_{3}\right)$

Gadamer $\in\left(B_{2} \cap B_{3}\right)$

Appel $\in\left(B_{2} \cap B_{3}\right)$

Entre otros muchos elementos. Ahora bien, la intersección es una operación que se puede repetir indefinidamente mediante la intersección de una intersección anterior con un nuevo conjunto. Siguiendo con el ejemplo anterior, si tenemos los mismos conjuntos

$U=\{x / H x\}$, donde $H$ es la propiedad "ser hombre".

$B_{2}=\{x / F x\}$, donde $F$ es la propiedad "ser filósofo".

$B_{3}=\{x / A x\}$, donde $A$ es la propiedad "ser alemán".

y agregamos un nuevo conjunto:

$B_{4}=\{x / V x\}$, donde $V$ es la propiedad de "haber vivido en el siglo XX".

entonces podemos realizar la intersección de $B_{2} \cap B_{3} \cap B_{4}$.

Como la intersección es una operación binaria, es decir, una operación que combina dos conjuntos, lo que debemos hacer es realizar la operación por pares, de la siguiente manera: 
Primero se hace la intersección $B_{2} \cap B_{3}$ y lo que resulta se intersecta con $B_{4}$. El nuevo conjunto $\left(B_{2} \cap B_{3}\right) \cap B_{4}$ se define de la siguiente manera:

$B_{2} \cap B_{3} \cap B_{4}=\left\{x / \in x B_{2} y x \in B_{3} y x \in B_{4}\right\}$

Es decir, el conjunto de los filósofos alemanes que vivieron en el siglo XX. Gráficamente ese conjunto se representa:

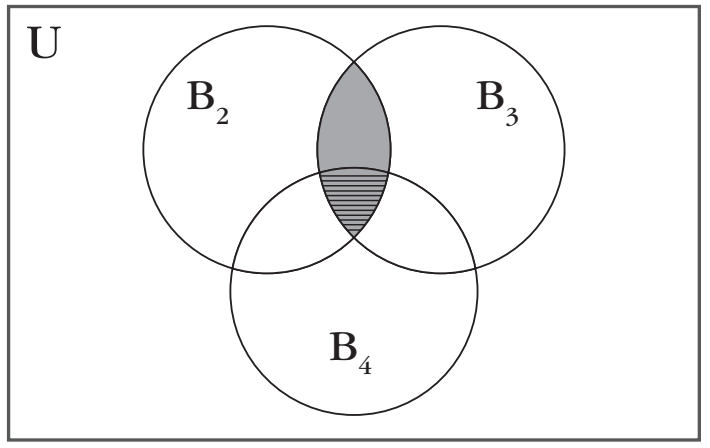

Con amarillo se remarca el conjunto $B_{2} \cap B_{3}$ y con líneas horizontales el conjunto

$\mathrm{B}_{2} \cap \mathrm{B}_{3} \cap \mathrm{B}_{4}$.

En ese nuevo conjunto,

Husserl $\in\left(B_{2} \cap B_{3}\right)$

Dilthey $\in\left(B_{2} \cap B_{3}\right)$

Adorno $\in\left(B_{2} \cap B_{3}\right)$

Horkheimer $\in\left(B_{2} \cap B_{3}\right)$

Heidegger $\in\left(B_{2} \cap B_{3}\right)$

Habermas $\in\left(B_{2} \cap B_{3}\right)$

Gadamer $\in\left(B_{2} \cap B_{3}\right)$

Appel $\in\left(B_{2} \cap B_{3}\right)$ 
entre otros elementos. Si se observa con atención, se descubrirá que entre más intersecciones realicemos, menos elementos tendrá el nuevo conjunto que se obtiene. Por ejemplo, si agregamos el conjunto $B_{5}=\{x / H x\}$, donde $H$ es la propiedad de "trabajar temas de Hermenéutica", la intersección $\left[\left(B_{2} \cap B_{3}\right) \cap B_{4}\right] \cap B_{5}$ será el conjunto de los filósofos alemanes que vivieron en el siglo XX y que trabajan temas de Hermenéutica.

$$
\begin{aligned}
& \mathrm{B}_{2} \cap \mathrm{B}_{3} \cap \mathrm{B}_{4} \cap \mathrm{B}_{5}=\{x / F x y \text { y } x \text { y } V x \text { y } H x\} \\
& \text { En nuestro ejemplo } \\
& \text { Habermas } \in\left[B_{2} \cap B_{3} \cap B_{4} \cap B_{5}\right] \\
& \text { Gadamer } \in\left[B_{2} \cap B_{3} \cap B_{4} \cap B_{5}\right]
\end{aligned}
$$

si queremos realizar todavía otra intersección, podemos llegar a un conjunto unitario, con un sólo elemento. Podemos agregar el conjunto $B_{\sigma}=\{x / E x\}$, donde $E$ es la propiedad de "haber pertenecido a la Escuela de Frankfurt". De esta manera, el conjunto

$$
\begin{aligned}
& \left\{\left[\left(B_{2} \cap B_{3}\right) \cap B_{4}\right] \cap B_{5}\right\} \cap B_{6} \text { se define como } \\
& \mathrm{B}_{2} \cap \mathrm{B}_{3} \cap \mathrm{B}_{4} \cap \mathrm{B}_{5} \cap \mathrm{B}_{6}=\{\mathrm{x} / \mathrm{Fx} \text { y Ax y Vx y Hx y Ex }\}
\end{aligned}
$$

Esto es, el conjunto de los filósofos alemanes que vivieron en el siglo $\mathrm{XX}$, trabajan temas de Hermenéutica y pertenecieron a la Escuela de Frankfurt.

Encontramos que sólo aparece

Habermas $\left[B_{2} \cap B_{3} \cap B_{4} \cap B_{5} \cap B_{6}\right]$

El orden de los conjuntos que intervienen en la intersección no influye en el resultado, es lo mismo $B_{2} \cap B_{3}$ que $B_{3} \cap B_{2}$. A la propiedad $B_{2} \cap B_{3}=B_{3} \cap B_{2}$ se le denomina propiedad conmutativa. 


\section{EJERCICIOS}

Suponga los conjuntos

$A_{4}=\{1,2,3,4,5,6,7,8,9\}$

$A_{5}=\{2,4,6,8,10,12,14,16,18,20\}$

\section{Ejercicio 35}

¿Cuál es el conjunto $A_{4} \cap A_{5}$ ?

$A_{4} \cap A_{5}=$

Si se tienen los conjuntos

$A_{2}=\{$ El conjunto de los libros de Bibliotecología $\}$

$A_{5}=\{$ El conjunto de las obras de Juan Rulfo $\}$

La intersección de $A_{2} \cap A_{5}=\varnothing$, ya que no existen elementos que pertenezcan a la vez a $A_{2}$ y a $A_{5}$.

Debido a lo anterior, se dice que $A_{2}$ y $A_{5}$ son mutuamente exclusivos o ajenos, o que están desunidos.

Supongamos que $A_{6}=\{$ Libros publicados en 1999 $\}$ y

$A_{7}=\{$ Libros cuyo autor es Hugo Sánchez $\}$

La intersección de $A_{6} \cap A_{7}=\varnothing$

Gráficamente, la representación sería:

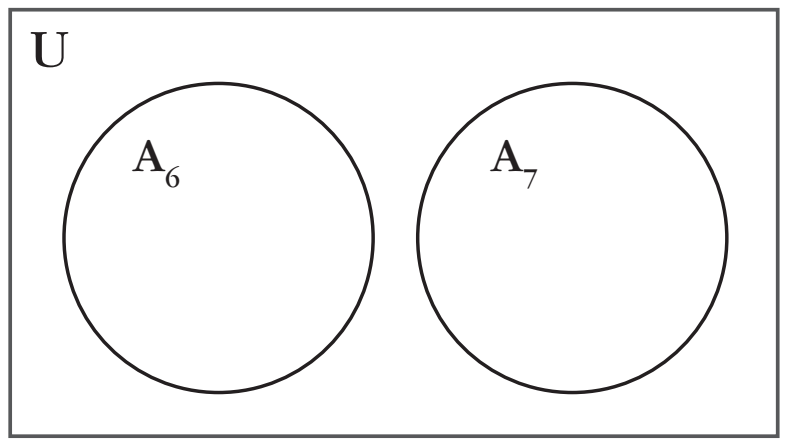


Introducción a la teoría de conjuntos...

Supongamos que

$U=\{$ Conjunto de libros publicados $\}$

$A_{2}=\{$ Conjunto de libros de Bibliotecología $\}$

$\bar{A}_{2}=\{$ Todos los libros excepto los de Bibliotecología $\}$

¿Cuál sería el conjunto $A_{2} \cap \bar{A}_{2}$ ?

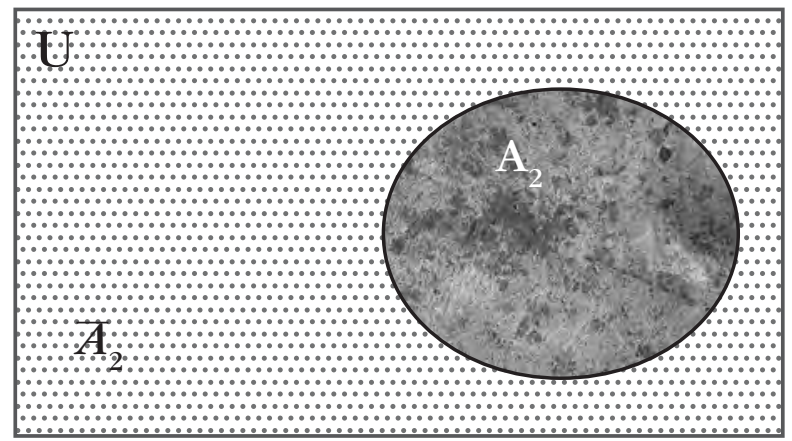

No existe un solo elemento común de $A_{2}$ y $\bar{A}_{2}$.

Para todo conjunto $A$ y su complemento $\bar{A} ; A \cap \bar{A}=\varnothing$, un elemento $x$ del universo es un elemento de $A$ o es un elemento de $\bar{A}$, pero no de ambos simultáneamente. Ahora bien, si tenemos los siguientes conjuntos:

$$
\begin{aligned}
U & =\{1,2,3,4,5,6,7,8,9,10\} \\
A & =\{1,3,5,7\} \\
B & =\{2,3,4,6,7\}
\end{aligned}
$$

podemos obtener el complemento relativo $A-B$. Esto es, el conjunto que contiene los elementos de $A$ que no están en $B$, lo que nos da por resultado:

$$
A-B=\{1,5\}
$$




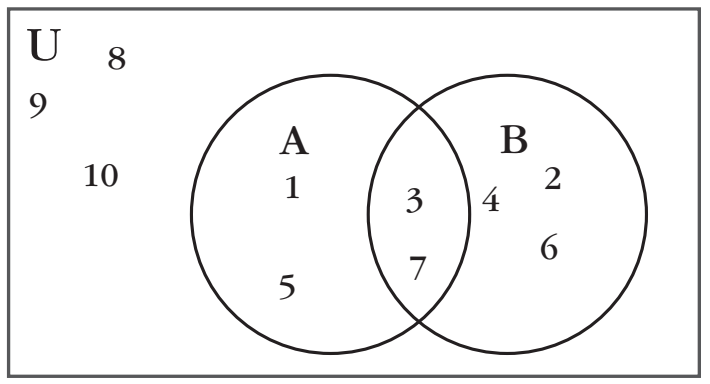

Por otro lado, sabemos que el complemento absoluto de $B$ (los elementos del universo que no pertenecen a $B$ ) es:

$$
\bar{B}=\{1,5,8,9,10\}
$$

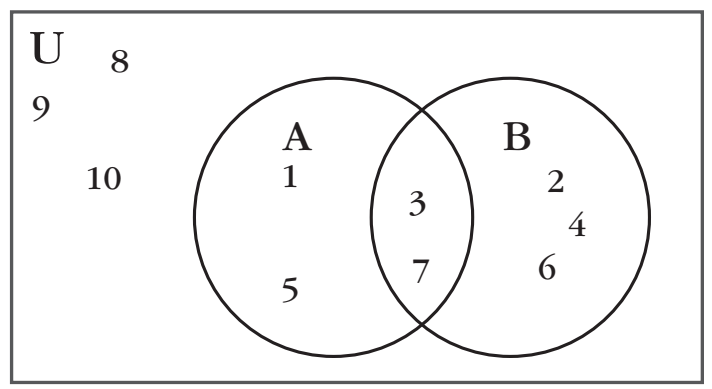

Y si además realizamos la intersección $\bar{A} \cap \bar{B}$, obtenemos:

$A \cap \bar{B}=\{1,5\}$

por lo tanto, $A-B=A \cap \bar{B}$

\section{EJERCICIOS}

Si

$$
\begin{aligned}
& U=\{1,2,3,4,5,6,7,8,9,0\} \\
& A=\{1,4,5,9,\}
\end{aligned}
$$


Introducción a la teoría de conjuntos...

$$
\begin{aligned}
& B=\{2,5,6,7,9\} \\
& C=\{3,4,6,7,9\}
\end{aligned}
$$

¿cuáles son los siguientes conjuntos?

\section{Ejercicio 36}

$A \cap B=\{$

\section{Ejercicio 37}

$A \cap C=\{$

\section{Ejercicio 38}

$B \cap C=\{$

\section{Ejercicio 39}

$\bar{A}=\{$

Ejercicio 40

$\bar{B}=\{$

Ejercicio 41

$\bar{B}=\{$

Ejercicio 42

$\bar{A} \cap B=\{$

Ejercicio 43

$A \cap \bar{B}=\{$

Ejercicio 44

$\bar{A} \cap C=\{$

Ejercicio 45

$A \cap \bar{C}=\{$ 
Ejercicio 46

$B \cap \bar{C}=\{(-$

Ejercicio 47

$\bar{A} \cap \bar{B}=\{$

Ejercicio 48

$\bar{A} \cap \bar{C}=\{$

Ejercicio 49

$\bar{B} \cap \bar{C}=\{(-$

Ejercicio 50

$A \cap B \cap C=\{$

Ejercicio 51

$A \cap B \cap \bar{C}=\{$

Ejercicio 52

$A \cap \bar{B} \cap C=\{$

Ejercicio 53

$\bar{A} \cap B \cap C=\{$

Ejercicio 54

$\bar{A} \cap \bar{B} \cap C=\{$

Ejercicio 55

$\bar{A} \cap \bar{B} \cap \bar{C}=\{$

Ejercicio 56

$A \cap \bar{B} \cap \bar{C}=\{$ 
Introducción a la teoría de conjuntos...

\section{Ejercicio 57}

$\bar{A} \cap B \cap \bar{C}=\{$

\section{Ejercicio 58}

$(\overline{A \cap B}) \cap \bar{C}=\{$

\section{Ejercicio 59}

$(\overline{A \cap B}) \cap C=\{$

\section{Ejercicio 60}

$A \cap(\overline{B \cap C})=\{$

\section{Ejercicio 61}

$\bar{A} \cap(\overline{B \cap C})=\{$

\section{Ejercicio 62}

$\overline{A \cap B \cap C}=\{$

\section{Ejercicio 63}

$\overline{\bar{A} \cap C}=\{$

\section{Ejercicio 64}

$\overline{\overline{A \cap B} \cap C}=\{$

\section{Ejercicio 65}

$\overline{A \cap \bar{B} \cap C}=$

Si

$U=\{$ Libros publicados $\}$

$D=\{$ Libros cuyo autor es Jesse Shera $\}$

$E=\{$ Libros en inglés $\}$

$F=\{$ Libros publicados después de 1980 $\}$ 
¿cómo se leen los siguientes conjuntos? Dibuja un diagrama de Venn que los represente y proporciona un ejemplo de un elemento que pertenezca a cada uno de ellos.

Ejercicio 66

$D \cap E \cap F=$

Ejercicio 67

$D \cap E \cap \bar{F}=$

Ejercicio 68

$D \cap \bar{E} \cap F=$

Ejercicio 69

$\bar{D} \cap E \cap F=$

Ejercicio 70

$\bar{D} \cap \bar{E} \cap F=$

Ejercicio 71

$\bar{D} \cap \bar{E} \cap \bar{F}=$ 
Introducción a la teoría de conjuntos...

\section{Ejercicio 72}

$D \cap \bar{E} \cap \bar{F}=$

Ejercicio 73

$\bar{D} \cap E \cap \bar{F}=$

Ejercicio $\mathbf{7 4}$

$(\overline{D \cap E}) \cap \bar{F}=$

Ejercicio 75

$(\overline{D \cap E}) \cap F=$

Ejercicio 76

$D \cap(\overline{E \cap F})=$

Ejercicio 77

$\bar{D} \cap(\overline{E \cap F})=$ 


\section{Ejercicio 78}

En el siguiente diagrama, marque con líneas verticales |||| el conjunto $\bar{A}$

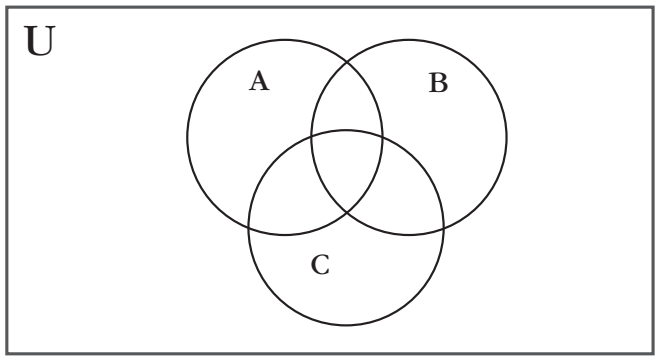

\section{Ejercicio 79}

En el siguiente diagrama, marque con líneas inclinadas /// $A \cap B$

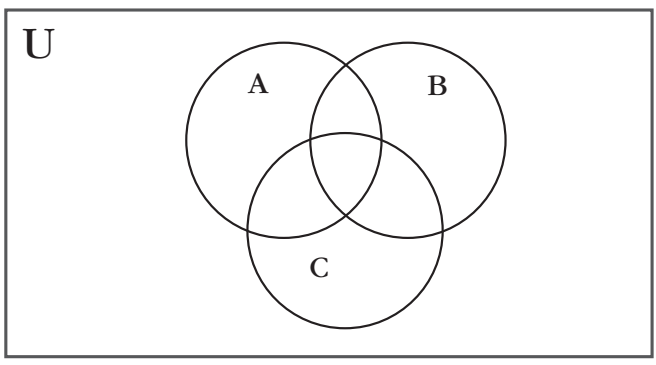

\section{Ejercicio 80}

En el siguiente diagrama, marque con líneas inclinadas $/ / / A \cap \bar{B}=(A-B)$

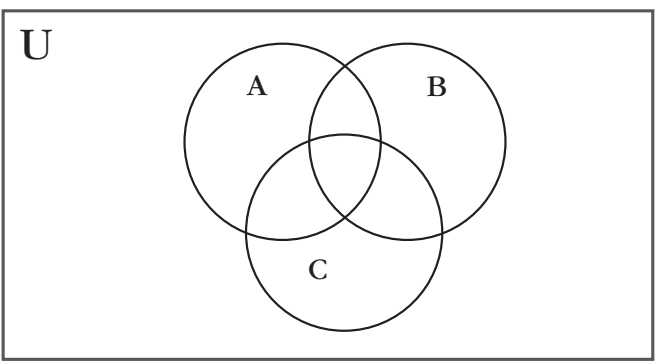


Introducción a la teoría de conjuntos...

\section{Ejercicio 81}

En el siguiente diagrama, marque con líneas verticales ||| el conjunto $\bar{A} \cap \bar{B}$

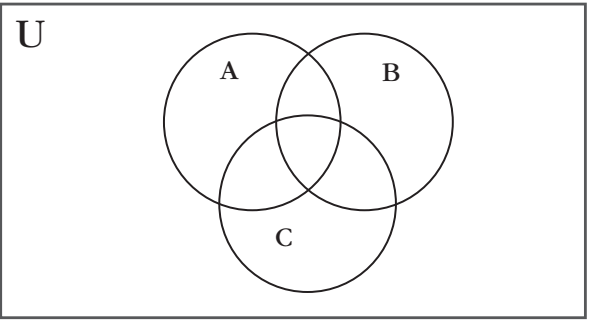

\section{Ejercicio 82}

En el siguiente diagrama, marque con líneas verticales ||| el conjunto $\overline{A \cap B}$

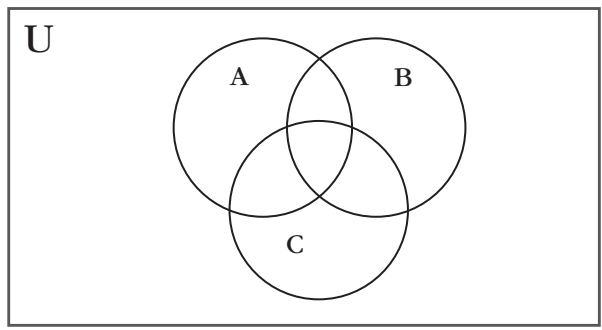

\section{Ejercicio 83}

En el siguiente diagrama, marque con líneas inclinadas $/ / / A \cap B \cap C$

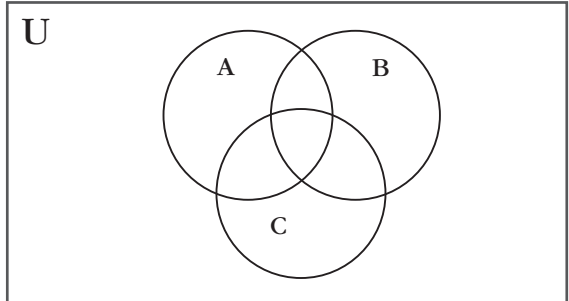




\section{Ejercicio 84}

En el siguiente diagrama, marque con líneas verticales || $\mid$ el conjunto $\bar{A} \cap \bar{B} \cap C$

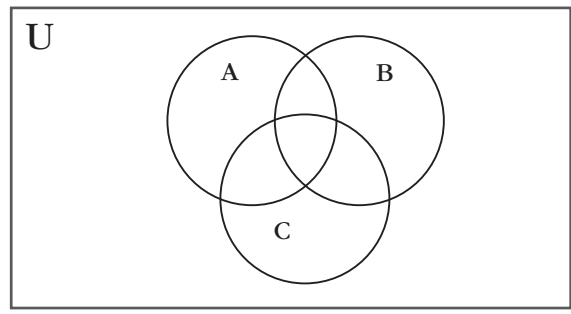

\section{Ejercicio 85}

En el siguiente diagrama, marque con líneas inclinadas $/ / / A \cap \bar{B} \cap \bar{C}$

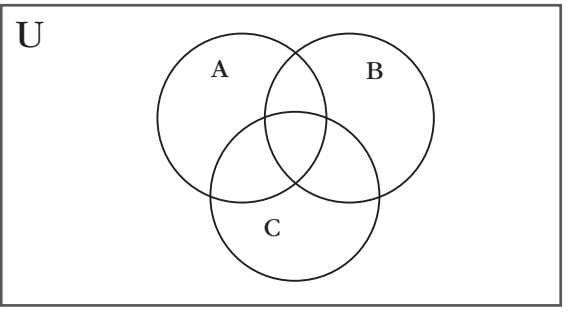

\section{Ejercicio 86}

En el siguiente diagrama, marque con líneas inclinadas /// $\bar{A} \cap \bar{B} \cap \bar{C}$

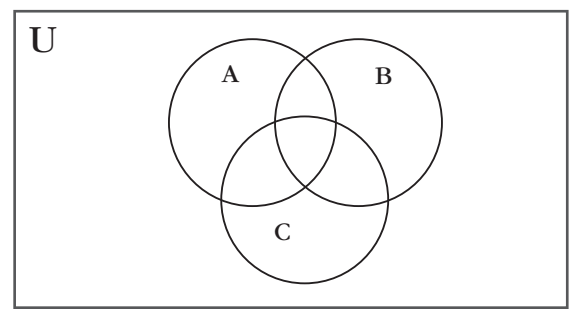




\section{Ejercicio 87}

En el siguiente diagrama, marque con líneas verticales ||| el conjunto $\overline{A \cap B \cap C}$

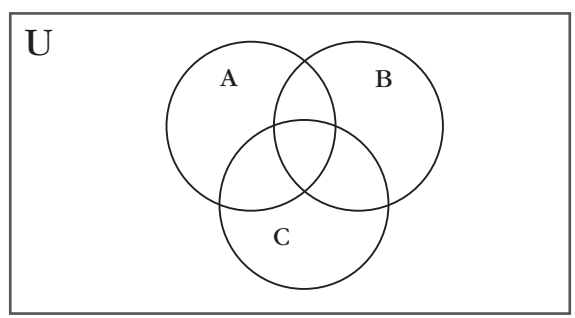

\section{Unión}

Supongamos que tenemos los siguientes conjuntos:

$U=\{x / L x\}$, donde $L$ es la propiedad "ser libro".

$A_{2}=\{x / B x\}$, donde $B$ es la propiedad "ser libro de Bibliotecología”.

$A_{4}=\{x / Q x\}$, donde $Q$ es la propiedad "ser libro de Química".

Podemos formar un conjunto con los elementos que pertenecen a $A_{2}$ o a $A_{4}$, esto es, los libros de Bibliotecología o Química donde la "o", también llamada disyunción, es no excluyente, es decir, puede darse el caso de que pertenezca simultáneamente a los dos conjuntos. Por ejemplo, si nos encontramos un libro que hable de las propiedades químicas de ciertos documentos y los pasos necesarios a seguir para su conservación en una unidad de información. Un ejemplo muy típico de una disyunción no excluyente es cuando una mamá le dice a su hijo: "te compro chocolate o helado" pero termina por comprarle las dos cosas.

Al conjunto de elementos que son miembros de $A_{2}$ o de $A_{4}$, o de ambos, se le llama unión o suma lógica de $A_{2}$ y $A_{4}$. Simbólicamente, 
se expresa: $A_{2} \cap A_{4}=\left\{x / x \in A_{2} o x \in A_{4}\right\}$. Como se podrá observar, el conjunto resultado de una unión de conjuntos contiene un mayor número de elementos que la intersección entre esos conjuntos.
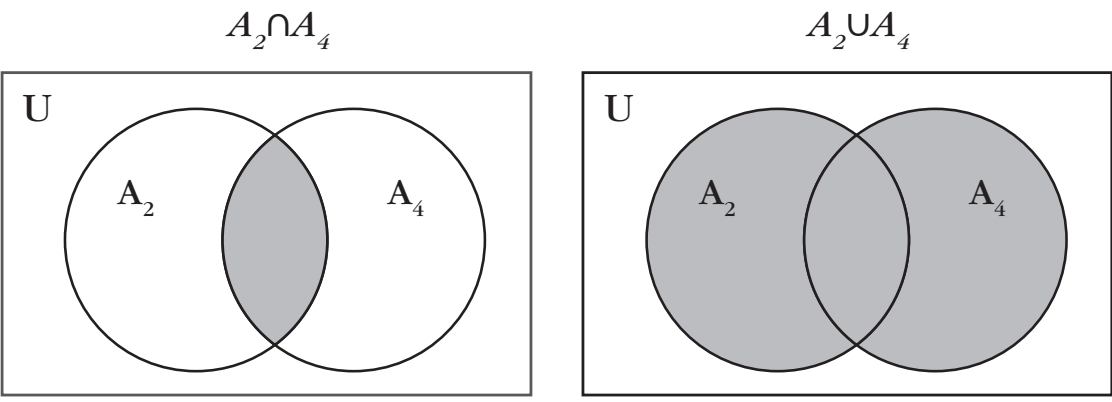

$\mathrm{Si}$

$$
\begin{aligned}
& A=\{\mathrm{a}, \mathrm{e}, \mathrm{i}, \mathrm{o}, \mathrm{u}\} \\
& B=\{\mathrm{a}, \mathrm{b}, \mathrm{c}, \mathrm{d}, \mathrm{e}\} \\
& \text { entonces } \\
& (A \cap B)=\{a, e,\} \\
& (A \cup B)=\{\mathrm{a}, \mathrm{e}, \mathrm{i}, \mathrm{o}, \mathrm{u}, \mathrm{b}, \mathrm{c}, \mathrm{d}\}
\end{aligned}
$$

Cuando vimos el caso de la intersección, descubrimos que entre más intersecciones realizamos, el número de elementos va disminuyendo. En el caso de la unión, es lo contrario: entre más uniones se hagan, el número de elementos va aumentando hasta llegar al universo mismo. Por ejemplo, si se tienen los conjuntos:

$U=\{x / V x\}$, donde $V$ es la propiedad "ser un ser vivo"

$C_{1}=\{x / B x\}$, donde $B$ es la propiedad "ser bípedo"

$C_{2}=\{x / P x\}$, donde $P$ es la propiedad "tener respiración pulmonar"

entonces el conjunto de todos los animales bípedos o que tienen respiración pulmonar es $C_{1} \cup C_{2}=\left\{x / x \in C_{1}\right.$ o $\left.x \in C_{2}\right\}$. 
Introducción a la teoría de conjuntos...

De este modo:

Hombre $\in\left(C_{1} \cup C_{2}\right)$

Canario $\in\left(C_{1} \cup C_{2}\right)$

Avestruz $\in\left(C_{1} \cup C_{2}\right)$

Perro $\in\left(C_{1} \cup C_{2}\right)$

León $\in\left(C_{1} \cup C_{2}\right)$

Cebra $\in\left(C_{1} \cup C_{2}\right)$

Canguro $\in\left(C_{1} \cup C_{2}\right)$

Delfín $\in\left(C_{1} \cup C_{2}\right)$

entre otros elementos.

Podemos agregar el conjunto $C_{3}$, el cual definimos como: $C_{3}=$ $\{x / O x\}$, donde $O$ es la propiedad "ser ovíparo" y realizar la unión $\left(C_{1} \cup C_{2}\right) \cup C_{3}$. De esta manera, nuestro conjunto crece y da la oportunidad de que no sólo los elementos anteriormente mencionados estén en el nuevo conjunto, sino que además encontramos nuevos miembros: todos los animales que nacen de huevos. Así, tenemos que:

Serpiente $\in\left(C_{1} \cup C_{2}\right) \cup C_{3}$

Cocodrilo $\in\left(C_{1} \cup C_{2}\right) \cup C_{3}$

Tortuga $\in\left(C_{1} \cup C_{2}\right) \cup C_{3}$

Salmón $\in\left(C_{1} \cup C_{2}\right) \cup C_{3}$

Entre otros elementos.

Podemos agregar otro conjunto, $C_{4}=\{x / I x\}$, donde $I$ es la propiedad "ser invertebrado". Si hacemos la unión $\left(\left(C_{1} \cup C_{2}\right) \cup C_{3}\right) \cup C_{4}$, encontramos que además de todos los elementos anteriores, aparecen nuevos, tales como:

Mosca $\in\left(\left(C_{1} \cup C_{2}\right) \cup C_{3}\right) \cup C_{4}$ Araña $\in\left(\left(C_{1} \cup C_{2}\right) \cup C_{3}\right) \cup C_{4}$ 
Cucaracha $\in\left(\left(C_{1} \cup C_{2}\right) \cup C_{3}\right) \cup C_{4}$

Gusano $\in\left(\left(C_{1} \cup C_{2}\right) \cup C_{3}\right) \cup C_{4}$

etcétera.

Es posible encontrar otro conjunto $C_{5}=\{x / U x\}$, donde $U$ es la propiedad "ser unicelular" y hacer otra unión donde tienen cabida las bacterias, los hongos y los virus: $\left(\left(C_{1} \cup C_{2}\right) \cup C_{3}\right) \cup C_{4} \cup C_{5}$

Por fin, se puede agregar el conjunto

$\mathrm{C}_{6}=\{\mathrm{x} / \mathrm{Tx}\}$, donde $T$ es la propiedad "ser vegetal" y hacer la unión $\left(\left(C_{1} \cup C_{2}\right) \cup C_{3}\right) \cup C_{4} \cup C_{5} \cup C_{6}$

para abarcar todo el universo (los seres vivos).

La unión también cumple con la propiedad conmutativa, ya que el resultado no varía independientemente de que sea $A \cup B$ o $B \cup A$.

Para todo conjunto universal $U$, para todo subconjunto $G$ de $U$ y para todo elemento $x$, si $x \in U$, entonces $x \in G$ o $x \in \bar{G}$, lo que significa que $x \in(G \cup \bar{G})$.

De hecho, siempre tenemos que la unión de un conjunto con su complemento es igual al universo:

$(G \cup \bar{G})=U$

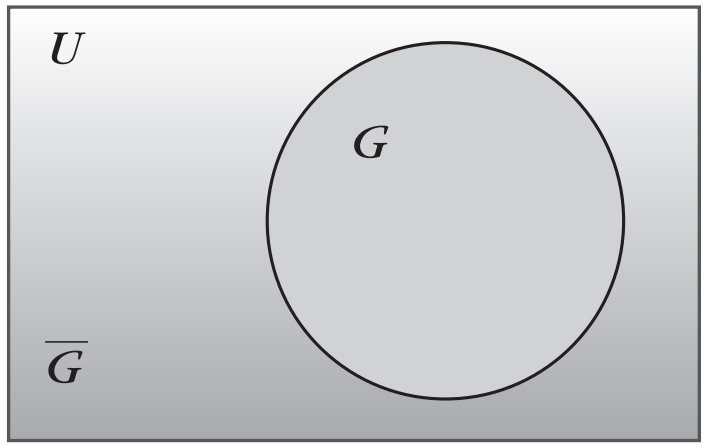


Introducción a la teoría de conjuntos...

\section{EJERCICIOS}

Si

$$
\begin{aligned}
& U=\{1,2,3,4,5,6,7,8\} \\
& A=\{2,5,6,8\} \\
& B=\{4,5,7,8\} \\
& C=\{3,7,8\}
\end{aligned}
$$

¿cuáles son los siguientes conjuntos?

\section{Ejercicio 88}

$A \cup B=\{$

Ejercicio 89

$A \cup C=\{$

Ejercicio 90

$B \cup C=\{$

Ejercicio 91

$$
\bar{A}=\{
$$

Ejercicio 92

$$
\bar{B}=\{
$$

\section{Ejercicio 93}

$$
\bar{B}=\{
$$

Ejercicio 94

$$
A \cup \bar{B}=\{
$$

\section{Ejercicio 95}

$$
\bar{A} \cup B=\{
$$


Ejercicio 96

$A \cup \bar{C}=\{$

Ejercicio 97

$\bar{A} \cup C=\{$

Ejercicio 98

$B \cup \bar{C}=\{$

Ejercicio 99

$\bar{A} \cup \bar{B}=\{$

Ejercicio 100

$\bar{A} \cup \bar{C}=\{$

Ejercicio 101

$\bar{B} \cup \bar{C}=\{$

Ejercicio 102

$A \cup B \cup \bar{C}=\{$

Ejercicio 103

$A \cup \bar{B} \cup C=\{$

Ejercicio 104

$A \cup \bar{B} \cup \bar{C}=\{$

Ejercicio 105

$\bar{A} \cup B \cup C=\{$

Ejercicio 106

$\bar{A} \cup B \cup \bar{C}=\{$ 
Introducción a la teoría de conjuntos...

Ejercicio 107

$\bar{A} \cup \bar{B} \cup C=\{$

Ejercicio 108

$\bar{A} \cup \bar{B} \cup \bar{C}=\{$

Ejercicio 109

$\overline{A \cup B \cup C}=\{$

\section{Uso de paréntesis}

La colocación de paréntesis es importante ya que de ello depende el resultado que se obtenga. Por ejemplo, no es lo mismo $A \cup(B \cap C)$ que $(A \cup B) \cap C$.

En el primer caso, tenemos el siguiente conjunto:

$$
A \cup(B \cap C)=\{x / x \in A \text { o } x \in(B \cap C)\}
$$

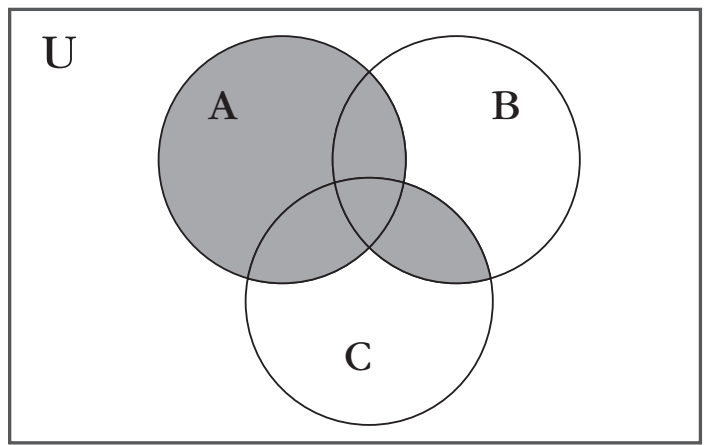

En el segundo, tenemos:

$(A \cup B) \cap C=\{x / x \in(A \cup B)$ y $x \in C\}$ 


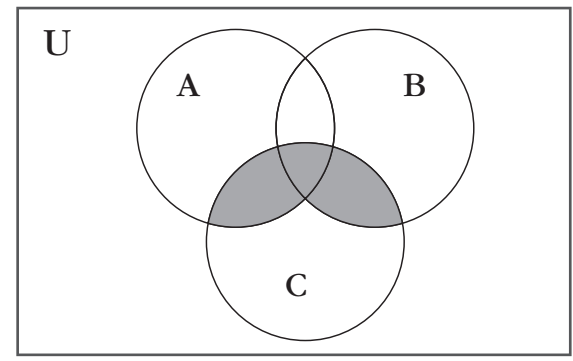

\section{EJERCICIOS}

Los ejercicios del 110 al 136 se resolverán nuevamente en la sección de álgebra booleana (138-169).

Dados los siguientes conjuntos

$$
\begin{aligned}
& U=\{1,2,3,4,5,6,7,8\} \\
& A=\{2,5,6,8\} \\
& B=\{4,5,7,8\} \\
& C=\{3,7,8\}
\end{aligned}
$$

¿qué resultado se obtiene de las siguientes operaciones?

\section{Ejercicio 110}

$(A \cup B) \cap C=\{$

Ejercicio 111

$A \cup(B \cap C)=\{$ 
Introducción a la teoría de conjuntos...

Ejercicio 112

$(\overline{A \cup B}) \cap C=\{$

\section{Ejercicio 113}

$A \cup(\overline{B \cap C})=\{$

Ejercicio 114

$(A \cup B) \cap \bar{C}=\{$

Ejercicio 115

$A \cup(B \cap \bar{C})=\{$

\section{Ejercicio 116}

$A \cup(\bar{B} \cap C)=\{$

Ejercicio 117

$(A \cup \bar{B}) \cap C=\{$

Ejercicio 118

$A \cup(\bar{B} \cap \bar{C})=\{$

Ejercicio 119

$(A \cup \bar{B}) \cap \bar{C}=\{$ 
Ejercicio 120

$\bar{A} \cup(B \cap C)=\{$

Ejercicio 121

$(\bar{A} \cup B) \cap C=\{$

Ejercicio 122

$\bar{A} \cup(B \cap \bar{C})=\{$

Ejercicio 123

$(\bar{A} \cup B) \cap \bar{C}=\{$

Ejercicio 124

$\bar{A} \cup(\bar{B} \cap \bar{C})=\{$

Ejercicio 125

$(\bar{A} \cap \bar{B}) \cup \bar{C}=\{$

Ejercicio 126

$\bar{A} \cap(\overline{B \cup C}))=\{$

Ejercicio 127

$(\overline{A \cap B)} \cup C=\{$ 
Introducción a la teoría de conjuntos...

Ejercicio 128

$\overline{A \cap(B \cup C)}=\{$

Ejercicio 129

$\overline{(A \cap B) \cup C}=\{$

Ejercicio 130

$(\overline{\overline{A \cap B}}) \cup \bar{C}=\{$

Dibujando diagramas de Venn, encuentra los siguientes conjuntos y represéntalos con letras y operaciones entre conjuntos correspondientes:

\section{Ejercicio 131}

Los libros de Bibliotecología de Héctor Alfaro López que no están en inglés.

\section{Ejercicio 132}

Los libros de Alfaro López en inglés que son de Filosofía.

\section{Ejercicio 133}

Los libros en inglés de Bibliotecología que no son de Alfaro López.

\section{Ejercicio 134}

Los libros que no son de Bibliotecología ni de Alfaro López pero que están en inglés. 
Teoría de conjuntos

\section{Ejercicio 135}

Los libros de Filosofía o Bibliotecología pero que no son de Alfaro López.

\section{Ejercicio 136}

Los libros de Filosofía o Bibliotecología o de Alfaro López. 
Capítulo II

\section{OPERADORES BOOLEANOS}




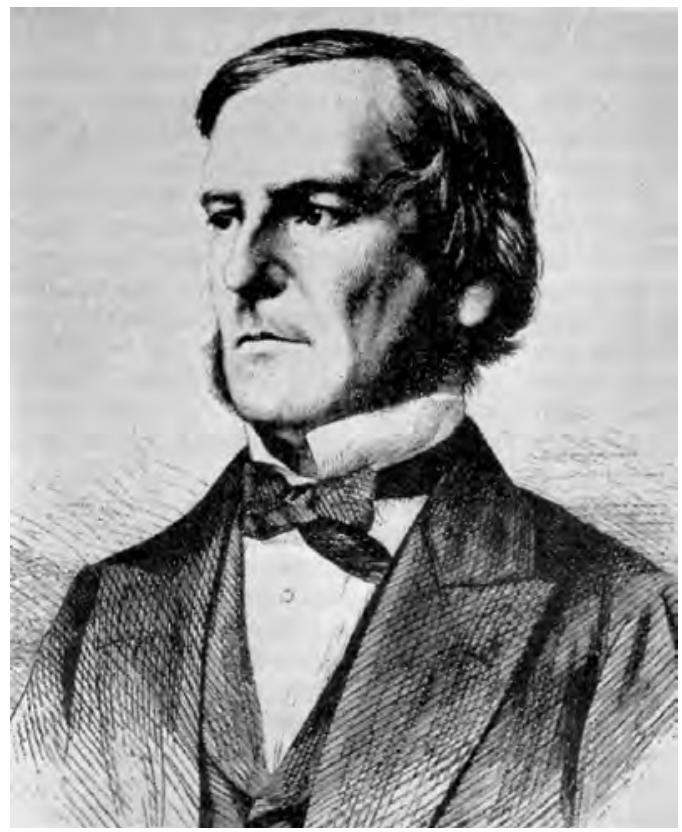

George Boole (1815-1864)

\section{Álgebra De BoOle}

or experiencia, al ingresar a catálogos en línea y realizar una búsqueda de obras que deseamos consultar, nos hemos en1 contrado con los operadores booleanos, que son el "no" (not), el "y" (and), así como el "o" (or).

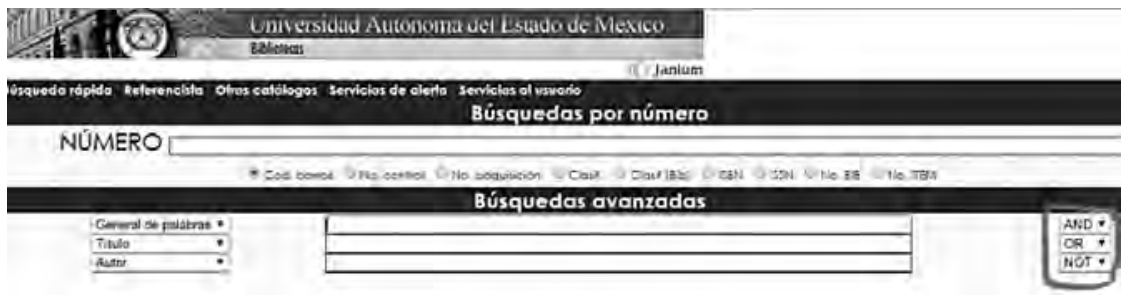


Ahora bien, es momento de indicar que en esos operadores, la negación (no), la conjunción (y) y la disyunción (o) tienen lugar en un sistema más amplio que es el álgebra de Boole. Como su nombre lo indica, el álgebra de Boole siguió el modelo del Álgebra en Matemáticas y se construyó como un sistema de cálculo en el cual, a partir de una expresión, y con la realización de ciertas operaciones, se puede obtener una segunda, que es idéntica a ella.

Así, por ejemplo, en Matemáticas, si tenemos el cuadrado de un binomio $(a+b)^{2}$, sabemos que a partir de él, obtenemos el cuadrado del primer término del binomio $a^{2}$ más el doble del producto del primero por el segundo $2 a b$, más el cuadrado del segundo término $b^{2}$, independientemente del valor que puedan tomar $a$ y $b$.

De esta manera, sabemos que:

$$
(a+b)^{2}=a^{2}+2 a b+b^{2} .
$$

De manera semejante, sucede con otras identidades algebraicas como pueden ser, entre muchas otras:

$$
\begin{aligned}
& (a-b)^{2}=a^{2}-2 a b+b^{2} \\
& (a+b)(a-b)=a^{2}-b^{2} \\
& (a+b)^{3}=a^{3}+3 a^{2} b+3 a b^{2}+b^{3} \\
& (a+b+c)^{2}=a^{2}+b^{2}+c^{2}+2(a b+b c+a c)
\end{aligned}
$$

El álgebra de Boole se construyó para demostrar la validez de ciertas expresiones que al ser trasformadas en otras equivalentes, resultaban ser tautologías (universalmente verdaderas) o contradicciones (universalmente falsas). Si en álgebra matemática los instrumentos que se utilizan para transformar las expresiones son las operaciones suma, resta, multiplicación y división, en el álgebra de Boole lo que nos permite transformar las expresiones son los operadores booleanos. 
Así pues, el álgebra de Boole es un sistema compuesto de los elementos 0,1 -que corresponden al conjunto vacío y el universo respectivamente-; de un conjunto $C$, y de tres operaciones definidas sobre él en el que se verifican ciertas propiedades. Las operaciones deben ser cerradas, es decir, aplicadas a dos elementos pertenecientes a $C$, y su resultado es otro elemento perteneciente a $C$.

De acuerdo con los elementos que contenga $C$, el álgebra de Boole puede hacerse entre conjuntos o entre proposiciones, es decir, los elementos de $C$ pueden ser conjuntos o proposiciones. En nuestro caso, para comprender la naturaleza de los operadores booleanos, es suficiente comprender el álgebra entre conjuntos. Por lo demás, la estructura algebraica entre conjuntos es idéntica -isomórfica - a la estructura algebraica entre proposiciones, lo que significa que a cada expresión algebraica entre conjuntos, le corresponde su expresión algebraica entre proposiciones.

Si simbolizamos la conjunción ("y") con $\varepsilon$, la disyunción ("o") con $\equiv$, la negación ("no") con $\sim$ y la equivalencia con $\equiv$, entonces nuestra álgebra booleana es el sistema $S=\{0,1, C, \&, \vee, \sim, \equiv\}$.

Por lo demás, podemos ver que las tres operaciones básicas entre los conjuntos que ya conocemos:

El complemento de $A: \bar{A}$

La intersección de $A$ y $B: A \cap B$

La unión de $A$ con $B$ : $A \cup B$

Corresponden a la negación "no" (not); la conjunción "y" (and) y la disyunción "o" (or) respectivamente, por lo que las operaciones booleanas "no", "y", "o" no son más que las ya conocidas operaciones: complemento, intersección y unión en los conjuntos.

Aprovechando la relación isomórfica entre la estructura de un álgebra de Boole con conjuntos y un álgebra de Boole con proposiciones, proporcionaremos ahora que ya se comprendió cómo funcionan los operadores booleanos de la negación, conjunción y disyunción, 
Introducción a la teoría de conjuntos...

un sistema con proposiciones, ya que es más intuitivo a cómo se maneja en el trabajo con catálogos. Por lo que nuestra álgebra de Boole se construye de la siguiente manera:

Los símbolos iniciales son:

1. Letras $x, y, z, x_{1}, y_{1}, z_{1}, x_{2}, y_{2}, z_{2}, \ldots x_{n}, y_{n}, z_{n}$, para simbolizar las proposiciones que componen el conjunto $C$.

2. Los símbolos \&, v, para representar los operadores booleanos "y", "o", "no" respectivamente.

3. El símbolo I I para representar la identidad.

4. Los símbolos 1 y 0 para el conjunto universal $U$ (tautología) y el conjunto vacío $\varnothing$ (contradicción).

5. Los símbolos técnicos (,).

Fórmulas bien formadas:

1. Cualquier proposición $A$ es fórmula bien formada.

2. Si $A$ y $B$ son fórmulas bien formadas, entonces $\sim A$ "no $A$ "; ( $A$ $\& B$ ) “ $A$ у $B$ "; $(A \vee B)$ " $A$ о $B$ "; $A|| B$ " $A$ es equivalente a $B$ "; $A$ I। $0 ; A|| 1$, son fórmulas bien formadas.

3. Ninguna otra expresión es fórmula bien formada.

De esta manera, la expresión en teoría de conjuntos $\bar{H}$ "complemento de $H$ " tiene su correlato en la lógica de Boole con proposiciones con la expresión $(\sim x)$ "no $x$ ". Del mismo modo, la expresión en la teoría de conjuntos $(H \bigcap G)$ "intersección del conjunto $H$ con el conjunto G" o " $H$ intersección $G$ ", en el álgebra de Boole con proposiciones tiene su equivalente a $(x \in z)$ " $x$ conjunción $z$ " o simplemente " $x$ y $z$ ".

Finalmente, la expresión $(H \bigcup G)$ "unión del conjunto $H$ con el conjunto G" o " $H$ unión $G$ " en la teoría de conjuntos, se transforma en el álgebra de Boole con proposiciones en $(x \vee z)$ " $x$ disyunción $z$ ” $\mathrm{o}$ “ $x$ о $z$ ". A continuación, proporcionaremos las principales 
equivalencias en la teoría de conjuntos y su correlato en el álgebra de Boole:

\begin{tabular}{|c|c|}
\hline Operaciones con conjuntos & Operaciones con proposiciones \\
\hline \multicolumn{2}{|c|}{ I. Propiedad conmutativa } \\
\hline 1. $A \cap B=B \cap A$ & $x \& y \equiv y \& x$ \\
\hline 2. $A \bigcup B=B \bigcup A$ & $x \vee y \equiv y \vee x$ \\
\hline \multicolumn{2}{|c|}{ II. Propiedad asociativa } \\
\hline 3. $A \cap(B \cap C)=(A \cap B) \cap C$ & $x \&(y \& z) \equiv(x \& y) \& z$ \\
\hline 4. $A \cup(B \cup C)=(A \cup B) \cup C$ & $x \vee(y \vee z) \equiv(x \vee y) \vee z$ \\
\hline \multicolumn{2}{|c|}{ III. Propiedad distributiva } \\
\hline$A \cap(B \cup C)=\stackrel{5}{A} \cap B) \cup(A \cap C)$ & $x \&(y \vee z) \equiv(x \& y) \vee(x \& y)$ \\
\hline$A \cup(B \cap C)=(\stackrel{6}{A} \cup B) \cap(A \cup C)$ & $x \vee(y \& z) \equiv(x \vee y) \&(x \vee z)$ \\
\hline \multicolumn{2}{|c|}{ IV. Propiedad de absorvencia } \\
\hline 7. $A \cap(A \cup B)=A$ & $x \&(x \vee y) \equiv x$ \\
\hline 8. $A \cup(A \cap B)=A$ & $x \vee(x \& y) \equiv x$ \\
\hline \multicolumn{2}{|c|}{ V. Existencia del elemento neutro } \\
\hline 9. $(A \cap U)=A$ & $(x \& 1) \equiv x$ \\
\hline 10. $(A \cup A)=A$ & $(x \vee 0) \equiv x$ \\
\hline \multicolumn{2}{|c|}{ VI. Propiedad de idempotencia } \\
\hline 11. $(A \cup A)=A$ & $(x \vee x) \equiv x$ \\
\hline 12. $(A \cap A)=A$ & $(x \& x) \equiv x$ \\
\hline
\end{tabular}


Introducción a la teoría de conjuntos...

\begin{tabular}{|c|c|}
\hline \multicolumn{2}{|c|}{ VII. Existencia de complementario } \\
\hline 13. $(A \cap \bar{A})=\varnothing$ & $(x \& \sim \mathrm{X}) \equiv 0$ \\
\hline 14. $(A \cup \bar{A})=U$ & $(x \vee \sim \mathrm{X}) \equiv 1$ \\
\hline \multicolumn{2}{|c|}{ VIII. Leyes de Morgan } \\
\hline 15. $(\overline{A \cap B})=\bar{A} \cup \bar{B}$ & $\sim(x \& y) \equiv \sim x \vee \sim y$ \\
\hline 16. $(\overline{A \cup B})=\bar{A} \cap \bar{B}$ & $\sim(x \vee y) \equiv \sim x \& \sim y$ \\
\hline \multicolumn{2}{|c|}{ IX. Relaciones entre operaciones } \\
\hline 17. $A \cap B=(\overline{\bar{A} \cup \bar{B})}$ & $(x \& y) \equiv \sim(\sim x \vee \sim y)$ \\
\hline 18. $A \cup B=(\overline{\bar{A} \cap \bar{B})}$ & $(x \vee y) \equiv \sim(\sim x \& \sim y)$ \\
\hline \multicolumn{2}{|c|}{ X. El complementario de un elemento es el propio elemento } \\
\hline 19. $\overline{\bar{A}}=A$ & $\sim(\sim x) \equiv x$ \\
\hline \multicolumn{2}{|c|}{$\begin{array}{l}\text { XI. Los dos términos neutros de las operaciones } \\
\text { son complementarios entre sí }\end{array}$} \\
\hline 20. $\bar{\varnothing}=U$ & $\sim \varnothing=1$ \\
\hline $21 \overline{\mathrm{U}}=\varnothing$ & $\sim 1=\varnothing$ \\
\hline \multicolumn{2}{|c|}{ XII. Propiedades de identidades } \\
\hline 22. $(A \cap \varnothing)=\varnothing$ & $(x \& 0) \equiv 0$ \\
\hline 23. $(A \cup U)=U$ & $(x \vee 1) \equiv 1$ \\
\hline
\end{tabular}




\section{EJERCICIOS}

\section{Ejercicio 137}

Escribir las expresiones de los siguientes ejercicios en el lenguaje de álgebra de Boole. Estos ejercicios son los mismos que los presentados anteriormente en la sección del usos de los paréntesis (110-136).

Ejercicio 138

$(A \cup B) \cap C=\{$

Ejercicio 139

$A \cup(B \cap C)=\{$

Ejercicio 140

$(\overline{A \cup B}) \cap C=\{$

Ejercicio 141

$A \cup(\overline{B \cap C})=\{$

Ejercicio 142

$(A \cup B) \cap \bar{C}=\{$

\section{Ejercicio 143}

$A \cup(B \cap \bar{C})=\{$

\section{Ejercicio 144}

$A \cup(\bar{B} \cap C)=\{$ 
Introducción a la teoría de conjuntos...

\section{Ejercicio 145}

$(A \cup \bar{B}) \cap C=\{$

Ejercicio 146

$A \cup(\bar{B} \cap \bar{C})=\{$

\section{Ejercicio 147}

$(A \cup \bar{B}) \cap \bar{C}=\{$

Ejercicio 148

$\bar{A} \cup(B \cap C)=\{$

Ejercicio 149

$(\bar{A} \cup B) \cap C=\{$

Ejercicio 150

$\bar{A} \cup(B \cap \bar{C})=\{$

Ejercicio 151

$(\bar{A} \cup B) \cap \bar{C}=\{$

Ejercicio 152

$\bar{A} \cup(\bar{B} \cap \bar{C})=\{$ 
Ejercicio 153

$(\bar{A} \cap \bar{B}) \cup \bar{C}=\{$

Ejercicio 154

$\bar{A} \cap(\overline{B \cup C})=\{$

\section{Ejercicio 155}

$(\overline{A \cap B}) \cup C=\{$

Ejercicio 156

$\overline{A \cap(B \cup C)}=\{$

\section{Ejercicio 157}

$$
\overline{(A \cap B) \cup C}=\{
$$

\section{Ejercicio 158}

$\overline{(A \cap B)} \cup \bar{C}=\{$

Dibujando gráficas, encuentra los siguientes conjuntos y represéntalos con las letras y operaciones entre conjuntos correspondientes:

\section{Ejercicio 159}

Los libros de Bibliotecología de Héctor Alfaro López que no están en inglés. 
Introducción a la teoría de conjuntos...

\section{Ejercicio 160}

Los libros de Alfaro López en inglés que son de Filosofía.

\section{Ejercicio 161}

Los libros en inglés de Bibliotecología que no son de Alfaro López.

\section{Ejercicio 162}

Los libros que no son de Bibliotecología ni de Alfaro López pero que están en inglés.

\section{Ejercicio 163}

Los libros de Filosofía o Bibliotecología pero que no son de Alfaro López.

\section{Ejercicio 164}

Los libros de Filosofía o Bibliotecología o de Alfaro López. 
Capítulo III

\section{TEORÍA DEL CONCEPTO}




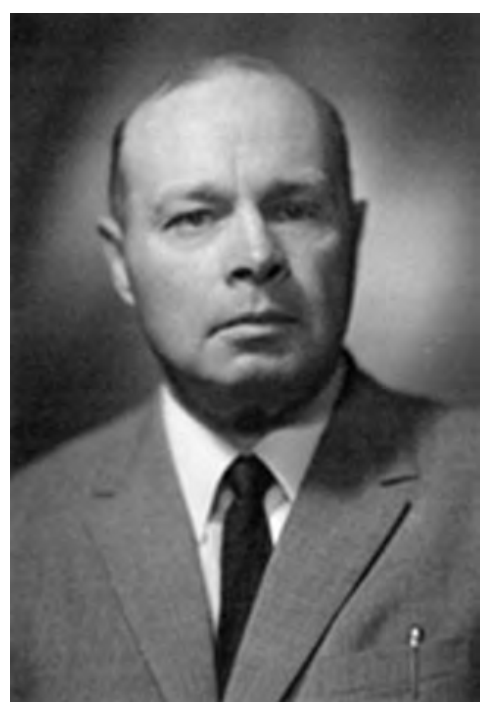

Евгений Казимирович Войшвилло (1913-2008)

(Evguenii Kazimirovicht Voishvillo)

\section{DEFINICIÓN DE CONCEPTO}

$1 \begin{aligned} & \text { emos visto que podemos describir un conjunto de mane- } \\ & \text { ra extensional al enumerar los elementos que lo componen } \\ & \text { y, de manera intensional, al dar las propiedades o caracte- }\end{aligned}$ rísticas que deben tener los elementos para formar un conjunto. Así pues, podemos formar de manera intensional el conjunto $A$, al decir que $A=\{x / P x$ y $Q x\}$ ( $A$ es el conjunto de todas las $x$, tales que $x$ es $P$ y $x$ es $Q$ ), donde $P$ es la propiedad "ser un cuerpo celeste" y $Q$ es la propiedad "girar alrededor de una estrella". Ahora bien, con base en esas propiedades $(P$ y $Q)$, podemos identificar los objetos que las poseen y agruparlos en un conjunto. El ejemplo anterior lo podemos representar gráficamente de la siguiente manera:

Tenemos como conjunto universal $U$ el conjunto de objetos existentes en el cosmos. De esta manera, $U$ incluye infinidad de objetos 
Introducción a la teoría de conjuntos...

que pueden ser elementos químicos, cuerpos celestes, seres vivos, seres humanos, etc. Estos objetos pertenecientes a $U$ los representaremos con puntos dentro del conjunto universal.

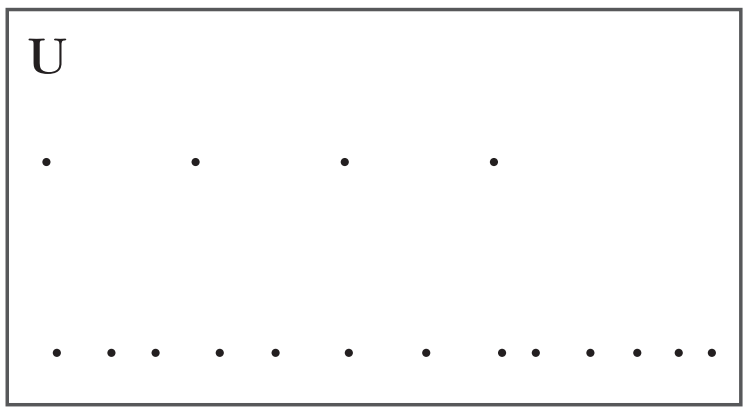

De acuerdo con la primera función, que es identificar los objetos que cumplen con las características dadas, ser cuerpo celeste y girar alrededor de una estrella, podemos establecer cuáles objetos las tienen y cuáles no. Pondremos una cruz a los objetos de $U$ que cumplen con las propiedades mencionadas:

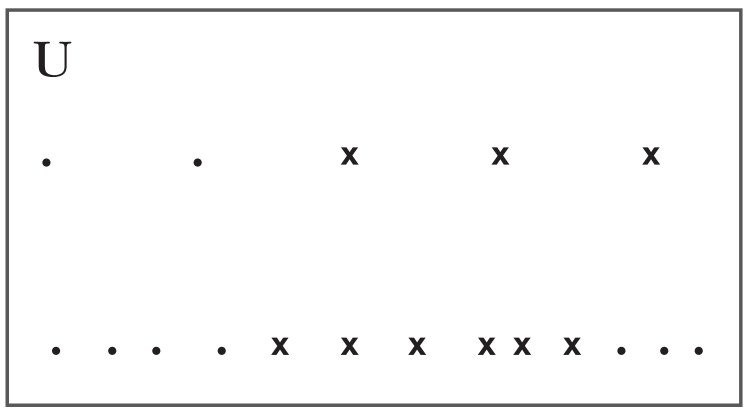

Posteriormente, con base en la segunda función, que es agrupar los objetos seleccionados, se forma el conjunto deseado: 


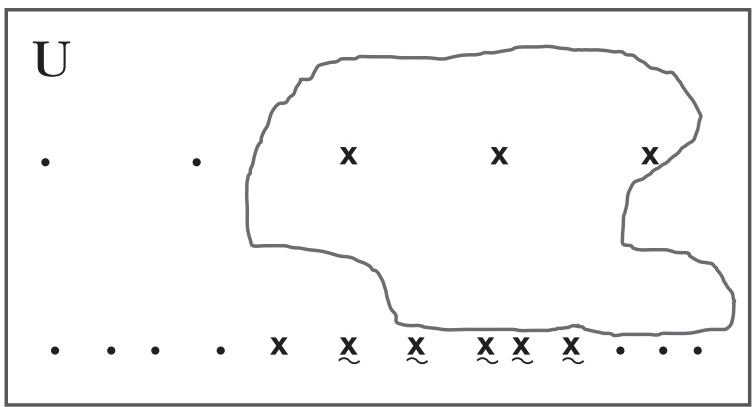

De esta manera, gracias a las propiedades $P$ y $Q$, llegamos al conjunto de planetas y podemos identificar todos los objetos que caen dentro de dicho concepto. Así pues, vamos a llamar concepto a la forma del pensamiento que, con base en ciertas propiedades, identifica y distingue ciertos objetos dentro de un universo y los agrupa en una clase.

Las características o propiedades que sirven de base para la identificación, distinción y agrupación de los objetos que las poseen se llaman contenido del concepto. Las clases o conjuntos que se forman al agrupar esos objetos, son llamadas volumen del concepto. El contenido del concepto es el elemento que nos proporciona la forma lógica del concepto; de esta manera, si el contenido del concepto es la propiedad "ser $A$ ", entonces la forma lógica del concepto se representa de la siguiente manera: $X A(X)$, que se lee "el objeto $X$ del correspondiente universo que cumple la propiedad 'ser $A$ ', donde la propiedad "ser $A$ " puede ser compleja, es decir, puede ser una composición de conjunciones, disyunciones, negaciones, condicionales y bicondicionales. ${ }^{?}$

9 Representaremos las constantes lógicas, aprovechando que ya se conocen los símbolos de la lógica booleana, de la siguiente manera: para la negación "no" (no es cierto, no es verdad); \& para la conjunción "y" (pero, asimismo, al mismo tiempo, simultáneamente, así como, también); $\vee$ para la disyunción

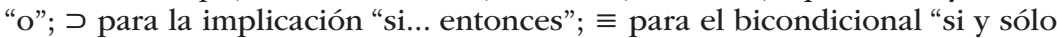


El universo en donde se encuentran los objetos $X$ se denomina género, y la propiedad $A$, diferencia específica. De esta manera, todo concepto identifica en el universo $U$ (género) aquellos y sólo aquellos objetos que poseen la diferencia específica $A$. Así por ejemplo, en el caso dado anteriormente, la forma lógica de planeta, que se construyó con las propiedades $P$, "ser un cuerpo celeste", y $Q$, "girar alrededor de una estrella", se puede construir de la siguiente manera:

Se puede considerar que el género (universo) son los cuerpos celestes y de éstos se identifican y agrupan los que giran alrededor de una estrella (diferencia específica), por lo que resulta: $x$ es planeta $\equiv x(Q(x))$; $-x$ es planeta si y sólo si el objeto $x$ del universo de los cuerpos celestes cumple con la propiedad "girar alrededor de una estrella".

Otro camino para construir la forma lógica de ese concepto es considerar que tanto ser un cuerpo celeste $(P)$ como girar alrededor de una estrella $(Q)$ son la diferencia específica, y por lo tanto el universo (género) es más amplio, por lo que se toma el conjunto de los objetos del universo (cosmos), tal como lo hicimos en el ejemplo dado al inicio de este apartado al formar el conjunto $A=\{x / P x y Q x\}$. En este caso, la forma lógica del concepto planeta es: $x$ es planeta

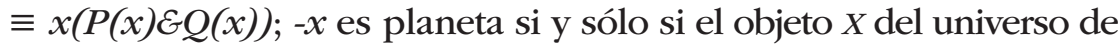
los objetos existentes en el cosmos cumple con las propiedades "ser un cuerpo celeste y girar alrededor de una estrella".

Como ya se indicó, el volumen del concepto es el conjunto formado por los objetos que poseen las características indicadas por el contenido. Si la propiedad del contenido es "ser $A$ " y la forma lógica del concepto es $X A(X)$, entonces el volumen del concepto se representa de la siguiente manera: $W X A(X)$, que se lee: "el conjunto de los objetos $X$ del correspondiente universo que cumplen la propiedad 'ser $A$ '”.

si"; $x, y, z, \ldots, x n, y n, z n$ para variables individuales; $\mathrm{P}, Q, R, S, T, U, V, \ldots P n$, $Q n, R n, S n, T n, U n, V n$ para predicados. Símbolos técnicos (,). 


\section{Errores en la construcción de conceptos}

Un concepto es adecuado cuando dentro del conjunto que se forma a partir de las características que se toman para su elaboración, entran todos y sólo todos los objetos que se identifican como elementos del volumen del concepto, es decir, no se tienen objetos de más en ese conjunto, en cuyo caso tendríamos un concepto muy amplio, ni se tienen objetos fuera del conjunto que debiendo estar no lo están, pues tendríamos un concepto estrecho. Un ejemplo de un concepto amplio es el afirmar que "documento" (en el ámbito bibliotecológico) se caracteriza por tener las propiedades $R$ : "ser un soporte material" y $S$ : "contener información": $x$ es documento $\equiv x(P(x) \mathcal{E Q}(x)) ;-x$ es documento si y sólo si el objeto $X$ de la correspondiente clase cumple con las propiedades "ser un soporte material" y "contener información".

En ese caso, existen diversos objetos que poseen ambas propiedades y consecuentemente son elementos del conjunto que se formó a partir de ellas, pero que difícilmente se podrían considerar documentos (bibliotecológicos), tales como los profesores, los átomos, las estrellas, entre otros.

Por otro lado, un ejemplo de un concepto estrecho es establecer que "Marginalia" es toda anotación manuscrita $(T)$ colocada en los márgenes de un libro $(U)$ o de un escrito cualquiera $(V)$ :

$x$ es marginalia $\equiv x[T(x) \mathcal{E}(U(x) V(x))] ;-x$ es marginalia si y sólo si el objeto $X$ de la correspondiente clase cumple con las propiedades "ser anotación manuscrita" y "estar colocada en los márgenes de un libro" o "estar colocada en un escrito cualquiera". El concepto anterior se considera estrecho porque en ese caso, las anotaciones impresas no caen dentro del conjunto formado aunque deberían estarlo. 
Introducción a la teoría de conjuntos...

\section{EJERCICIOS}

\section{Ejercicio 165}

Proporciona dos ejemplos de conceptos amplios.

\section{Ejercicio 166}

Proporciona dos ejemplos de conceptos estrechos.

\section{TIPOS DE CONCEPTOS}

Existen diferentes criterios para distinguir distintos tipos de conceptos. Entre ellos, se encuentran el número de elementos que contienen sus volúmenes, la naturaleza de los objetos que se incluyen en el volumen del concepto y las características de las propiedades por las que se forma el concepto.

\section{Tipos de conceptos por el número de elementos en su volumen}

De acuerdo con el número de objetos que contiene el concepto, éste último puede ser:

\section{Concepto vacío}

Es aquel cuyo volumen no contiene ningún elemento, es decir, el conjunto formado a partir de las características elegidas como criterios de identificación y agrupamiento de objetos es un conjunto vacío: $W x A(x)=\varnothing$. 
Algunos ejemplos de conceptos vacíos: 1. "colonias griegas fundadas en Australia"; 2. "el número natural mayor que todos los números"; 3. "cuerpo cuyo movimiento es mayor a la velocidad de la luz", 4. "metal que no conduce la electricidad"; 5. "cuadrado que es y no es a la vez cuadrado" (círculo cuadrado). Como se podrá observar, las causas por las cuales ciertos conceptos resultan vacíos pueden ser de naturaleza fáctica, por circunstancias históricas o ir contra las leyes de la naturaleza; o de naturaleza lógica, que contravienen las leyes de la lógica y su diferencia específica es una contradicción.

\section{EJERCICIOS}

\section{Ejercicio 167}

Proporciona dos ejemplos de conceptos vacíos.

\section{Conceptos no vacíos}

Son aquellos cuyo volumen contiene uno o más elementos. Estos a su vez, pueden ser:

Concepto individual

Es aquel cuyo volumen contiene solamente un elemento, es decir, el conjunto formado a partir de las características elegidas como criterios de identificación y agrupamiento de objetos es un conjunto unitario:

$$
\mathbf{W X A}(\mathbf{x})=\{a\}
$$


Introducción a la teoría de conjuntos...

Como ejemplos de conceptos unitarios, pueden servir: "número primo que es par", en este caso es el número 2; "autor de la novela en verso Eugenio Oneguin", que es el escritor ruso Alexander Pushkin; "compuesto químico cuya molécula está constituida por dos átomos de hidrógeno y uno de oxígeno", que es el agua. Desde el punto de vista lógico, no se deben confundir nombres, descripciones y conceptos unitarios. Los dos primeros, los nombres y las descripciones, denotan un individuo, mientras que el concepto, como sabemos, forma un conjunto, aunque éste pueda ser de un solo elemento.

\section{EJERCICIOS}

\section{Ejercicio 168}

Proporciona dos ejemplos de conceptos individuales.

Concepto general

El concepto general es aquel cuyo volumen contiene más de un elemento, es decir, el conjunto formado a partir de las características elegidas como criterios de identificación y agrupamiento de objetos, no es un conjunto vacío ni unitario: $W x A(x)=\{a, b, c, d, e\}$.

Por ejemplo, cuando se proporciona la característica "substancia química cuya molécula está formada por átomos del mismo tipo", se obtiene el concepto de elemento, el cual incluye varios como el hidrógeno, litio, sodio, potasio, etc. Otro caso es el concepto de incunable: "libro impreso entre el periodo que va de la invención de la imprenta hasta el año 1500”, que abarca varios ejemplares. 


\section{EJERCICIOS}

\section{Ejercicio 169}

Proporciona dos ejemplos de conceptos generales.

Dentro de los conceptos generales se distinguen los conceptos universales.

\section{Conceptos universales}

Es aquel cuyo volumen coincide con el universo (género) de dicho concepto, es decir, el conjunto formado a partir de las características elegidas como criterios de identificación y agrupamiento de objetos, es un conjunto universal: $W x A(x)=U$.

Estrictamente hablando, este tipo de conceptos no contienen información alguna sobre los objetos del universo, no indican una diferencia específica. Por ejemplo, "cuadrados de cuatro lados", "individuos solteros no casados”. Es fácil ver que existe una relación entre conceptos vacíos y universales; si se niega el contenido de un concepto vacío, se obtiene un concepto universal y viceversa, si se niega un concepto universal, resulta un concepto vacío.

\section{EJERCICIOS}

\section{Ejercicio 170}

Proporciona dos ejemplos de conceptos universales. 
Introducción a la teoría de conjuntos...

\section{Tipos de conceptos por la naturaleza de los elementos de su volumen}

Se puede realizar otra tipología de los conceptos tomando como criterio la naturaleza de los objetos que comprende el volumen del concepto. De esta manera tenemos:

\section{Conceptos concretos y abstractos}

Aunque todo concepto por su naturaleza es abstracto, es una forma de pensamiento y, por tanto, no tiene una ubicación espaciotemporal, se dice que un concepto es concreto cuando los objetos que constituyen su volumen son concretos, esto es, son objetos que pueden ser localizados mediante coordenadas espacio-temporales. Así, por ejemplo, en esta categoría se encuentran conceptos como documento, usuario, centro de información, fondo antiguo, galaxia, planeta, metal, etc. Por su parte, los conceptos abstractos contienen en su volumen objetos abstractos, por ejemplo el concepto de información, número, Estado, amistad, belleza, etcétera.

\section{EJERCICIOS}

\section{Ejercicio 171}

Proporciona dos ejemplos de conceptos concretos.

\section{Ejercicio 172}

Proporciona dos ejemplos de conceptos abstractos. 


\section{Conceptos colectivos y no colectivos}

Los conceptos colectivos son aquellos cuyos elementos representan un conjunto, es decir, que su volumen se encuentra formado por conjuntos que son en sí mismos una unidad, y ésta a su vez está constituida por individuos. Ejemplos de este tipo de conceptos son colección bibliotecaria, catálogo, ejército, Cámara de diputados, entre otros. Por su parte, los conceptos no colectivos son los que tienen elementos individuales en su volumen. Por ejemplo, el concepto de Institución de Educación Superior tiene dentro de su volumen instituciones concretas: UNAM, UAM, IPN, ITAM, ITESM, UIA, UIC, UAEM, BUAP, entre otras.

\section{EJERCICIOS}

Ejercicio 173

Proporciona dos ejemplos de conceptos colectivos.

\section{Ejercicio 174}

Proporciona dos ejemplos de conceptos no colectivos.

Tipos de conceptos por las características de las propiedades por las que se forma el concepto

\section{Conceptos simples y compuestos}

Por concepto simple se entiende aquel cuyo contenido está formado por una sola característica, y en su forma lógica no aparecen 
Introducción a la teoría de conjuntos...

conectivos lógicos. Así, por ejemplo, "tener cuatro lados iguales". El concepto compuesto es aquel cuyo contenido está formado por dos o más características unidas por constantes lógicas (negación, disyunción, conjunción, implicación y bicondicional). Es el caso de "número divisible sólo entre sí mismo y la unidad": el número primo, o de "persona nacida en México o por lo menos de un padre mexicano $o$ con carta de naturalización $y$ mayor de dieciocho años": ciudadano mexicano.

\section{EJERCICIOS}

\section{Ejercicio 175}

Proporciona dos ejemplos de conceptos simples.

\section{Ejercicio 176}

Proporciona dos ejemplos de conceptos compuestos.

\section{Conceptos positivos y negativos}

Son positivos aquellos conceptos en cuyo contenido se tienen propiedades sobre la presencia de ciertas características en los objetos. Por ejemplo, "número divisible entre dos", los números pares. Si el contenido del concepto hace referencia a la ausencia de una característica, entonces el concepto es negativo. Así tenemos "número no divisible entre dos", los números impares. 


\section{EJERCICIOS}

\section{Ejercicio 177}

Proporciona dos ejemplos de conceptos positivos.

\section{Ejercicio 178}

Proporciona dos ejemplos de conceptos negativos.

\section{Conceptos relativos y no relativos}

Por concepto relativo, se entiende aquél en cuyo contenido se utilizan características que representan relaciones entre individuos, como causa y efecto; estímulo y respuesta; mayor que; menor que, entre otros. Por su parte, los conceptos no relativos hacen referencia a la presencia o ausencia de una característica de sí mismos sin hacer referencia a relaciones con otros objetos, como "ser substancia simple", "ser animal racional", "ser documento de publicación periódica”, entre otros.

\section{EJERCICIOS}

\section{Ejercicio 179}

Proporciona dos ejemplos de conceptos relativos. 
Introducción a la teoría de conjuntos...

\section{Ejercicio 180}

Proporciona dos ejemplos de conceptos no relativos.

\section{RELACIONES ENTRE CONCEPTOS}

Entre los conceptos, se dan algunas relaciones objetivas que existen independientemente de nuestra voluntad o deseos. El hecho de que dos conceptos se encuentran en cierta relación uno con otro se puede determinar con ayuda tanto de su contenido como de su volumen.

\section{Conceptos comparables y no comparables}

Dos conceptos $X A(X)$ y $X B(X)$ son incomparables si y sólo si en el primer concepto $X \in U_{1}$ y en el segundo concepto $X \in U_{2}$, además de que $U_{1} \neq U_{2}$. Es decir, si el género del primer concepto es distinto al género del segundo. Por ejemplo, los conceptos ser bumano y número natural; fórmula y cuerpo celeste; libro y zapato, son incomparables.

Dos conceptos $X \mathrm{~A}(X)$ y $X B(X)$ son comparables si y sólo si coinciden sus géneros, es decir, $U_{1}=U_{2}$. Por ejemplo los conceptos de poesía épica y poesía lírica poseen el mismo universo de ser ambas un género literario. 


\section{EJERCICIOS}

\section{Ejercicio 181}

Proporciona dos ejemplos de conceptos que sean no comparables.

\section{Ejercicio 182}

Proporciona dos ejemplos de conceptos que sean comparables.

\section{Tipos fundamentales de relaciones comparables}

Dentro de los posibles pares de conceptos comparables, distinguiremos los que se encuentran en tres tipos fundamentales de esta relación. Se llaman fundamentales porque con ayuda de sus combinaciones es posible construir otras relaciones. Así pues, dentro de estos tipos fundamentales de relaciones tenemos la compatibilidad, la inclusión y la completud.

\section{Compatibilidad}

Dos conceptos $X A(X)$ y $X B(X)$ son compatibles si y sólo si la intersección de sus volúmenes no es vacío, es decir, $W X A(X) \cap W X B(X) \neq \emptyset$. Lo anterior significa que se tiene en el universo por lo menos un elemento que posee la propiedad $A$ y $B$. Por ejemplo, los conceptos obras de arte y obras de Filosofía son compatibles porque existen objetos que a la vez son obras de la literatura universal (arte en sentido general) y de Filosofía, como Los hermanos Karamásov de Dostoievsky o La peste de Albert Camus, entre otros.

Dos conceptos $X A(X)$ y $X B(X)$ son incompatibles si y sólo si la intersección de sus volúmenes es vacío, es decir, $W X A(X) \cap W X B(X)=\emptyset$. 
Introducción a la teoría de conjuntos...

Es el caso de los conceptos números enteros y números irracionales. No encontraremos un número que sea a la vez entero e irracional.

\section{EJERCICIOS}

\section{Ejercicio 183}

Proporciona dos ejemplos de conceptos que sean no compatibles.

\section{Ejercicio 184}

Proporciona dos ejemplos de conceptos que sean compatibles.

\section{Inclusión}

El concepto $X A(X)$ está incluido en el concepto $X B(X)$ si y sólo si cada elemento de $W X A(X)$ es elemento de $W X B(X)$. Lo anterior se representa de la siguiente manera: $X A(X) \subseteq X B(X)$, donde $\subseteq$, como ya indicamos al hablar de la inclusión entre conjuntos, es el símbolo que se utiliza para representar esta relación. Por ejemplo, el concepto biblioteca está incluido en el concepto de unidad de información.

\section{EJERCICIOS}

\section{Ejercicio 185}

Proporciona dos ejemplos de pares de conceptos donde se dé la relación de inclusión. 


\section{Completud}

Dos conceptos $X \mathrm{~A}(X)$ y $X B(X)$ se encuentran en la relación de completud si y sólo la unión de sus volúmenes da como resultado el universo, esto es $W X \mathrm{~A}(X) \cup W X \mathrm{~B}(X)=U$. Esto significa que cada objeto del universo es elemento del primer o el segundo concepto. Tenemos esta relación entre los conceptos mujer embarazada o mujer no embarazada. Si la anterior condición no se cumple, es decir, si $W X A(X) \cup W X \mathrm{~B}(X) \neq U$, entonces dichos conceptos se encuentran en una relación de incompletud. Por ejemplo, el concepto de escultura y música no agotan el universo del arte.

\section{EJERCICIOS}

\section{Ejercicio 186}

Proporciona dos ejemplos de pares de conceptos donde se dé la relación de incompletud.

\section{Ejercicio 187}

Proporciona dos ejemplos de pares de conceptos donde se dé la relación de completud.

Tomando en consideración las anteriores relaciones fundamentales entre conceptos, podemos distinguir otras relaciones entre conceptos, tales como: 
Introducción a la teoría de conjuntos...

Relaciones de compatibilidad

Relación de equivalencia. Dos conceptos $X A(X)$ y $X B(X)$ se encuentran en la relación de equivalencia si y sólo si son compatibles, el primero está incluido en el segundo, el segundo está incluido en el primero, y además están en relación de incompletud. La relación de equivalencia generalmente se simboliza $X A(X)=X B(X)$. Un ejemplo de esta relación se ve en los conceptos triángulo equilátero y triángulo equiángulo. La anterior relación se representa de la siguiente manera:

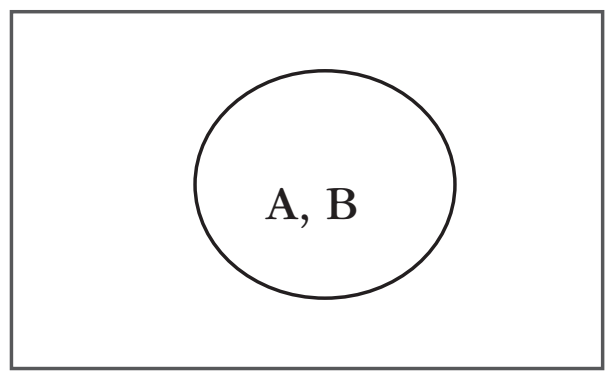

EJERCICIOS

\section{Ejercicio 188}

Proporciona dos ejemplos de pares de conceptos donde se dé la relación de equivalencia.

Relación de subordinación. El concepto $X \mathrm{~A}(X)$ se encuentra en la relación de subordinación con respecto a $X B(X)$ si y sólo si son compatibles, el primero está incluido en el segundo, pero no se da el caso contrario, y están en relación de incompletud. La rela- 
ción de subordinación se simboliza $X \mathrm{~A}(X) \subset X B(X)$, donde $X \mathrm{~A}(X)$ es la diferencia específica y $X B(X)$ el género.

En esta relación, se encuentran, por ejemplo, planeta y cuerpo celeste, biblioteca especializada y biblioteca.

Gráficamente, esta relación se representa con el siguiente diagrama:

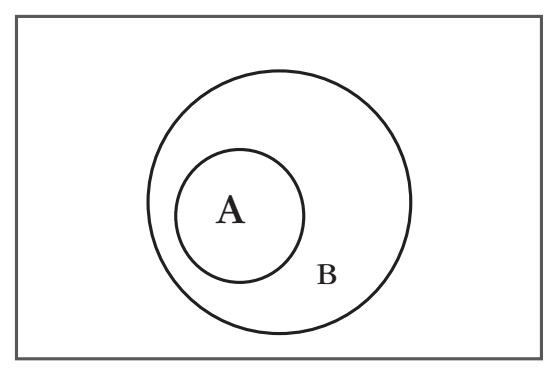

\section{EJERCICIOS}

\section{Ejercicio 189}

Proporciona dos ejemplos de pares de conceptos donde se dé la relación de subordinación.

Relación de intersección. Dos conceptos $X \mathrm{~A}(X)$ y $X B(X)$ se encuentran en la relación de intersección si y sólo si son compatibles, el primero no está incluido en el segundo ni el segundo en el primero, y se encuentran en relación de incompletud. En otras palabras, se puede decir que una porción del volumen del primero es parte del volumen del segundo y viceversa.

En dicha relación están los conceptos de filósofos y matemáticos en el universo de seres humanos.

El diagrama que representa esta relación es el siguiente: 
Introducción a la teoría de conjuntos...

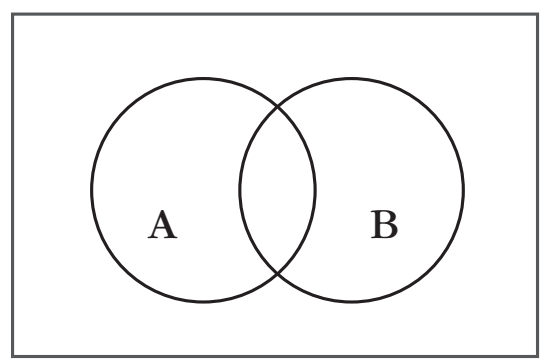

\section{EJERCICIOS}

\section{Ejercicio 190}

Proporciona dos ejemplos de pares de conceptos donde se dé la relación de intersección.

Relación de complementariedad. Dos conceptos $X \mathrm{~A}(X)$ y $X B(X)$ se encuentran en la relación de complementariedad si y sólo si son compatibles, están en relación de completud, pero no se incluyen mutuamente.

En esta relación, tenemos los conceptos número menor de 500 y número mayor de 400 en el universo de los números naturales.

Su representación gráfica es:

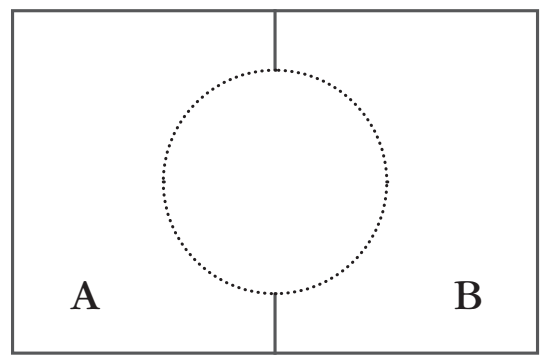


Donde el conjunto $A$ (número menor de 500) está representado por:

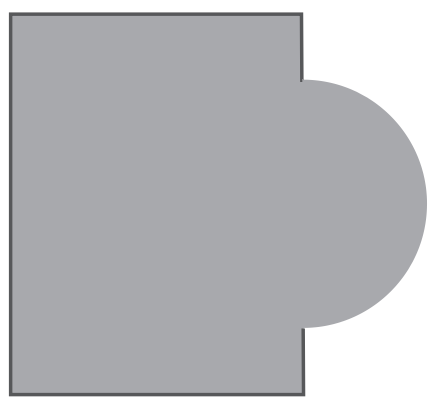

y el conjunto $B$ (número mayor de 400 ) por:

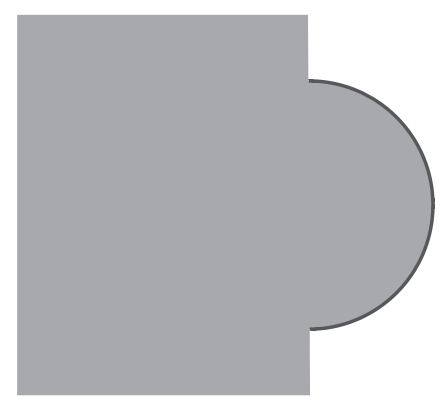

\section{EJERCICIOS}

Ejercicio 191

Proporciona dos ejemplos de pares de conceptos donde se dé la relación de complementariedad.

Relaciones de incompatibilidad

Existen otras relaciones entre los conceptos en donde no son compatibles pero siguen siendo comparables, es decir, comparten el 
Introducción a la teoría de conjuntos...

universo. Así, tenemos las relaciones de cosubordinación, contrariedad y contradicción.

Relación de cosubordinación. Dos conceptos $X A(X)$ y $X B(X)$ se encuentran en la relación de cosubordinación si y sólo si son incompatibles, por consecuencia no tienen elementos comunes, están en relación de incompletud, y además son subconjuntos de un mismo universo que los hace ser subordinados a ambos con respecto a dicho universo.

En esta relación, se encuentran los conceptos planeta y cometa en relación al universo de los cuerpos celestes; movimiento rectilíneo y movimiento circular con respecto al movimiento. La representación de esta relación es:

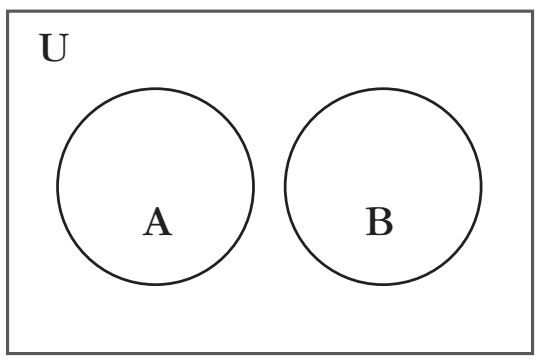

EJERCICIOS

\section{Ejercicio 192}

Proporciona dos ejemplos de pares de conceptos donde se dé la relación de cosubordinación

Relación de contradicción. Dos conceptos $X A(X)$ y $X B(X)$ se encuentran en relación de contradicción si y sólo si son incompatibles, 
consecuentemente no tienen elementos comunes, y están en relación de completud. En esta relación, se encuentran todos los conceptos que tienen como diferencia específica la presencia de una característica $X A(X)$ con otros que tienen como diferencia específica la negación de esa misma característica $X \sim A(X)$.

Por ejemplo, "ser palabra variable de la oración" con "ser palabra invariable de la oración"; "ser un ser vivo" con "ser un ser no vivo".

Su representación es:

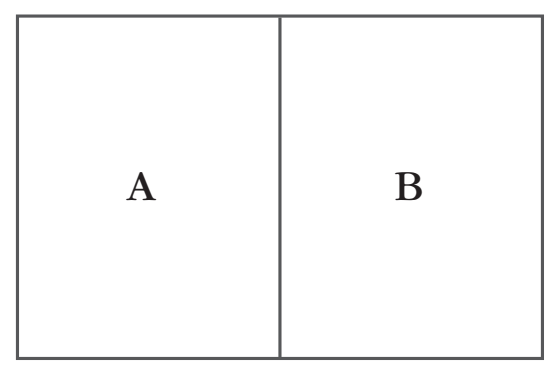

\section{EJERCICIOS}

\section{Ejercicio 193}

Proporciona dos ejemplos de pares de conceptos donde se dé la relación de contradicción.

Relación de contrariedad. Algunos autores reconocen la existencia de otra relación entre conjuntos que es la relación de contrariedad. ${ }^{10}$ Desde el punto de vista sintáctico, es difícil definir dicha relación. Por lo general, se entiende como conceptos contrarios

$10 C f$. Evguenii Kasimírivich Voishvillo y M. G. Degtiarev (1994: 76). 
Introducción a la teoría de conjuntos...

aquellos que poseen ciertas características en grados extremos según cierta escala. De esta manera, se supone que existe la posibilidad de un orden jerárquico entre los objetos. Son conceptos incompatibles, que no se incluyen, pero tampoco son contradictorios porque su unión no da todo el universo, existe un campo intermedio en el que se encuentran diversos elementos que no pertenecen a uno ni a otro concepto. Se pueden concebir como cosubordinados al universo, pero con la particularidad de que cada concepto abarca el extremo del universo.

Como ejemplos de esta relación, pueden servir los conceptos países desarrollados y países no desarrollados; blanco y negro; servicio bibliotecario eficaz y servicio bibliotecario ineficaz.

Gráficamente, esta relación se representa de la siguiente manera:

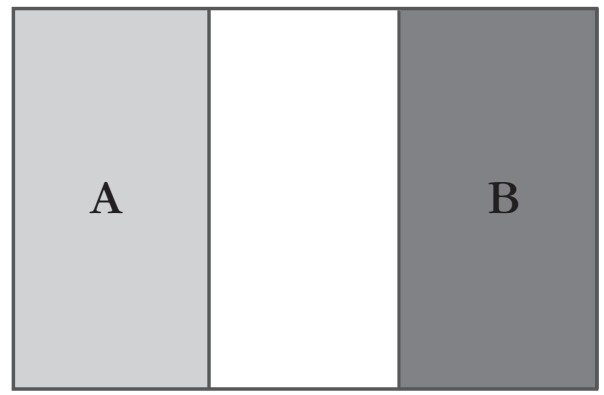

EJERCICIOS

\section{Ejercicio 194}

Proporciona dos ejemplos de pares de conceptos donde se dé la relación de contrariedad. 
En Lógica dialéctica, se habla también de contrarios, pero en este caso se entienden los conceptos, que son reflejo de una realidad igualmente dialéctica, y que representan hechos, procesos, fenómenos, ideas que por un lado se excluyen recíprocamente, uno es lo opuesto a lo otro, pero que por otro se necesitan el uno al otro para poder existir, funcionar y comprenderse. Asimismo, esa tensión (lucha entre ellos) y unión (no pueden existir sin uno de ellos) da como resultado el movimiento, el desarrollo y el conocimiento.

En esta relación, se encuentran, por ejemplo, la libertad y la necesidad; la necesidad y la contingencia; la verdad absoluta y la verdad relativa; la forma y el contenido; la metodología científica y la creatividad del científico; la sociedad y el individuo; el valor de uso y el valor de cambio, entre otros.

\section{RELACIONES ENTE JUICIOS}

Para finalizar este apartado, creemos necesario hacer la advertencia de que no se deben confundir las relaciones entre conceptos con las relaciones entre juicios, llamados actualmente proposiciones o enunciados. Ya hemos mencionado lo que se entiende por concepto: una forma de pensamiento que, con base en ciertas características, identifica y diferencia ciertos objetos que las poseen, y que agrupa a dichos objetos en un conjunto. Es por ello que, estrictamente hablando, no se puede hablar de verdad o falsedad de un concepto, así como no se puede hablar de verdad o falsedad de una fotografía, sino más bien de que sea adecuado, claro, completo o no al formarlo, ya que debe incluir a todos y sólo a todos los objetos que están bajo ese concepto. El concepto se empieza a valorar como verdadero o falso en el momento en que su contenido, esto es, las características elegidas como criterio para identificar, distinguir y agrupar los objetos, se enuncian como juicio y se contrastan con la realidad, pero en ese momento se está 
Introducción a la teoría de conjuntos...

trabajando ya no con el concepto como tal, sino con un juicio o proposición.

Así pues, un juicio es una forma del pensamiento en la que se afirma o niega la presencia o ausencia de ciertos atributos o relaciones a un sujeto (situación, hecho, fenómeno, objeto, idea). En la lógica contemporánea, se expresa que un enunciado o proposición es una expresión lingüística que puede ser calificada como verdadera o falsa, pero no verdadera y falsa a la vez. De esta forma, sólo los juicios o enunciados pueden ser calificados como verdaderos o falsos.

Los juicios o enunciados también tienen sus relaciones entre ellos y se clasifican en diferentes tipos. Esto se analiza dentro del apartado de la lógica que corresponde a la teoría del juicio, por lo que no cae dentro de los límites del presente trabajo, que tiene como objetivo la teoría de conjuntos y la lógica booleana, y la expansión que de éstas pueda hacerse para analizar la teoría del concepto con los instrumentos que nos puedan proporcionar. Solamente mencionaremos que entre los juicios o enunciados se dan las relaciones de contradicción, contrariedad, subcontrariedad, subordinación, consecuencia lógica, equivalencia lógica e independencia lógica.

Dos juicios $A$ y $B$ son contradictorios si y sólo si $A$ es verdadero, entonces $B$ necesariamente es falso y viceversa, o si $A$ es falso, $B$ es verdadero y viceversa. Esto es, no es posible que ambos sean al mismo tiempo verdaderos o que los dos sean al mismo tiempo falsos. Son incompatibles en la verdad e incompatibles en la falsedad. Un ejemplo de esta relación lo muestran los siguientes enunciados: "todos los usuarios de la biblioteca satisfacen sus necesidades de información" y "algunos usuarios de la biblioteca no satisfacen sus necesidades de información" o también: "ningún usuario de la biblioteca satisface sus necesidades de información" y "algunos usuarios satisfacen sus necesidades de información".

Dos juicios $A$ y $B$ son contrarios si y sólo si uno de ellos es verdadero, el otro necesariamente es falso, aunque pueden coincidir 
en que los dos sean falsos. Son incompatibles en la verdad y compatibles en la falsedad. En esta relación, se encuentran los juicios "todos los usuarios de la biblioteca satisfacen sus necesidades de información" y "ningún usuario de la biblioteca satisface sus necesidades de información”. Si uno de ellos es verdadero, el otro será falso, pero puede darse el caso de que ambos sean falsos.

Dos juicios $A$ y $B$ son subcontrarios si y sólo si uno de ellos es falso, en cuyo caso el otro necesariamente será verdadero, aunque los dos pueden ser verdaderos simultáneamente. Son incompatibles en la falsedad y compatibles en la verdad. Por ejemplo, los enunciados "algunos usuarios de la biblioteca satisfacen sus necesidades de información" y "algunos usuarios de la biblioteca no satisfacen sus necesidades de información" se encuentran en esta relación.

Un juicio $B$ se encuentra subordinado a otro $A$ si y sólo si $A$ es verdadero, entonces $B$ también lo será, pero no se da el caso contrario. Por ejemplo, tenemos que el enunciado "algunos usuarios de la biblioteca satisfacen sus necesidades de información" está subordinado al enunciado "todos los usuarios de la biblioteca satisfacen sus necesidades de información" porque si el primero es verdadero, el segundo necesariamente también lo será. También se da esta relación entre los enunciados "algunos usuarios no satisfacen sus necesidades de información” y "ningún usuario de la biblioteca satisface sus necesidades de información”.

El enunciado $B$ es consecuencia lógica de $A$ si y sólo si $A$ es verdadero, entonces $B$ necesariamente es verdadero; es decir, es imposible que $A$ sea verdadero y $B$ falso. Su representación simbólica es $A \mid=B$, que se lee: de $A$ se sigue lógicamente $B$; a $A$ se le llama premisa y a $B$ se le llama conclusión. También puede existir la consecuencia lógica entre un conjunto de enunciados $A_{1}, A_{2}$, $A_{3}, \ldots, A_{n}, B$, de los cuales el último es la conclusión y los demás son las premisas, si y sólo si $A_{1}, A_{2}, A_{3}, \ldots, A_{n}$ son verdaderas y $B$ es necesariamente verdadera, esto es, no puede darse el caso de 
Introducción a la teoría de conjuntos...

que $A_{1}, A_{2}, A_{3}, \ldots, A_{n}$ sean verdaderas y $B$ falsa. Simbólicamente se escribe: $A_{1}, A_{2}, A_{3}, \ldots, A_{n} \mid=B$.

Dos juicios $A$ y $B$ son equivalentes lógicamente si y sólo si $A$ |= $B$ у $B \mid=A$. Se representa $A \Leftrightarrow B$.

Dos juicios $A$ y $B$ son independientes lógicamente si y sólo si son compatibles en la verdad y en la falsedad, y no son consecuencia lógica uno del otro.

Tradicionalmente, se ha utilizado el llamado cuadrado lógico como un instrumento didáctico para recordar las relaciones de contradicción, contrariedad, subcontrariedad y subordinación entre los juicios atributivos categóricos. Estos juicios afirman o niegan sólo propiedades (atributos) de un sujeto. Se pueden dividir por cantidad en universales (todos) y particulares (algunos), y por calidad en afirmativos y negativos. Al combinar esos cuatro tipos de juicios entre sí, obtenemos que los juicios atributivos categóricos pueden ser:

Universal afirmativo. "Todos los $S$ son $P$ ".

Universal negativo. "Ningún $S$ es $P$ ".

Particular afirmativo. "Algunos $S$ son $P$ " o puede ser "Algún $S$ es $P$ ".

Particular negativo. "Algunos $S$ no son $P$ " o puede ser "Algún $S$ no es $P$ ".

A los juicios universales afirmativos, se les representó con la letra $A$ y a los particulares afirmativos con la letra $I$ (son las primeras vocales de la palabra latina afirmo).

A los juicios universales negativos, se les representó con la letra $E$ y a los particulares negativos con la letra $O$ (son las primeras vocales de la palabra latina nego).

El cuadrado lógico tiene la siguiente forma: 


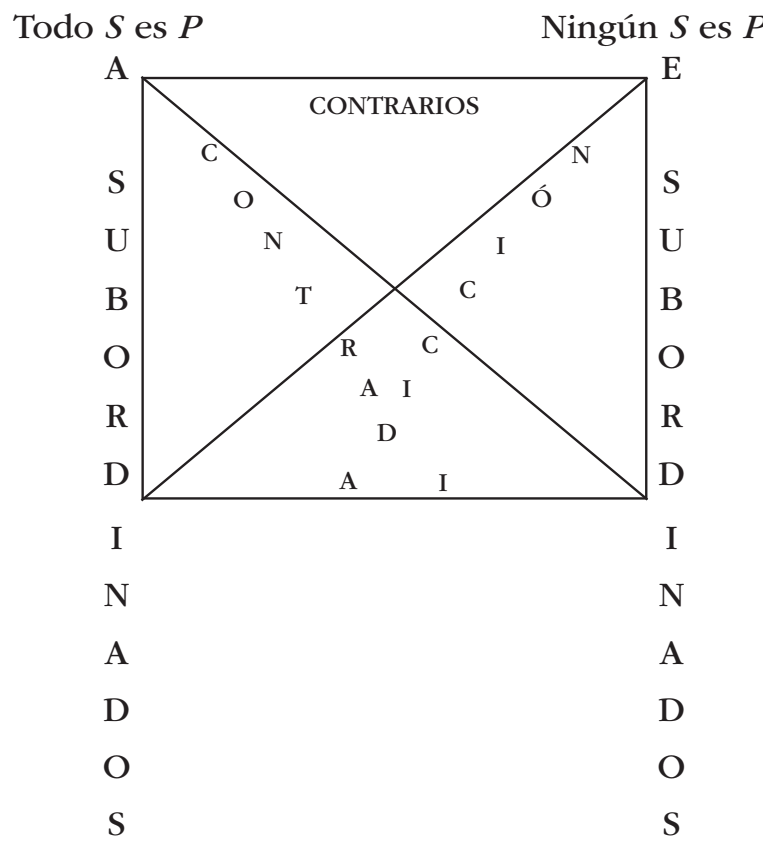

I

$\mathrm{O}$
Algunos $S$ son $P$
Algunos $S$ no son $P$

De esta manera, los juicios universal afirmativo $(A)$ y particular negativo $(O)$, así como universal negativo $(E)$ y particular afirmativo (I) son contradictorios.

Los juicios universal afirmativo $(A)$ y universal negativo $(E)$ son contrarios.

Los juicios particular afirmativo $(I)$ y particular negativo $(O)$ son subcontrarios.

Los juicios particulares afirmativos $(I)$ son subordinados a los universales afirmativos $(A)$; así como los particulares negativos $(O)$ son subordinados a los universales negativos $(E)$. 
Introducción a la teoría de conjuntos...

Después de esta breve inmersión en la teoría del juicio, continuemos analizando el concepto y dirijamos nuestra atención a las operaciones que se pueden realizar con ellos.

\section{OPERACIONES ENTRE CONCEPTOS}

\section{Limitación de un concepto}

La limitación de un concepto es el paso de un concepto con un volumen mayor a otro concepto con volumen menor. Por ejemplo, en Biología tenemos:
$A$. Reino animal
$B$. Philum: cordados
$C$. Clase: Mamíferos
$D$. Orden: Primates
E. Familia: Homínidos
$F$. Género: Homo
G. Especie: Sapiens
$H$. Individuo: Ramiro Lafuente López

Dentro del conjunto $A$ (animales), encontramos una multitud de objetos: animales vertebrados, invertebrados, terrestres, acuáticos, unicelulares, etc. Al pasar al conjunto $B$ (vertebrados), se agrupan ya no todos los animales, sino que se dice que además de ser animal, debe tener columna vertebral. Es decir, se agregó una propiedad con la que se hace una intersección: es animal $y$ tiene columna vertebral. A este conjunto, pertenecen sólo los peces, los reptiles, los anfibios, las aves y los mamíferos, y se dejan fuera los insectos, artrópodos, moluscos, etcétera.

En el conjunto $C$ (mamíferos), se limita más el número de elementos porque se dejan fuera los peces, los reptiles, los anfibios 
y las aves. Se pide que los objetos sean animales $y$ vertebrados $y$ tengan sangre caliente, su cuerpo esté cubierto de pelo, y que las hembras tengan glándulas mamarias con cuya secreción alimentan a sus crías.

En el conjunto $D$ (primates), se pide que además de las características anteriores (se agrega una conjunción), tenga el dedo pulgar de las extremidades anteriores opuesto. De esta manera, se excluyen los felinos, caninos, ungulados, etcétera.

En el conjunto $E$ (homínidos), se restringe aún más el conjunto al exigir que se cumpla con determinadas características anatómicas. De esta forma, quedan fuera todos los primates que no las cumplen: mandriles, mono araña, gibones, etc. Y quedan únicamente los monos antropomorfos, el hombre y ciertas especies desaparecidas.

En el conjunto $F$ (homo), se agrega una característica más: ser bípedo, tener una capacidad craneal desarrollada. Resulta un conjunto mucho más pequeño, tal que en la actualidad sólo existe una especia, aunque en épocas anteriores agrupaba al Homo habilis y Homo erectus.

El conjunto $G$ (sapiens), descarta especies que no tengan cultura y civilización desarrolladas (o, irónicamente, que se destruya a sí mismo y a su medio ambiente).

Por último, el conjunto $H$ es tan restringido que sólo tiene un elemento. Se obtiene al agregar otras características: haber nacido en tal fecha y lugar, haber estudiado tal cosa, trabajar en tal dependencia. Otro ejemplo que nos puede ilustrar es:
A. Institución constituida por la sociedad
B. Institución educativa
C. Institución de educación preescolar
D. Institución de educación preescolar pública
E. Institución de educación preescolar pública ubicada en la Ciudad de México


Introducción a la teoría de conjuntos...

F. Institución de educación preescolar pública ubicada en la Ciudad de México que lleva el nombre de un cuento infantil G. Kínder La Sirenita.

Como se podrá observar, la limitación de un concepto se realizó mediante la adición de nuevas características, lo que nos indica que se realizaron sucesivas intersecciones con los nuevos conjuntos que se van introduciendo. De esta manera, podemos decir que la limitación de un concepto consiste en partir de un conjunto con un mayor número de elementos para llegar a uno con menor número de ellos, gracias a que el contenido va aumentado, se va haciendo más específico. La relación anterior entre volumen y contenido de un concepto expresa una ley que rige dicha relación, la cual indica una relación inversamente proporcional entre el volumen y el contenido de un concepto: entre menos contenido (menos información) contenga un concepto, más grande será el conjunto de elementos que se forme a partir de ese concepto, y entre más contenido tenga el concepto, el conjunto será menor.

\section{EJERCICIOS}

\section{Ejercicio 195}

Realiza la limitación del concepto: documento.

\section{Ejercicio 196}

Realiza la limitación del concepto: unidad de información. 


\section{Generalización de un concepto}

La operación contraria a la limitación del concepto se llama generalización del concepto. Es la que va de un concepto con una clase menor a un concepto con una clase mayor. La generalización entonces iría en el ejemplo dado anteriormente del conjunto $H$ al $A$.

Tomando otro caso tendríamos:

$A_{1}$ : Conjunto formado por "Colmillo blanco" (animal vertebrado, carnívoro, canino, lobo, que lleva por nombre "Colmillo blanco").

$B_{1}$ : Conjunto formado por los lobos (lupus) (animal vertebrado, carnívoro, canino, lobo)

$C_{1}$ : Conjunto formado por los caninos (animal vertebrado, carnívoro, canino)

$D_{1}$ : Conjunto formado por los carnívoros (animal vertebrado, carnívoro)

$E_{1}$ : Conjunto formado por los vertebrados (animal vertebrado)

$F_{1}$ : conjunto formado por los animales (animal)

\section{EJERCICIO}

\section{Ejercicio 197}

Encuentra las propiedades que se agregan o eliminan en el camino de $A_{1}$ a $F_{1}$. 
Introducción a la teoría de conjuntos...

En general, se puede decir que para limitar un concepto se le agrega una conjunción ("y", intersección) o se elimina una disyunción ("o", unión): $A$ se limita con $A \cap B$ (Ser animal se limita con ser animal y vertebrado), y $A \cup B$ se limita con $A$ (Ser mamífero o reptil se limita con mamífero). Se puede observar que el conjunto de los animales y vertebrados tiene menos elementos que el conjunto de los animales, así como el conjunto de los mamíferos tiene menos elementos que el conjunto de los mamíferos o reptiles.

En ambos casos, se tiene una relación de inclusión:

$(A \cap B) \subseteq A$

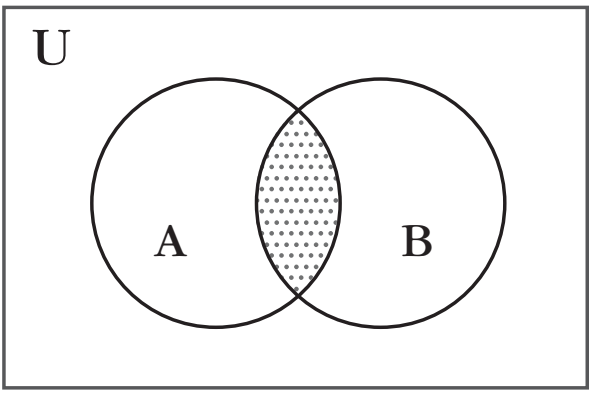

$A \subseteq(A \cup B)$

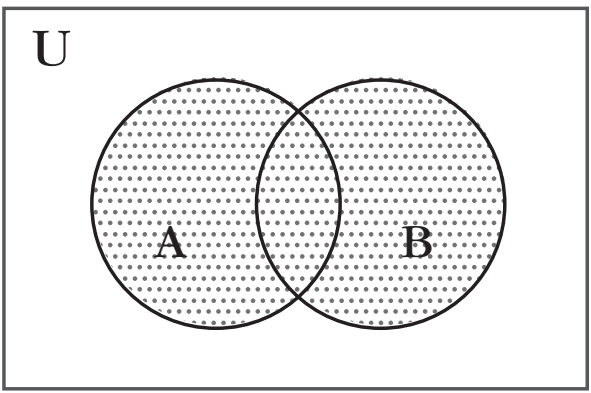

Por otro lado, también se puede establecer la regla de que para generalizar un concepto se le agregue a éste una disyunción ("o", unión) o se elimine una conjunción ("y", intersección). De esta ma- 
nera, por ejemplo, $A$ se generaliza con $A \cup B$ ("ser animal doméstico" se generaliza con "ser animal doméstico o animal silvestre"). Por su parte, $A \cap B$ se generaliza con $A$ ("ser libro de Bibliotecología" y "publicado en México" se generaliza con "ser libro de Bibliotecología"). Podemos constatar que el conjunto de los animales domésticos o silvestres tiene más elementos que el conjunto de los animales domésticos, así como el conjunto de los libros de bibliotecología tiene más elementos que el conjunto de los libros de bibliotecología publicados en México. En este caso, también se da una relación de inclusión que podemos representar de la siguiente manera:

\section{$A \subseteq(A \cup B)$}

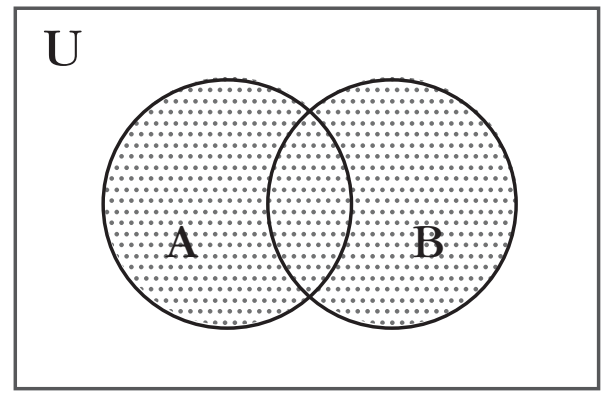

$(A \cap B) \subseteq A$

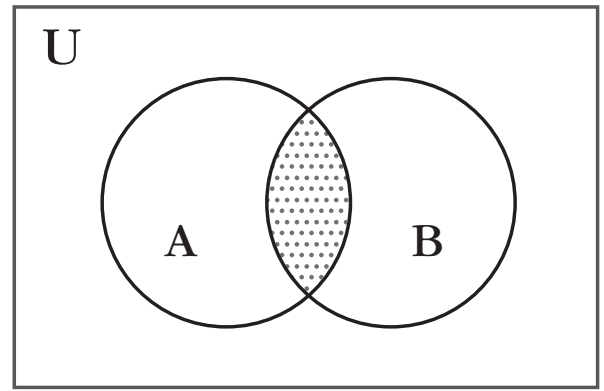


El paso de un conjunto a otro mediante la limitación o generalización, recorre el siguiente camino:

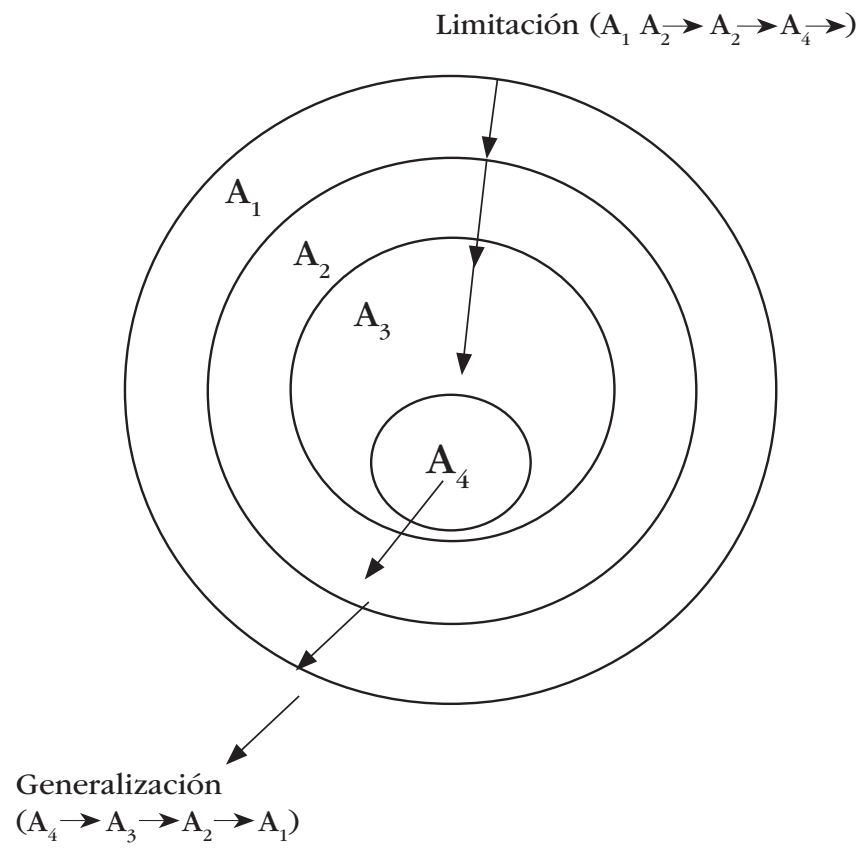

Así pues, se dan las siguientes relaciones:
$\mathrm{A}_{2} \subseteq \mathrm{A}_{1}$
$\mathrm{A}_{3} \subseteq \mathrm{A}_{2}$
$\mathrm{A}_{4} \subseteq \mathrm{A}_{3}$

Y por transitividad:

Si $A_{2} \subseteq A_{1}$ y $A_{3} \subseteq A_{2}$, entonces $A_{3} \subseteq A_{1}$

Si $A_{3} \subseteq A_{2} y A_{4} \subseteq A_{3}$, entonces $A_{4} \subseteq A_{2}$

Si $\mathrm{A}_{2} \subseteq \mathrm{A}_{1}$ y $\mathrm{A}_{4} \subseteq \mathrm{A}_{2}$, entonces $A_{4} \subseteq A_{1}$ 


\section{EJERCICIOS}

\section{Ejercicio 198}

Realiza la limitación de dos conceptos agregando conjunciones o eliminando disyunciones.

\section{Ejercicio 199}

Realiza la generalización de dos conceptos agregando disyunciones o eliminando conjunciones.

\section{División de conceptos}

La división de conceptos consiste en ir descubriendo el volumen del concepto mediante la formación de subconjuntos sucesivos a partir de un conjunto dado. Esto es, se tiene una relación de inclusión entre conjuntos que se van construyendo. Es necesario distinguir la inclusión de conjuntos de otras relaciones tales como la pertenencia, $x \in B$ no es lo mismo que $A \subseteq B$, así como también de la relación del todo con sus partes. 
Introducción a la teoría de conjuntos...

Por ejemplo, se puede dividir

\begin{tabular}{l|l|l} 
medio de transporte & $\begin{array}{l}\text { marítimo } \\
\text { anfibio }\end{array}$ \\
& aéreo & $\begin{array}{l}\text { trolebús } \\
\text { tranvía } \\
\text { terrestre }\end{array}$ \\
metro
\end{tabular}

Pero sería un error querer dividir el transporte terrestre eléctrico en volante, ruedas, motor, etc. La división puede ser dicotómica, que consiste en separar el conjunto original en dos subclases que se excluyen mutuamente, con base únicamente en un criterio de división y su negación, y separar así a los objetos en clases que poseen ese criterio o no. En teoría de conjuntos, lo que se realiza es que se toma el conjunto $A$ y su complemento absoluto $\bar{A}$.

Ya hemos visto que

$$
\begin{aligned}
& A \cup \bar{A}=U \mathrm{y} \\
& (A \cap \bar{A})=\varnothing
\end{aligned}
$$

Por ejemplo, podemos dividir a los seres en vivos y no vivos; los libros de Filosofía y los que no son de Filosofía; las mujeres casadas y las solteras; los alumnos responsables y los irresponsables; los académicos con doctorado y los que no tienen doctorado; los cuerpos celestes con luz propia y los que no tienen luz propia, etc. Este tipo de división deja las clases muy amplias, por ejemplo en el último caso, los cuerpos celestes que no tienen luz propia engloba a planetas, satélites, meteoritos y cometas. Además, la división dicotómica es muy ambigua, lo que incluso se ha prestado para 
ironizar en las relaciones sociales: los hombres se dividen en ricos y todos los demás; las mujeres se dividen en las bonitas y todas las demás.

Es por eso que podemos utilizar otros criterios en la división que nos dan como resultado no un conjunto y su complemento, sino varios subconjuntos. Un ejemplo es el que se señaló de medio de transporte, otro es la división de los triángulos según sus lados:

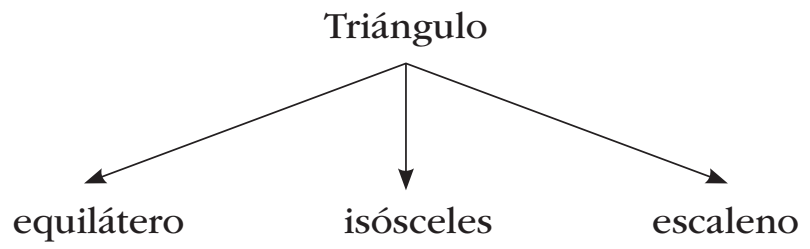

Otro caso es la división de las palabras en español según la sílaba con acento prosódico:

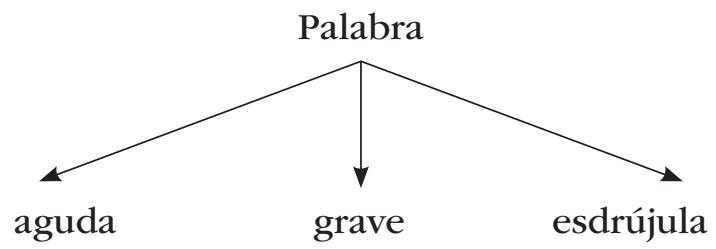

\section{Reglas de la división}

Para realizar una división de conceptos correcta, es necesario observar las siguientes reglas:

1. Cada división debe hacerse bajo un solo y único criterio.

2. Las subclases obtenidas en la división deben ser excluyentes entre sí (su intersección debe ser igual a $\varnothing$ ). 
Introducción a la teoría de conjuntos...

3. La suma de las subclases obtenidas en la división debe ser equivalente al conjunto del que se partió (su unión debe ser igual al conjunto que se divide).

4. Si se utilizan diversos criterios, estos deberán guardar un orden en atención a la extensión y el contenido.

Es importante hacer notar que cada subclase obtenida por la división del conjunto es la limitación del conjunto inicial.

\section{EJERCICIO}

\section{Ejercicio 200}

Realiza la división de dos conceptos.

\section{Clasificación}

La clasificación es la aplicación práctica de la división. Debido a lo anterior, para clasificar debemos saber limitar conceptos y aplicar las reglas de la división que se enunciaron anteriormente. La clasificación consiste en elaborar un árbol donde el tronco es el concepto inicial, las ramas se obtienen de la división de ese tronco con base en un criterio, los retoños de las ramas son otra división, ahora de las ramas, con base en otro criterio; las hojas son el resultado de la 
división de los retoños con un tercer criterio, y así sucesivamente, utilizando tantos criterios cuantos sean necesarios.

Reglas de clasificación

1. Utilizar sólo un criterio a la vez, nunca mezclar dos o más

2. Las subclases no deben contener elementos comunes

3. La unión de las subclases debe ser igual a al conjunto inicial

4. Los criterios deben guardar un orden

Errores en la clasificación

Un error por no respetar la primera regla es clasificar las ciencias en naturales, sociales, humanas, formales, interesantes, aburridas, desarrolladas en la Antigüedad, desarrolladas en el Renacimiento y desarrolladas en la Modernidad. En este caso, se incluyen en un solo conjunto una amalgama de objetos inconexos porque se utilizaron a la vez tres criterios: según el objeto de estudio; el interés y su historia de desarrollo.

Otro error puede ocurrir por violar la segunda regla. Esto sucede cuando se clasifica un mismo objeto en dos clases simultáneamente. Por ejemplo, si se clasifica a los países en desarrollados y no desarrollados y se coloca a Argentina, Brasil y México en las dos clases porque se considera que son desarrollados pero también son no desarrollados.

Un tercer caso de incorrección en la clasificación surge al no considerar la tercera regla de completar las subclases para tener completo el conjunto que se está dividiendo. Así por ejemplo, si se dividen los vertebrados en peces, reptiles, aves y mamíferos. Su suma no involucra todos los vertebrados porque faltarían los anfibios.

Por último, se puede realizar una clasificación errónea al no observar la cuarta regla y mezclar elementos que no sigan ningún orden o jerarquía, así por ejemplo cuando se clasifican los países primero en sudamericanos, luego americanos, después en los del Mercosur y terminar con los latinoamericanos. 
Introducción a la teoría de conjuntos...

El esquema de un árbol de clasificación es el siguiente:

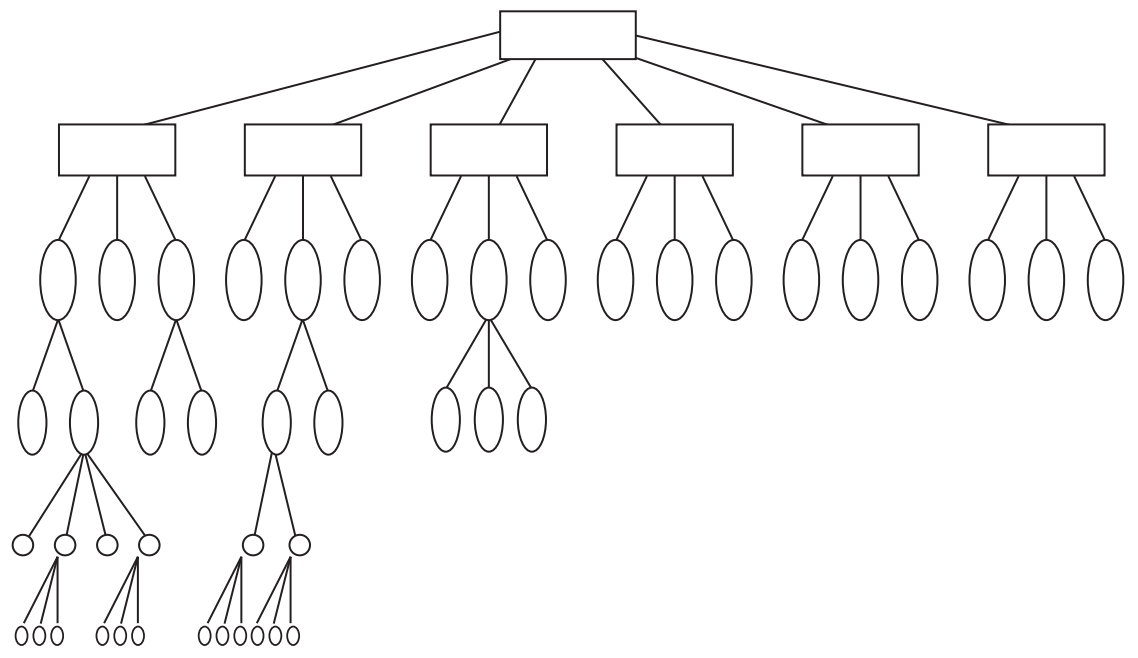

\section{EJERCICIO}

\section{Ejercicio 201}

Realiza una clasificación.

\section{LÓGICAS NO CLÁSICAS}

Para terminar nuestro trabajo, consideramos importante señalar que existen otros intentos por formalizar el razonamiento, que son distintos al que se ha expuesto hasta el momento. Lo que se ha presentado en la teoría de conjuntos y la lógica booleana corresponde a lo que se conoce como lógica clásica. Ésta se caracteriza porque respeta algunos principios fundamentales como la ley del tercer excluido, que indica que un elemento pertenece o no a un conjunto, o desde el punto de vista de la verdad, se afirma que un enunciado 
es o verdadero o falso, esto es, se tiene el principio bivalente del valor de verdad; asimismo se observa el principio de no contradicción de acuerdo con el cual no es posible que un objeto sea y no sea a la vez elemento de un conjunto, o que un enunciado sea verdadero y falso al mismo tiempo.

Si no se reconoce el principio del tercer excluido o el principio bivalente de la verdad, entonces un enunciado puede calificarse no sólo como verdadero o falso, sino con otro valor de verdad que puede ser tomado dentro de un conjunto finito o infinito de posibilidades. A este tipo de lógicas, se les llama lógicas polivalentes. Un ejemplo de ellas es el sistema propuesto por J. Lukasiewicz, quien expresó que un enunciado podía ser verdadero, falso o indeterminado. Por ejemplo, la proposición "mañana va a llover" no se puede calificar como verdadera o falsa. Otro sistema polivalente es el propuesto por Y. Ivliev, quien partió del supuesto de que un enunciado puede no sólo ser verdadero, sino que es verdadero contingentemente, como "hoy hace calor", o verdadero necesariamente, como "el triángulo tiene tres lados"; también, la proposición puede ser falsa contingentemente, como "este libro tiene 350 páginas", o falsa necesariamente, como "existe un número mayor que todos los números". De esta manera, se acepta que existen cuatro valores de verdad para un enunciado. Se pueden encontrar lógicas polivalentes con un número infinito de valores de verdad, donde el 1 corresponde a "verdadero" y 0 a "falso", y los puntos entre el 1 y el 0 son todos los posibles valores de verdad que puede obtener un enunciado.

Otro tipo de lógica que niega el principio del tercer excluido es la lógica intuicionista, la cual, al reflexionar sobre conjuntos infinitos, declara que existen enunciados que no pueden ser calificados como verdaderos o falsos, pero a diferencia de las lógicas polivalentes, no les asigna otro valor de verdad concreto. Así pues, si se demostró que un enunciado no es verdadero, debido a la infinitud del conjunto, esto no significa necesariamente que sea falso. Se le asignará el valor de falsedad hasta que ésta se haya demostrado. 
De esta manera, el valor de verdad de una proposición depende de su comprobación.

Un último sistema lógico no-clásico que mencionaremos es la conocida fuzzy logic que se ha traducido como lógica borrosa o lógica difusa. Este tipo de lógica pretende reproducir ciertos tipos de razonamientos en los que se utilizan predicados que indican cierta imprecisión o relatividad, como "ser grande", "ser rico", "ser alto", entre otros, que dependen mucho del contexto en donde se pronuncien. Así, por ejemplo, si se afirma que $P$ es grande, no se sabe con certeza si ese enunciado es verdadero o falso si no se contextualiza tal afirmación. Si se habla de una catedral que tiene una altura de 10 metros, tal vez no sea considerada grande, pero si se habla de un insecto que mide 30 centímetros, entonces sí se aceptaría que la magnitud es grande. Debido a que el objetivo de este libro no contempla directamente el análisis de las lógicas no-clásicas, se recomienda a los interesados consultar la bibliografía que se ofrece al final. 


\section{Bibliografía}

Boole, George. (1984). El análisis matemático de la lógica. Madrid: Cátedra.

—. (1982). Investigación sobre las leyes del pensamiento. Madrid: Paraninfo.

Buckley, James J. (2002). An introduction to fuzzy logic and fuzzy sets. Heidelberg: Physica-Verlag.

Cantor, Georg. (1883). Grundlagen einer Allgemeinen Mannichfaltigkeitslehre. Ein Mathematisch-Philosophischer Versuch in der Lehre des Unendlichen (Fundamentos para una teoría general de conjuntos). Leipzig: B. G. Teubner.

Cheifetz, Philip M. (1974). Lógica y teoría de conjuntos. Madrid: Alhambra.

Cohen, Morris Raphael y E. Nagel. (1968). Introducción a la lógica y al método científico. 2 vol. Buenos Aires: Amorrurtu.

Copi, Irving M. (1995). Introducción a la lógica. México: Limusa.

Frege, Gottlob. (1998). Ensayos de semántica y filosofía de la lógica. Edición, introducción, traducción y notas Luis M. Valdés Villanueva. Madrid: Tecnos.

—. (1972). Conceptografia. Los fundamentos de la Aritmética; otros estudios filosóficos. Traducción de Hugo Padilla. México: Instituto de Investigaciones Filosóficas-UNAM.

_. (1972). Los fundamentos de la aritmética: Investigación lógico-matemática sobre el concepto del número. Prólogo de Jesús Mosterín, versión castellana de Ulises Moulines. Barcelona: Laia. 
Introducción a la teoría de conjuntos...

. (1972). "Conceptografía". En Gottlob Frege. Conceptografía. Los fundamentos de la Aritmética. Otros estudios, 3-59. México: Instituto de Investigaciones Filosóficas-UNAM.

(1879). Begriffsschrift, eine der Arithmetischen Nachgebildete Formelsprache des Reinen Denkens. Halle: Verlang von Louis Nebert.

_. (1884). Die Grundlagen der Arithmetik; eine Logisch-Mathematische Untersuchung uber den Begriff der Zabl. Breslau: Verlag von Wilhelm Koebner.

Gutiérrez Ducons, Juan Luis. (1985). Conjuntos: Teorías. México: Cultural.

Halmos, Paul Richard. (1966). Teoría intuitiva de los conjuntos. México: Continental.

Hernández Hernández, Fernando. (1998). Teoría de conjuntos. México: Sociedad Matemática Mexicana.

Heyting, Arend. (1976). Introducción al intuicionismo. Madrid: Tecnos.

Hilbert, David. (1953). Fundamentos de la Geometría. Madrid: Publicaciones del Instituto Jorge Juan de Matemáticas.

Kant, Inmanuel. Prólogo a la segunda edición de 1787 de Crítica a la Razón Pura. Biblioteca Virtual Universal. Acceso en julio de 2016 en http://www.biblioteca.org.ar/libros/89799.pdf

Lipschutz, Seymour. (1991). Teoría y problemas de teoría de conjuntos y temas afines. México: McGraw-Hill.

Lógica I: Álgebra de Boole. (1974). México: McGraw-Hill.

Lorenzo, Javier de. (1972). Iniciación a la teoría intuitiva de conjuntos. Madrid: Tecnos.

Lukasiewicz, Jan. (1975). Estudios de lógica y filosofía. Madrid: Revista de Occidente.

Masip Bruin, Xavier. (1993). Álgebra de Boole y funciones lógicas. Barcelona: Universidad Politécnica de Catalunya. 
Quine, Willard Van Orman. (1993). Los métodos de la lógica. Barcelona: Planeta-Agostini.

—_. (1983). Lógica elemental. México: Grijalbo.

Quintanilla, Miguel A. (1980). Aplicaciones del álgebra de Boole al análisis de teorías. Salamanca, España: Universidad de Salamanca.

Rieger, Ladislav. (1967). Algebraic Methods of Mathematical Logic. Praga: Academia.

Russell, Bertrand y Alfred Whitehead. (1960). Principia Mathematica. 3 v. [1903, 1912, 1913]. Cambridge: Eng. University.

Salazar Resines, Javier. (1970-1971). Introducción a la lógica deductiva y teoría de los conjuntos. Vol. 1 y 2. México: DGP-UNAM.

Sánchez Algarra, Pedro. (1986). Álgebra de Boole, lógica elemental y métodos de demostración matemática. Barcelona: Promociones y publicaciones universitarias.

Sánchez Pozos, Javier. (1989). "Principios generales de una teoría fregeana del nombre para la lógica formal". En Signos. Anuarios de Humanidades. 10: 229-236. Tomo 2. México: Departamento de Filosofía-División de Ciencias Sociales-UAM-I.

_. "Forma lógica. Aspectos metodológicos". (1993). En Contactos. Revista de Educación en Ciencias Básicas e Ingeniería, 1993: 50-61.

Strawson, Peter Frederick. (1967). Philosophical Logic. Londres: Oxford University.

_. (1963). Introducción a una teoría de la lógica. Buenos Aires: Nova. 310 p.

Tarski, Alfred. (1968). Introducción a la lógica y a la metodología de las ciencias deductivas. Madrid: Espasa-Calpe.

Trillas, Enric; Claudia Alsina y Josep Maria Terricabras. (1995). Introducción a la lógica borrosa. Barcelona: Ariel. 
Introducción a la teoría de conjuntos...

Voishvillo, Evguenii Kasimírivich. (1989). Poniatie kak forma muisbleniia (El concepto como forma del pensamiento). Moscú: Izdatelstvo Moskovskogo Universitieta.

Voishvillo, Evguenii Kasimírivich y M. G. Degtiarev. (1994). Loguica kak tchas toerii poznania i nautchnoi metodologii. (La lógica como parte de la teoría del conocimiento y metodología científica). Libro 2. Moscú: Nauka. 


\title{
Índice de ejercicios
}

\author{
Capítulo I \\ TEORÍA DE CONJUNTOS
}

Ejercicio $1 \ldots \ldots \ldots .14$

Ejercicio $2 \ldots \ldots \ldots .17$

Ejercicio $3 \ldots \ldots \ldots .19$

Ejercicio $4 \ldots \ldots \ldots \ldots$

Ejercicio $5 \ldots \ldots \ldots \ldots 21$

Ejercicio $6 \ldots \ldots \ldots 21$

Ejercicio $7 \ldots \ldots \ldots 22$

Ejercicio $8 \ldots \ldots \ldots 23$

Ejercicio $9 \ldots \ldots \ldots 24$

Ejercicio $10 \ldots \ldots \ldots .24$

Ejercicio $11 \ldots \ldots \ldots 25$

Ejercicio $12 \ldots \ldots \ldots .25$

Ejercicio $13 \ldots \ldots \ldots .27$

Ejercicio $14 \ldots \ldots \ldots 27$

Ejercicio $15 \ldots \ldots \ldots .28$

Ejercicio $16 \ldots \ldots . .29$

Ejercicio $17 \ldots \ldots \ldots 30$

Ejercicio $18 \ldots \ldots \ldots .33$

Ejercicio $19 \ldots \ldots \ldots .33$

Ejercicio $20 \ldots \ldots \ldots . \quad 34$

Ejercicio $21 \ldots \ldots \ldots .34$

Ejercicio $22 \ldots \ldots \ldots$
Ejercicio $23 \ldots \ldots \ldots .37$

Ejercicio $24 \ldots \ldots \ldots \ldots$

Ejercicio $25 \ldots \ldots \ldots .37$

Ejercicio $26 \ldots \ldots \ldots .37$

Ejercicio $27 \ldots \ldots \ldots .37$

Ejercicio $28 \ldots \ldots \ldots .37$

Ejercicio $29 \ldots \ldots \ldots .38$

Ejercicio $30 \ldots \ldots \ldots .38$

Ejercicio $31 \ldots \ldots \ldots \quad 38$

Ejercicio $32 \ldots \ldots \ldots \quad 38$

Ejercicio $33 \ldots \ldots \ldots \quad 38$

Ejercicio $34 \ldots \ldots \ldots .38$

Ejercicio $35 \ldots \ldots \ldots .43$

Ejercicio $36 \ldots \ldots \ldots .46$

Ejercicio $37 \ldots \ldots \ldots .46$

Ejercicio $38 \ldots \ldots \ldots .46$

Ejercicio $39 \ldots \ldots \ldots .46$

Ejercicio $40 \ldots \ldots \ldots .46$

Ejercicio $41 \ldots \ldots \ldots .46$

Ejercicio $42 \ldots \ldots \ldots .46$

Ejercicio $43 \ldots \ldots \ldots .46$

Ejercicio $44 \ldots \ldots \ldots .46$ 
Introducción a la teoría de conjuntos...

Ejercicio $45 \ldots \ldots \ldots 46$

Ejercicio $46 \ldots \ldots . \ldots 47$

Ejercicio $47 \ldots \ldots . \ldots 47$

Ejercicio $48 \ldots \ldots . \ldots 47$

Ejercicio $49 \ldots \ldots . \ldots 47$

Ejercicio $50 \ldots \ldots . \ldots 47$

Ejercicio $51 \ldots \ldots . \ldots 47$

Ejercicio $52 \ldots \ldots . \ldots 47$

Ejercicio $53 \ldots \ldots . \ldots 47$

Ejercicio $54 \ldots \ldots . \ldots 47$

Ejercicio $55 \ldots \ldots \ldots 47$

Ejercicio $56 \ldots \ldots . \ldots 47$

Ejercicio $57 \ldots \ldots \ldots 48$

Ejercicio $58 \ldots \ldots \ldots . \ldots 48$

Ejercicio $59 \ldots \ldots \ldots . \ldots 48$

Ejercicio $60 \ldots \ldots \ldots . \ldots 48$

Ejercicio $61 \ldots \ldots \ldots . \ldots 48$

Ejercicio $62 \ldots \ldots \ldots . \ldots 48$

Ejercicio $63 \ldots \ldots \ldots 48$

Ejercicio $64 \ldots \ldots \ldots . . \ldots 48$

Ejercicio $65 \ldots \ldots \ldots . \ldots 48$

Ejercicio $66 \ldots \ldots . \ldots 49$

Ejercicio $67 \ldots \ldots . \ldots 49$

Ejercicio $68 \ldots \ldots \ldots$..... 49

Ejercicio $69 \ldots \ldots . \ldots 49$

Ejercicio $70 \ldots \ldots . \ldots 49$

Ejercicio $71 \ldots \ldots . \ldots 49$

Ejercicio $72 \ldots \ldots \ldots$

Ejercicio $73 \ldots \ldots 50$

Ejercicio $74 \ldots \ldots \ldots$

Ejercicio $75 \ldots \ldots \ldots$

Ejercicio $76 \ldots \ldots . \ldots 50$

Ejercicio $77 \ldots \ldots \ldots$
Ejercicio $78 \ldots \ldots \ldots 51$

Ejercicio $79 \ldots \ldots \ldots 51$

Ejercicio $80 \ldots \ldots \ldots 51$

Ejercicio $81 \ldots \ldots \ldots 52$

Ejercicio $82 \ldots \ldots \ldots 2$

Ejercicio $83 \ldots \ldots \ldots 5$

Ejercicio $84 \ldots \ldots \ldots 5$

Ejercicio $85 \ldots \ldots \ldots 5$

Ejercicio $86 \ldots \ldots \ldots 3$

Ejercicio $87 \ldots \ldots \ldots 54$

Ejercicio $88 \ldots \ldots \ldots$

Ejercicio $89 \ldots \ldots \ldots$

Ejercicio $90 \ldots \ldots \ldots$

Ejercicio $91 \ldots \ldots \ldots 58$

Ejercicio $92 \ldots \ldots \ldots$

Ejercicio $93 \ldots \ldots \ldots 58$

Ejercicio $94 \ldots \ldots \ldots$

Ejercicio $95 \ldots \ldots \ldots$

Ejercicio $96 \ldots \ldots$...... 59

Ejercicio $97 \ldots \ldots$. . . . 59

Ejercicio $98 \ldots \ldots . . . .59$

Ejercicio $99 \ldots \ldots . . . . .59$

Ejercicio $100 \ldots \ldots 59$

Ejercicio $101 \ldots . . . .59$

Ejercicio $102 \ldots . . . .59$

Ejercicio $103 \ldots . . . .59$

Ejercicio $104 \ldots . . . .59$

Ejercicio $105 \ldots . . . .59$

Ejercicio $106 \ldots \ldots$..... 59

Ejercicio $107 \ldots \ldots$...... 60

Ejercicio $108 \ldots \ldots . \ldots 60$

Ejercicio $109 \ldots \ldots$. . . . 60

Ejercicio $110 \ldots \ldots 61$ 
Ejercicio $111 \ldots \ldots \ldots .61$

Ejercicio $112 \ldots \ldots \ldots .62$

Ejercicio $113 \ldots \ldots \ldots .62$

Ejercicio $114 \ldots \ldots \ldots 62$

Ejercicio $115 \ldots \ldots \ldots .62$

Ejercicio $116 \ldots \ldots \ldots 62$

Ejercicio $117 \ldots \ldots \ldots 62$

Ejercicio $118 \ldots \ldots \ldots .62$

Ejercicio $119 \ldots \ldots \ldots .62$

Ejercicio $120 \ldots \ldots \ldots 63$

Ejercicio $121 \ldots \ldots \ldots 63$

Ejercicio $122 \ldots \ldots \ldots 63$

Ejercicio $123 \ldots \ldots \ldots 63$
Ejercicio $124 \ldots \ldots \ldots .63$

Ejercicio $125 \ldots \ldots \ldots .63$

Ejercicio $126 \ldots \ldots \ldots 63$

Ejercicio $127 \ldots \ldots \ldots 6$

Ejercicio $128 \ldots \ldots \ldots .64$

Ejercicio $129 \ldots \ldots \ldots .64$

Ejercicio $130 \ldots \ldots \ldots 64$

Ejercicio $131 \ldots \ldots \ldots .64$

Ejercicio $132 \ldots \ldots \ldots .64$

Ejercicio $133 \ldots \ldots \ldots 64$

Ejercicio $134 \ldots \ldots \ldots .64$

Ejercicio $135 \ldots \ldots \ldots 65$

Ejercicio $136 \ldots \ldots \ldots 65$

Capítulo II

OPERADORES BOOLEANOS

Ejercicio $137 \ldots \ldots \ldots .75$

Ejercicio $138 \ldots \ldots \ldots .75$

Ejercicio $139 \ldots \ldots \ldots .75$

Ejercicio $140 \ldots \ldots \ldots .75$

Ejercicio $141 \ldots \ldots \ldots .75$

Ejercicio $142 \ldots \ldots \ldots .75$

Ejercicio $143 \ldots \ldots \ldots 75$

Ejercicio $144 \ldots \ldots \ldots .75$

Ejercicio $145 \ldots \ldots \ldots .76$

Ejercicio $146 \ldots \ldots \ldots .76$

Ejercicio $147 \ldots \ldots \ldots 76$

Ejercicio $148 \ldots \ldots \ldots .76$

Ejercicio $149 \ldots \ldots \ldots .76$

Ejercicio $150 \ldots \ldots \ldots 76$
Ejercicio $151 \ldots \ldots \ldots .76$

Ejercicio $152 \ldots \ldots \ldots .76$

Ejercicio $153 \ldots \ldots \ldots .77$

Ejercicio $154 \ldots \ldots \ldots .77$

Ejercicio $155 \ldots \ldots \ldots .77$

Ejercicio $156 \ldots \ldots \ldots .77$

Ejercicio $157 \ldots \ldots \ldots .77$

Ejercicio $158 \ldots \ldots \ldots .77$

Ejercicio 159 . . . . . . 77

Ejercicio $160 \ldots \ldots \ldots .78$

Ejercicio $161 \ldots \ldots \ldots .78$

Ejercicio $162 \ldots \ldots \ldots .78$

Ejercicio $163 \ldots \ldots \ldots .78$

Ejercicio $164 \ldots \ldots \ldots .78$ 
Introducción a la teoría de conjuntos...

Capítulo III

TEORÍA DEL CONCEPTO

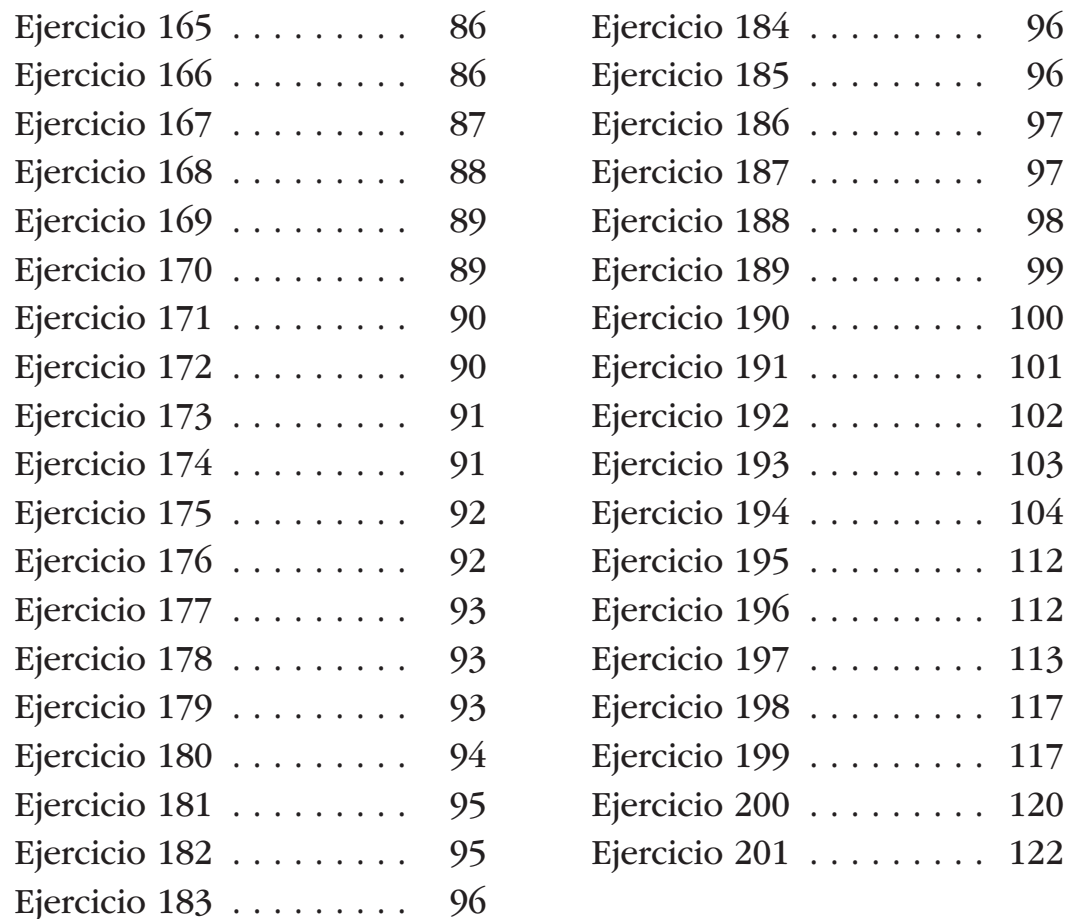


Introducción a la teoría de conjuntos, los operadores booleanos y la teoría de concepto para profesionales de la información documental. La edición consta de 100 ejemplares. Coordinación editorial, Carlos Ceballos Sosa; corrección de estilo y cotejo, Valeria Guzmán González; formación editorial y corrección de pruebas, Patricia Pérez Ramírez. Fue impreso en papel cultural de $90 \mathrm{~g}$. Se terminó de imprimir en el mes de agosto de 2017 en AGYS Alevin S. C., Retorno de Amores No. 14, colonia Del Valle, c.p. 03100, delegación Benito Juárez, México, CDMX. 